\title{
Social Media Platforms for Construction Project Management
}

\author{
By
}

Viliame Rawalai

A thesis submitted to the School of Architecture, in fulfilment of the requirements for the degree of Masters of Building Science

Victoria University of Wellington

2017 



\section{Acknowledgements}

The completion of this written work would not have been possible without the help of my close family and friends. I would like to say a big "Vinaka Vakalevu", to my Parents Luke and Kini for their support throughout the process.

I would also like to acknowledge my supervisor Marc for his patient guidance.

My deepest gratitude also goes to Koi and the Suva-shore family for being with me every step of the way. 


\section{i. Abstract}

There is a need for all stakeholders of building process to interact efficiently and effectively. However, this is not always possible due to the different knowledge background and complexity of building projects. Technologies transfer communication, leadership, democratic interaction, teamwork, social engagement and responsibility away from the instructors to the participants. Implementing social network-enabled communication can move design and production beyond its conventional realm and enables stakeholders to develop architectural, management and production knowledge that is embedded into a community of experts with their expertise both online and offline. Current media tools that are available need to be adopted and optimized to match the specific tasks of project delivery. The current single communication tools don't allow the inclusion of all stakeholders and don't support a social and collaborative project environment. Communication management is a crucial knowledge area for Project Managers (PMs) who are expected to effectively and efficiently communicate the four constraints (Scope, Time, Cost, Quality) of a project to other stakeholders. This thesis explores the concept of using social media (SM) for construction project management (CPM) and in supporting collaboration within construction project teams. This thesis employs the research methods of a Literature Review, Survey, and a Software Review to achieve this. The literature review identified that there was a knowledge gap regarding SM use by PMs. While construction industry professionals recognised a need for SM, there were no strategies in place to capitalise on SM use. Current tools being used by construction PMs as identified in this thesis include, web-based project management software (WPMS) and Social Software/Groupware. Both tools are used to support core PM processes while also providing a collaborative electronic workspace on the Internet. The emergence of Project Management 2.0 (PM 2.0) and Social Project Management (SPM) methodology/Software as a response to Web 2.0, has seen the adaptation of the social networking (SN) and the 're-tweet' paradigm in project communities. Currently there are SPM software available which is being largely used by PMs in the information technology (IT) industry. A Survey which was administered online to industry professionals, showed that survey respondents while dubious about the use of SM for project related work were interested in using software that integrated more SM-like features. The survey further identified that survey respondents were not aware of SPM software but that they were using some semblance of Social software which were akin to SPM. The dissertation presented a review of current stateof-the-art SPM software and was also used to identify core PM features. In addition to this, ten SPM software were reviewed for features that were fundamentally Web 2.0/ SM based. The findings from the software review and literature review is finally culminated in the outline of the conceptual SPM software-Gantt 2.0 which is intended for CPM. 


\section{Table of Contents}

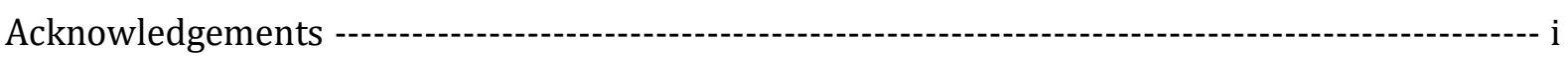

i. Abstract---

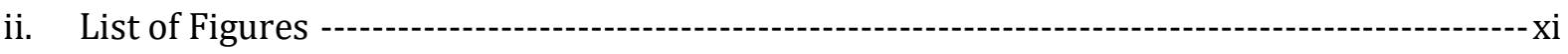

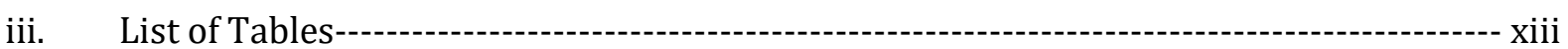

iv. List of Abbreviations --

1 Introduction - 1

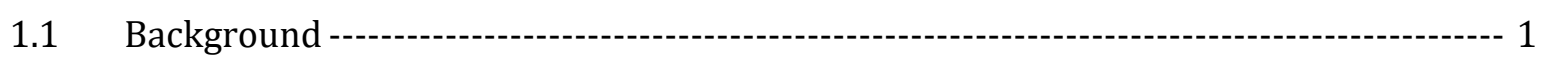

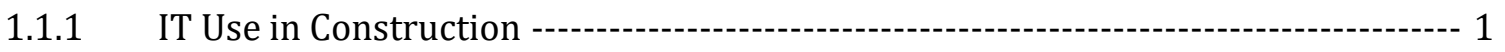

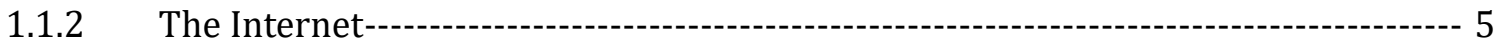

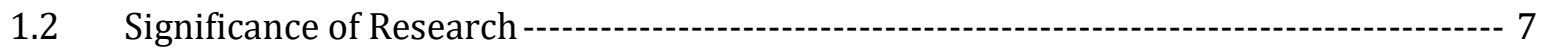

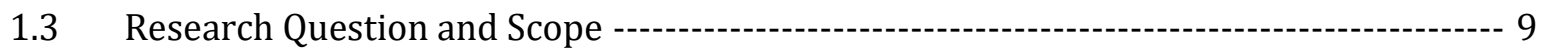

2 Thesis Outline -

2.1 Introduction -- 12

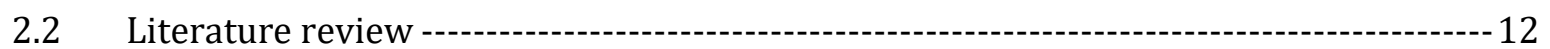

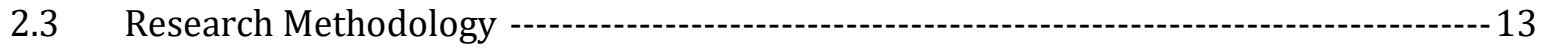

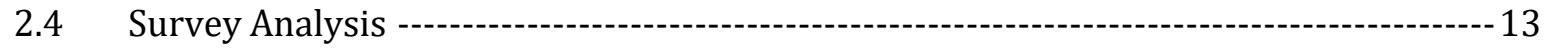

2.5 Software Review -- 13

2.6 Concept Platform -- 13

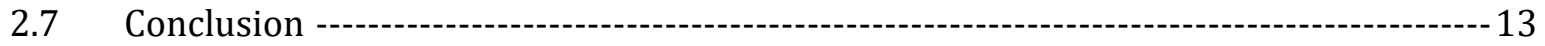

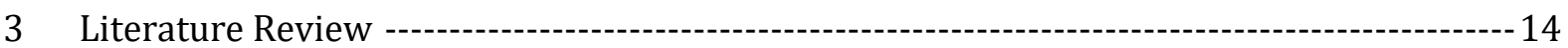

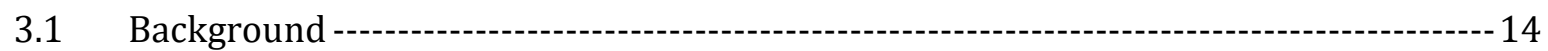

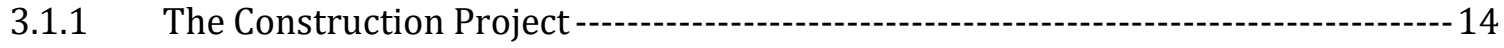

3.1.2 Information Flow -- 15

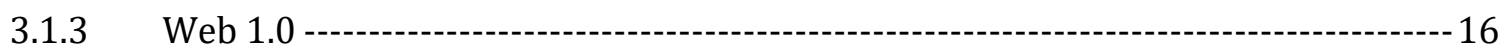

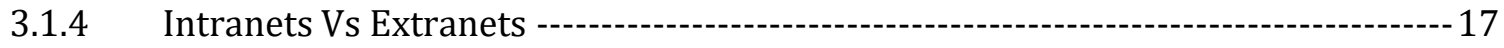

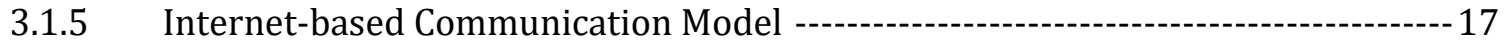

3.1.6 Project Management Software --- 18 


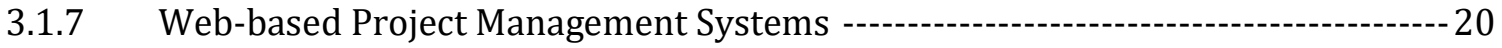

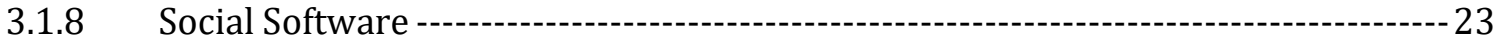

3.1.9 Summary - 25

3.2 Web 2.0 -

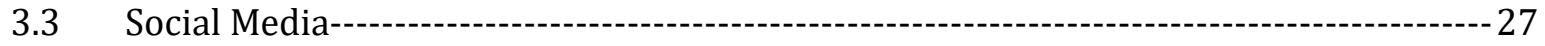

3.3.1 Social Media in the AEC ---

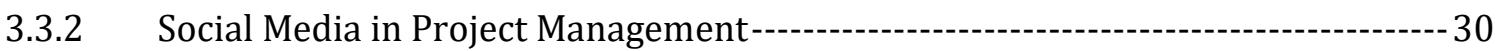

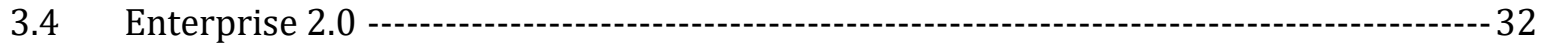

3.5 Project management 2.0 ---

3.5.1 Social Project Management -- 38

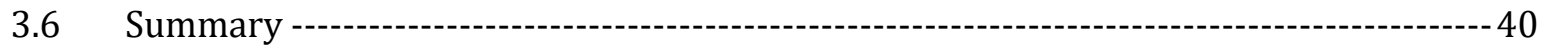

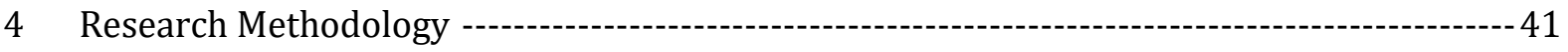

4.1 Survey---- 41

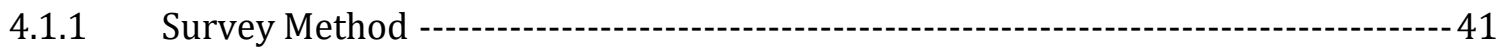

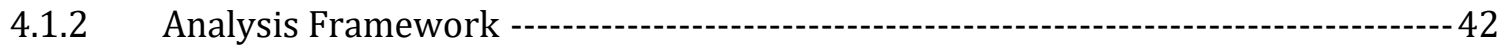

4.2 Software Review -

4.2.1 Software Criteria--

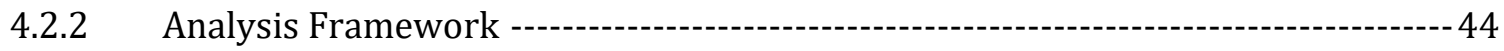

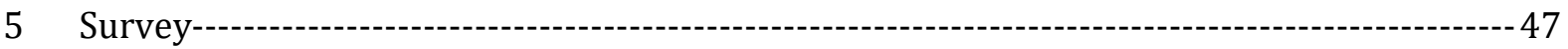

5.1 Results --- 47

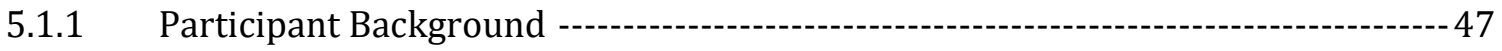

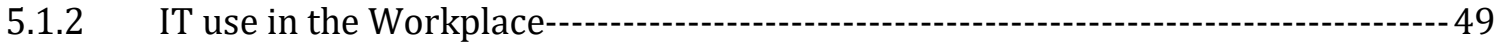

5.1.3 Social Media Use -- 54

5.1.4 Social Software Awareness---on

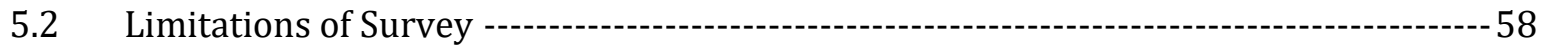

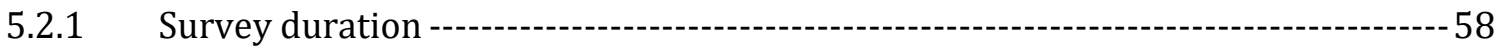

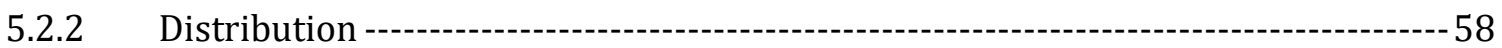

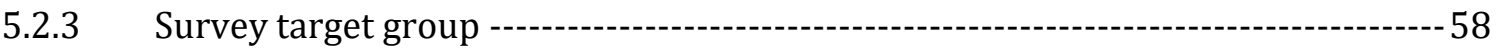

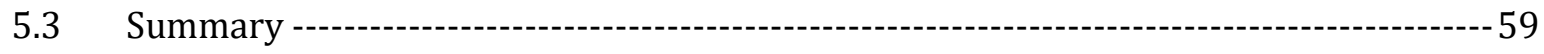




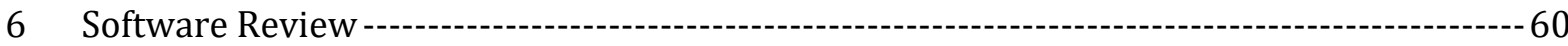

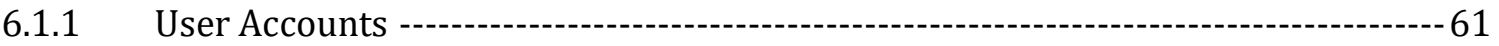

6.1.2 Graphical User Interface (GUI) -

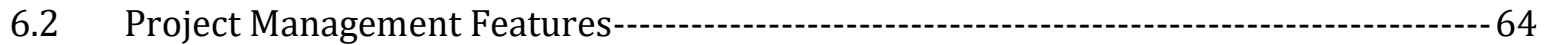

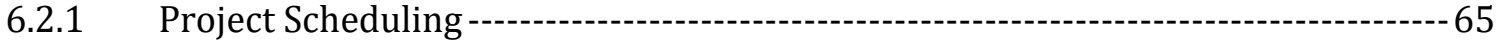

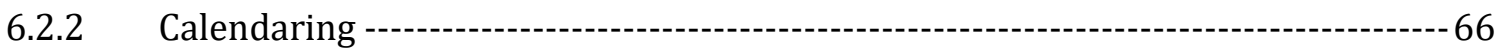

6.2.3 Document Management --.-- 67

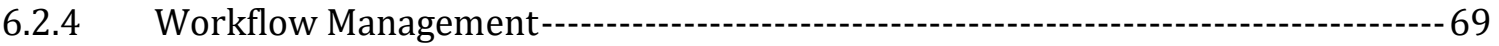

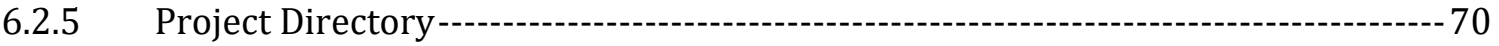

6.2.6 Advanced Searching ---

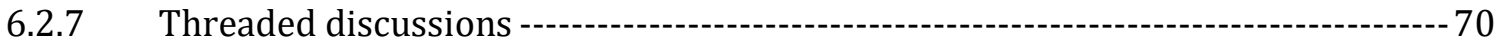

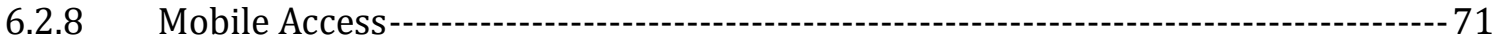

6.2.9 Time Tracking --- 72

6.2.10 Project Portfolio Management (PPM) ----:-

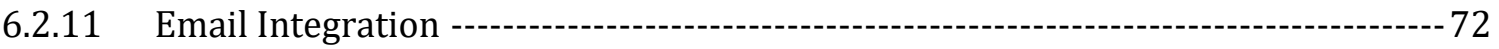

6.3 Social and Collaborative Features -- 74

6.3.1 Social Networking (SN) --

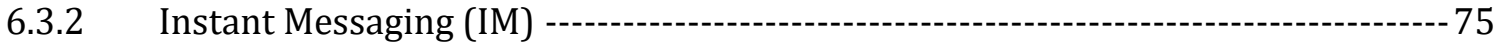

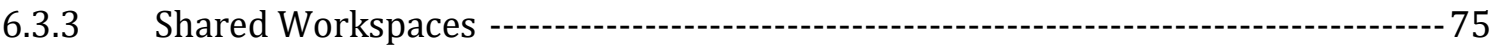

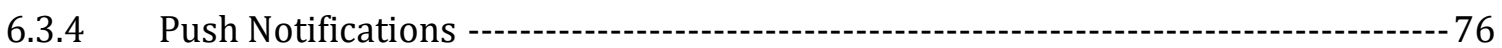

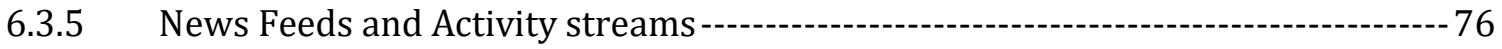

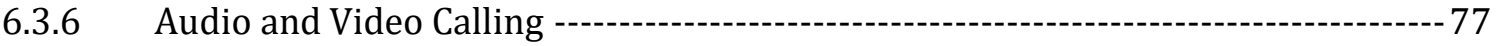

6.3 .7 Wikis - 77

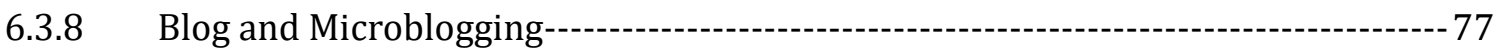

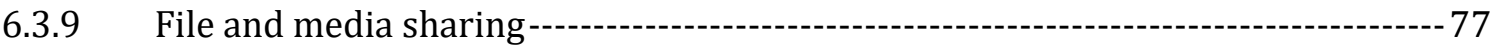

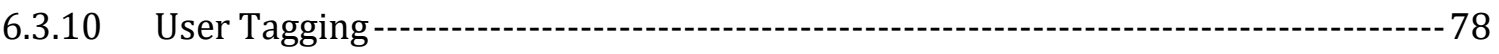

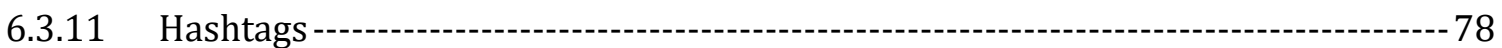

6.3.12 RSS feeds -

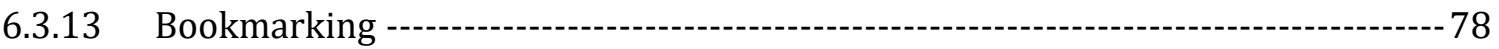




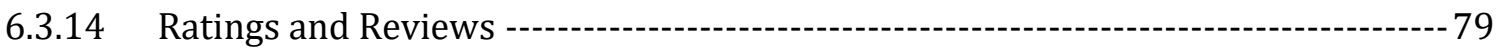

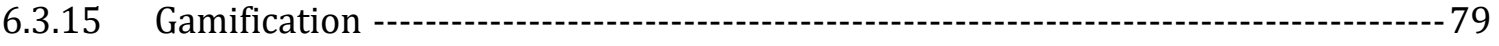

6.4 Integrations ---

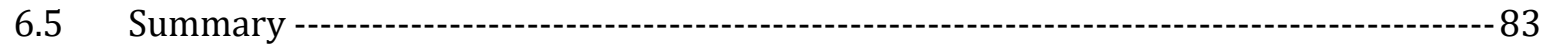

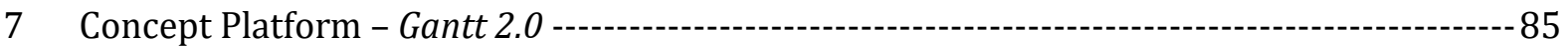

7.1 Intended User ---o- 85

7.2 Precedents -

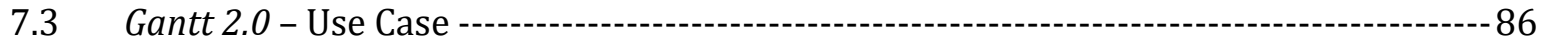

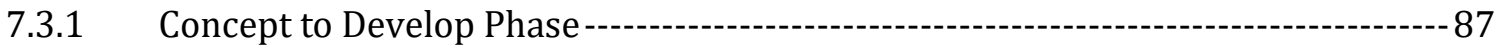

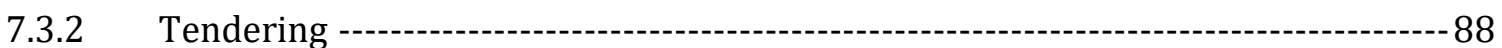

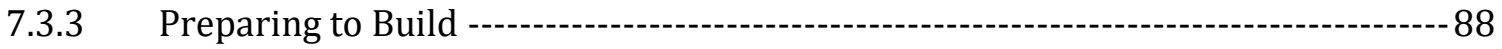

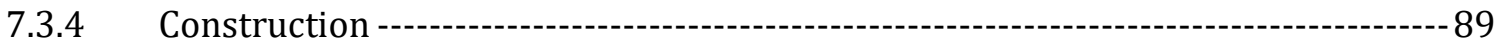

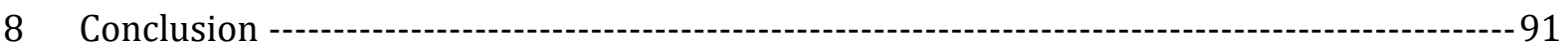

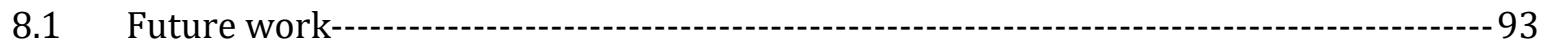

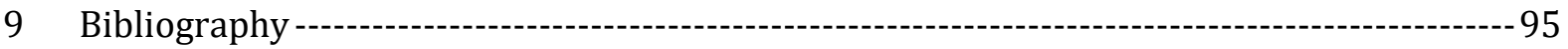

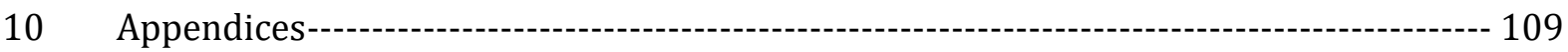

Appendix A: Software background - 109

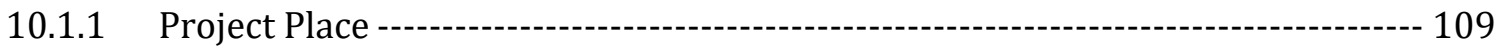

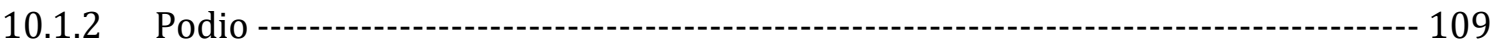

10.1.3 Zoho Projects --- 109

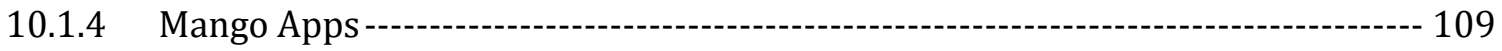

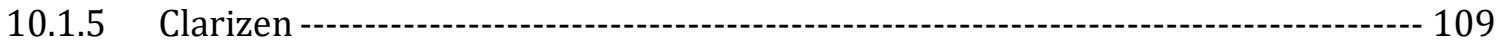

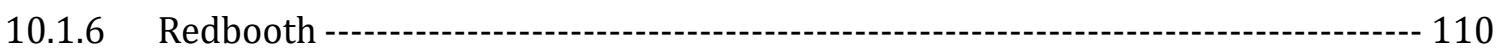

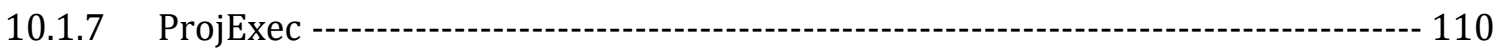

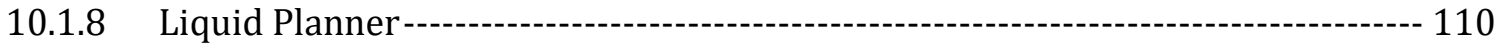

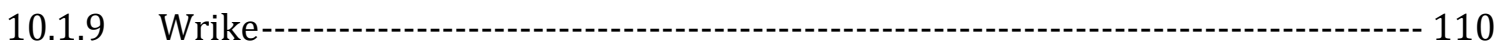

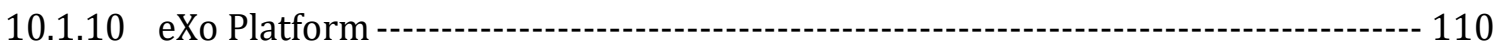

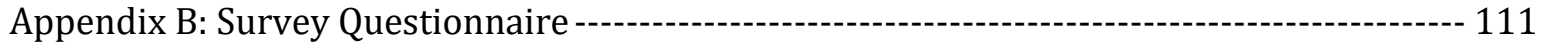

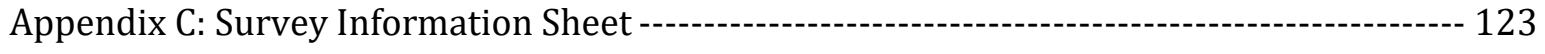


Appendix D: Supplementary Tables--

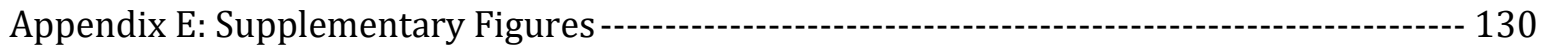

Appendix F: Ethics Approval 


\section{ii. List of Figures}

FIGURE 1: The CIC research landscape by (Boddy, Rezgui, Cooper, \& Wetherill, 2006).................... 2

FIGURE 2: Construction industry productivity improvements compared to other industries. This has to do with a slow ICT uptake. The industry is proactive adopting e-business as a tool to increase competitiveness adapted from (Valsson, 2012).............................................................................. 3

FIGURE 3: Results of the survey by PMI to the left the amount at risk for every US $\$ 1$ billion spent on construction projects with 1 in every 5 projects failing due to ineffective communication, adapted from (Project Management Institute, 2013) 7

FIGURE 5: A generic project management overview of a construction project from concept to the final built phase of the project adapted from (Young, 2008) ............................................................... 14

FIGURE 6: The conventional communication model adapted from (Shami \& Elzarka, 2000) ...... 17

FIGURE 7: Internet-based communication model adapted from (Shami \& Elzarka, 2000) ........... 18 FIGURE 8: Classification of Social Media by social presence/media richness and selfpresentation/self-disclosure adapted from (Kaplan \& Michael, 2010).

FIGURE 9: Summary of survey findings for social media use adapted from (Azhar \& Abeln, 2014)

FIGURE 10: graph showing the 9 ways in which survey respondents used social media for project work adapted from (Harrin, Social Media In a Project Managment Environment, 2011)

FIGURE 11: Social technologies that can be used by consumers and Enterprise by (Chui, et al., 2012) 32

FIGURE 13: The emergence of PM 2.0 and tracing the Web 2.0 influence on project management 2.0 34

FIGURE 15: Classification of tools and services found in the reviewed software. ............................ 46

FIGURE 16: Graph showing the years of experience of the survey participants................................ 47

FIGURE 17: The chart above shows the respondents roles that participated in the survey.......... 48

FIGURE 18: What IT do you use and for what purposes? .................................................................... 49

FIGURE 19: What types of software do you use currently or have used in the past in projects? 51 FIGURE 20: The above graph shows the purposes for which respondents use social media. ...... 54

FIGURE 21: Have you ever used SM for project work? ……………………………............................... 55

FIGURE 22: Account creation page for platforms. From left to right Wrike, eXo Platform and Zoho Projects SOURCE: 1. https://www.wrike.com/login/ https://community.exoplatform.com/portal/intranet/register 3. https://ww w.zoho.com/projects/login.html 61 
FIGURE 23: The workspace GUI for Podio SOURCE: http://www.effortlessinternetmarketing.com/wp-content/uploads/2012/03/Screen-Shot2012-03-08-at-12.47.55-PM.png 62

FIGURE 24: Wrike Gantt chart view. SOURCE: https://www.wrike.com/help/project-schedule/ 65

FIGURE 25: The calendar view for Zoho Projects. SOURCE: https://www.zoho.com/projects/features.html 66

FIGURE 26: Document management system for Zoho Projects SOURCE: https://www.zoho.com/projects/document-management.html. 67

FIGURE 27: document management for Project Place software with important functions highlighted SOURCE: http://bit.ly/1VYhziS. 68

FIGURE 28: Example of a physical Kanban board. SOURCE: http://leankit.com/learn/kanban/kanban-board/.

FIGURE 29: The Conversations Tab in Project Place SOURCE: https://help.projectplace.com/wiki/index.php/Work_with_conversations

FIGURE 30: The timesheet view for Zoho Projects showing a breakdown of hours spent on tasks SOURCE: https://www.zoho.com/projects/features.html. 72

FIGURE 31: The timesheet view for Zoho Projects showing a breakdown of hours spent on tasks SOURCE: https://www.zoho.com/projects/features.html 75

FIGURE 32: Gamification user interface for Zoho Projects Gamescope SOURCE: https://www.zoho.com/projects/gamescope.html 79

FIGURE 33: Some of the integration options for Podio SOURCE: https://podio.com/site/en/tour 82

FIGURE 36: Mapping the tools onto the different phases. Social tools are to the left and the Pm tools are listed to the right.

FIGURE 37: Categories of collaborative tools adapted from (Bafoutsou \& Mentzaz, Review and Functional Classification of Collaborative Systems, 2002). 130

FIGURE 38: The honeycomb of social Media by (Kietzmann, Hermkens, McCarthy, \& Silvestre, 2011) . .130

FIGURE 39: System architecture of a social collaboration platform (Li, Chen, Zhang, \& Fu, 2012)

FIGURE 40: Functional scheme of a WPMS (Nitithamyong \& Skibniewski, Web-based Construction Projetc Management Systems: How to make them successful?, 2004) 131 


\section{iii. List of Tables}

TABLE 1: Research question matched against proposed research methods

TABLE 2: Software review websites with the number of available PM software compared to Software specific to PMs in AEC industry

TABLE 3: Top 10 web-based construction project management (CPM) software from (Software

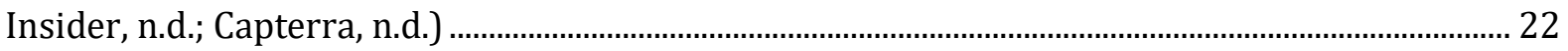

TABLE 4: List of team collaboration software (Capterra, n.d.)............................................................... 23

TABLE 5: The four categories of collaboration services adapted from (Bafoutsou \& Mentzaz, 2002) 24

TABLE 6: Key differences between Web 1.0 and Web 2.0 adapted from (Han, 2012)....... 26

TABLE 7: The six different types of social media platforms that are available adapted from (Kaplan \& Michael, 2010) 28

TABLE 8: Matrix showing social media matched against different project tasks adapted from (Harrin, 2010). 36

TABLE 9: Project management comparison adapted from (Andres, 2013) 38

TABLE 10: Three paradigm shifts of project theory for Social Project Management adapted from (Casanova \& Bellifemine, 2012) 39

TABLE 11: A summary table of colaborative software and tools that were identified by respondets in the survey 52

TABLE 12: How do you feel about the following statements? 53

TABLE 13: List of Software chosen for review. 60

TABLE 14: Software features matrix matched against specific software. 64

TABLE 15: Software matched against social and collaborative tools. 74

TABLE 16: Table showing some of the benefits and risks associated with the implementation of gamification methods in project management adapted from (Association for Project Management (APM), 2014). 81

TABLE 17: Social tools and Pm tools identified form precedent platforms, Clarizen and ProjExec 86

TABLE 18: Network technologies and their impacts by (Lientz \& Rea, 2002) .................................125

TABLE 19: The Four different computer Networks adapted from (Onyegiri, et al., 2011) ..........126

TABLE 20: The three categories of PM-ASPs adapted from (Scott, et al., 2003)... 127

TABLE 21: Categorisation of construction project extranets adapted from (Becerik, 2004)......127

TABLE 22: Barriers against the adoption of PM-ASPs adapted from (Nitithamyong \& Skibniewski, 2004) .128 
TABLE 23: Differences between Enterprise 1.0 and Enterprise 2.0 adapted from (Klinc, et al., 2008)

TABLE 24: Difference comparison of project management adapted from (Li, et al., 2012) ........129 


\section{iv. List of Abbreviations}

AEC - Architecture, Engineering and Construction industry

ASP - Application Service Provider

CDEF - Concept, Design, Execution and Finish model of a building project lifecycle

CPE - Construction Project Extranets

CPM - Construction Project Management

CSCW - Computer Supported Collaborative Work

ECS - Enterprise Collaboration Systems

EDMS - Electronic Document Management System

EMS - Electronic Meeting System

ESN - Enterprise Social Network

ICT - Information, Communication Technology

IT - Information Technology

PM - the acronym is used to refer to either Project Management or Project Manager(s)

PMBOK - Project Management Body of Knowledge

PM-ASP - Project Management as Application Service Provider

PM 2.0 - Project Management 2.0

SaaS - Software as a Service

SES - Social Enterprise Software

SM - Social Media

SMEs - Small to Medium Sized Enterprises

SNS - Social Networking Sites

SPM - Social Project Management

UGC - User Generated Content

WPMS - Web-based Project Management System 


\section{Introduction}

\subsection{Background}

The Construction industry otherwise also known as the Architecture, Engineering and Construction (AEC) industry is fundamentally project-based. Building projects are complex, unique, information intensive, and require the submittal of large quantities of documents. The number of documents for a single project typically run somewhere in the order of 10,000 or more. This information is expected to be communicated between the multidisciplinary teams that undertake these projects (Miller 2011). Many empirical studies and reports undertaken in the past have highlighted the problems concerning communication in the industry (Emmerson 1962, Banwell 1964, Egan 1998, Higgin and Jessop 1965). Issues such as the sectors fragmented nature, stringent organisational hierarchies, provision of inadequate information, and lack of coordination between design and construction phases are just some of the fundamental issues that were continually highlighted in these studies (Emmitt and Gorse 2003). An improvement in communications amongst project stakeholders could lead to, a reduction in project failures, better innovative technical solutions, improved quality of the project and better decision during project briefings (Hoezen, Reymen and Dewulf 2006). To solve the fragmentation issues plaguing the industry and to improve communication, the industry would have to adopt new forms of collaboration and the process oriented technology to implement them. These issues relating to communication in the industry has led to various research efforts into the use of information technology (IT).

\subsubsection{IT Use in Construction}

Communication is a difficult subject as it is multidimensional and indefinable. In the case of the AEC industry, there is an excess of diverse communication between the different participants (Zulch 2014). Communication can either be, computer-mediated communication (CMC) or nonCMC. Information and Communications Technology (ICT) is an umbrella term that covers a wide range of computer-based technology and can be defined as,

...technology that encompass computer hardware, software and devices that allow the sharing and access of information conveniently locally and worldwide

(Forbes and Ahmed 2010)

This dissertation uses the term IT, which is more apt as it relates to the use of computers, software, networking and other IT infrastructures in big companies and corporation. ICT is a 
term that is more appropriate towards the education setting (Julita 2011). Improving communication and collaboration through the application of IT in the AEC industry is a major topic within scientific research and industry. Over the past 50 years, research and development on IT use in the AEC industry has been largely focussed on software development and the use of computer networks to help manage project information, and support communication and collaboration (Amor, et al. 2002, Becerik, A review on past, present and fututre of web based

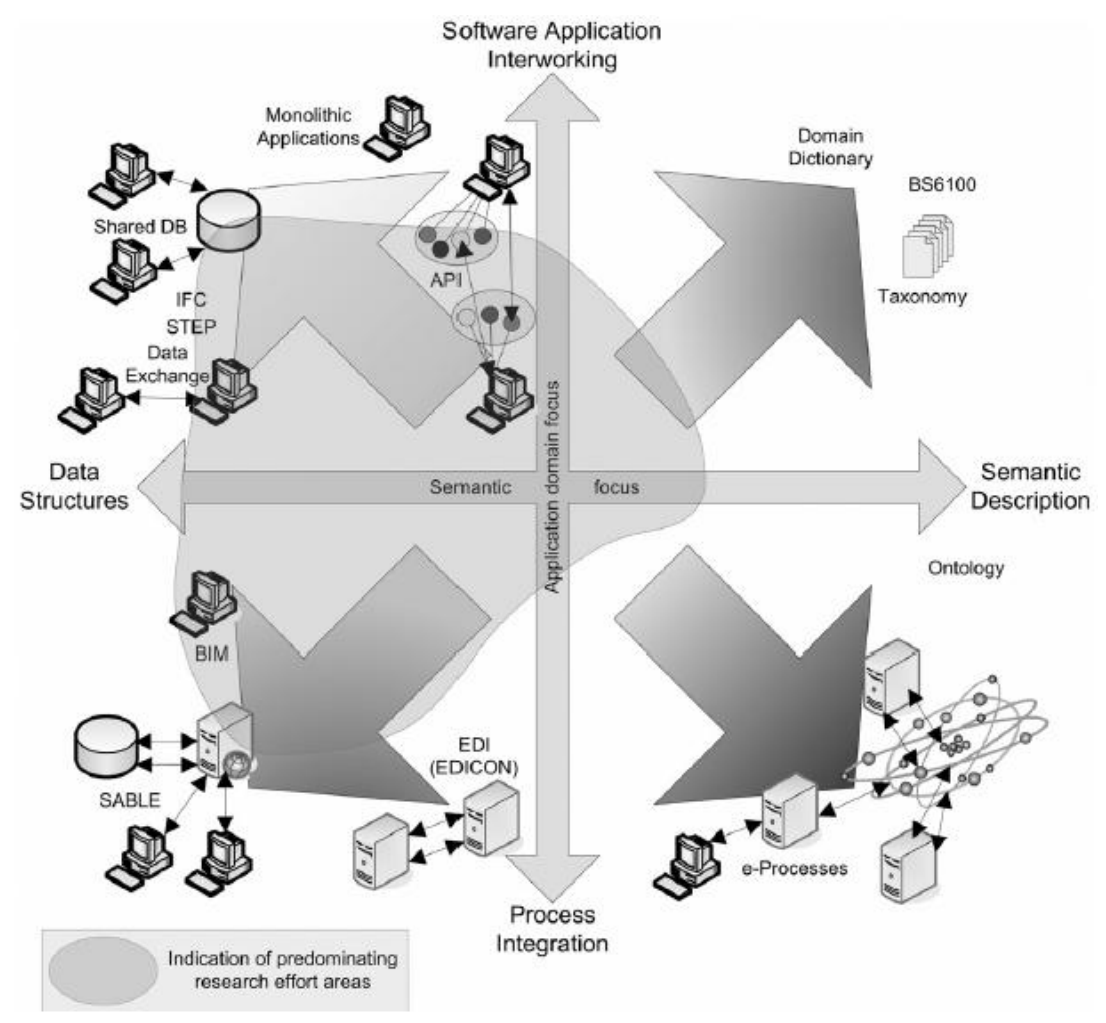

FIGURE 1: The CIC research landscape by (Boddy, et al. 2006) 
project management \& collaboration tools and their adoption by the US AEC industry 2004).

Research surrounding IT and use in the construction industry are synonymous with terms such as; computer integrated construction (CIC), 'computing in civil engineering', 'information technology in construction', 'construction IT' and construction informatics (CI) (Turk, Construction Informatics: Definition and Ontology 2006). Due to the fragmentation of the industry a variety of software were developed in isolation. Currently there are seven categories of software for AEC projects (Matheu 2005). Figure 1 shows the research landscape concerning IT use according to Boddy et al. Researchers have in the past, considered the implementation of building information modelling (BIM), developing CAD from $3 \mathrm{D}$ to $\mathrm{nD}$, interoperability and standardisation of data formats, and the development of semantic resources in the construction sector ranging from domain dictionaries to specialized taxonomies (Boddy, et al. 2006). The BIM research subject has been the focus of much research over the past 30 years, however it has yet to be widely adopted and implemented in the industry. The fundamental question of: 'How can practitioners solve their current communication problems?' has been largely ignored due to this (Wikforss and Lofgren 2007).

More recently there has been a focus on web-based technological solutions, collaborative visualisation, virtual reality and CAD applications (Abuelmaatti and Ahmed 2010).

The adoption of IT is still lagging in the construction industry. Adoption of IT in the industry is piecemeal, discrete and non-systematic. This is often attributed to negative perceptions of technologies, which can only be avoided though experiencing its advantages. The openness of these technologies is receiving attention of not only academics and amateurs but also of
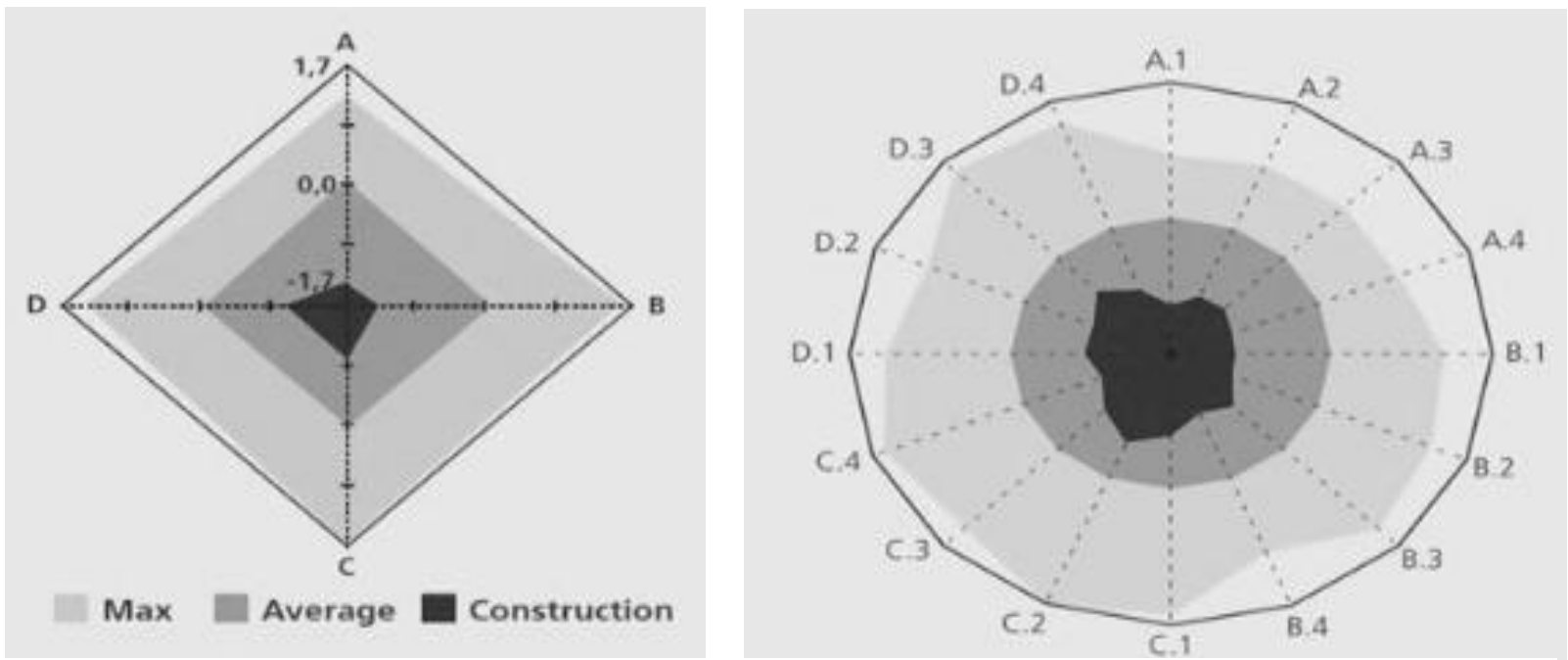

FIGURE 2: Construction industry productivity improvements compared to other industries. This has to do with a slow ICT uptake. The industry is proactive adopting e-business as a tool to increase competitiveness adapted from (Valsson 2012) 
business entities and government organisations (Mak 2001)

Issues such as the industry's fragmentation, cost of technology, interoperability and information overload are just some of the barriers against IT adoption (Dainty, Moore and Murray 2006). Figure 2 compares the productivity gains as seen in other industries against the construction industry. The construction industry has a relatively low productivity gain. This is directly related to a lag in IT adoption and investment from organisations in the industry. The AEC industry employs a reactive approach rather than a proactive approach towards the adoption of tools for e-business which ultimately sees organisations losing out on potential benefits provided by IT (Valsson 2012). 


\subsubsection{The Internet}

The Advanced Research Agency Network (ARPANET) computer network (between 1969 and 1987) comprising of four computers was mostly used by scientists and academics. ARPANET rapidly grew into a global network of computers culminating in the introduction of the 1993 graphically (text, full-colour graphics and photos, audio and video) based World Wide Web (WWW, W3 or Web) (Tam 1999). The use of the Internet in the construction industry is not a new concept. Conventional Internet-based IT in the modern workplace include email, file sharing with email attachment, shared databases, intranet, extranets and the Internet itself (Walker and Betts 1997). The Internet enabled the development of distributed systems that supported cross-organisational collaboration, while also providing the opportunity to automate teamwork and workflow processes. Small to Medium Sized Enterprises (SMEs) make up most of the construction industry and stand to benefit from adopting these web-based tools for communication and collaboration. However, there is a general mistrust in the use of the Internet for disseminating important information by SMEs resulting in a slow uptake of web technologies in the industry (Matheu 2005).

Web 2.0 was coined in the "O'Reilly Media Web 2.0 Conference" in 2004 to describe the second generation of Internet-based tools and services that persists today. It describes a paradigm shift in the Internet's use, from passive consumption of content, to a more participative one (O'Reilly, What Is Web 2.0? 2005). Kabir gives a construction-based analogy comparing Web 2.0 to its predecessor;

Web 1.0 was like building houses from cement, sand, crushed bricks and aluminium. You had to mix cement, bricks and sand together to make concrete, then use concrete to make the house. With newer Web 2.0 technologies you effectively have concrete, prefabricated walls, corrugated iron sheets, etc. to build houses. So, you can make more interesting and elaborate houses than before.

(Kabir 2006)

The introduction of Web 2.0 tools, technologies and associated theories has provided a platform for its adoption across different sectors and by various disciplines. This has seen the connotation of the '2.0' in 'Web 2.0' in various contexts. Web 2.0 has had applications in corporate settings, the education sector, government, pharmaceutical companies and even in military. Although, some researchers argue that, the '2.0' (two-point- 0 ) is just a buzzword and a catch-all term that has been misused/misplaced in some instances. The most well-known application of Web 2.0 technologies is in enabling Social Media (SM) platforms. Today there are various types of SM platforms that provide a variety of tools and services for its users. Popular 
SMs include social networking sites (SNS) Facebook and Twitter and media sharing sites such as YouTube, Flickr.

A survey by Chui et al (2012) recorded over 1.5 billion Social Networking (SN) users globally, with $80 \%$ of users interacting via SN on a regular basis. Moreover, a remarkable $70 \%$ of organisations surveyed were also using some type of social technology with $90 \%$ of them reporting some business benefit from using them. The current use of SM is laggard and minimal within the AEC industry compared to other sectors. A study by the Society for Marketing Professional Services (SMPS), entitled "The Clients use of Social Media and Social Networking" indicated that AECs use of SM was divided up into 36\% Engineering, 24\% Architecture and 17\% for construction landscape design and facility owners.

SM was found to be mostly used as a recruiting tool or a marketing tool to build awareness and nurture relationships. Collaborative tools such as blogs, wikis, tagging etc. which had potential use for content management, information sharing, knowledge management, and collaboration were mostly ignored (Bolton, et al. 2011, Butcher 2015). With this initial interest and use of SM in the AEC it would be beneficial for construction project management (CPM) to start looking at further avenues in the application of SM technologies and theories to bolster project collaboration, alleviate the adversarial relationships amongst project participants and enhance the management of information within project teams. 


\subsection{Significance of Research}

Construction projects require collaborative and coordinated working by a diverse team of project organisations. Collaboration is essential to the success of construction projects. Collaboration is defined as;

A process in which entities share information, resources and responsibilities to jointly plan and implement and evaluate a programme of activities to achieve a common goal

(Ollus, et al. 2011)

Collaborative working relies on the communication and the flow of information between people and technological artefacts (Valsson 2012). Communication is an important knowledge area in the, project management (PM) body of knowledge (PMBOK). PMBOK defines it as, the knowledge area that employs the processes required to ensure the timely and appropriate:

...generation, collection, distribution, storage, retrieval and ultimate disposition of project information

(Project Management Institute 2013)

Project communication is vital to Project Managers (PMs) who spend about $75 \%$ to $90 \%$ of their time managing communication within project teams and to important external stakeholders that have a vested interest in the project. About 15\% of the PM's Day is spent on searching for information alone. The construction industry requires a system that can provide real time information and be efficient in generating information for communication, storage and retrieval (Ahuja, et al., 2006).

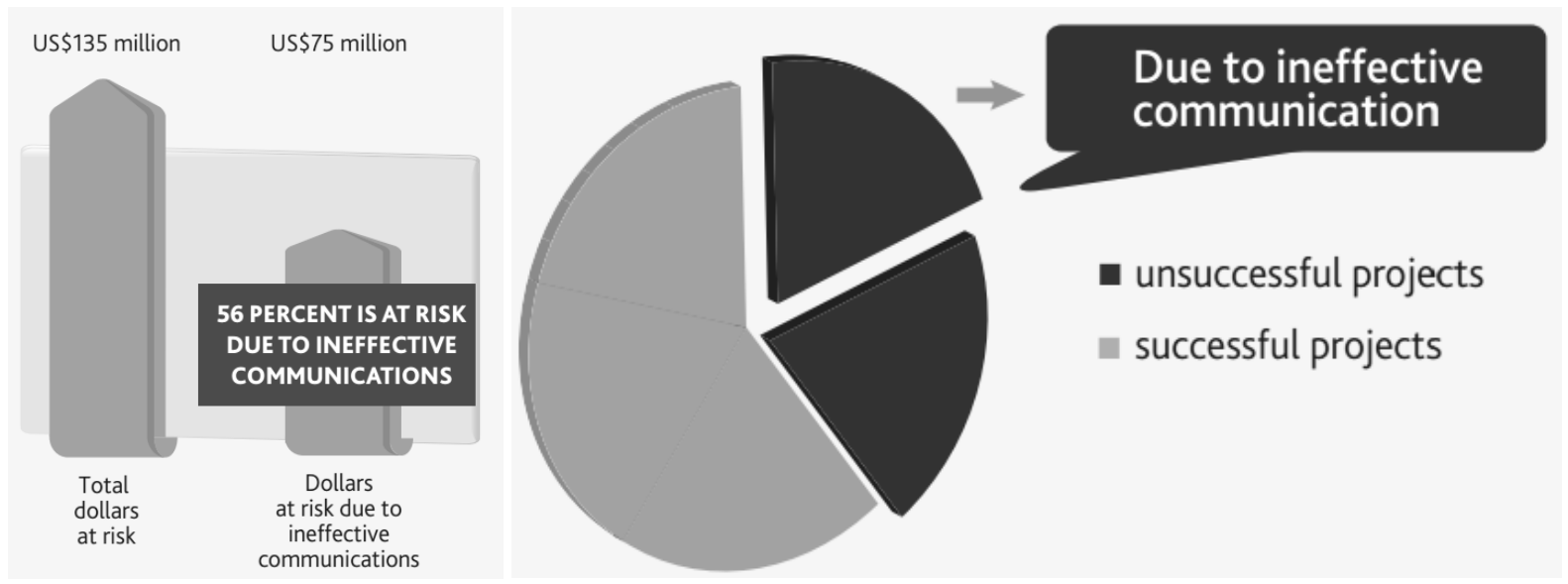

FIGURE 3: Results of the survey by PMI to the left the amount at risk for every US\$1 billion spent on construction projects with 1 in every 5 projects failing due to ineffective communication, adapted from (Project Management Institute 2013) 
The success of the project hinges on the PM's ability to communicate effectively and efficiently regarding the four constraints of a Project (Scope, Time, Cost and Quality) (Zulch 2014) . Figure 3 demonstrates failed projects due to communication inadequacies. A survey conducted by the Project management Institute (PMI) in 2013, revealed that for every US\$1 Billion spent in the construction industry about US $\$ 135$ Million is at risk. Two fifths of projects fail by not meeting project goals or business intent. Out of this just over one fifth of failed projects is due to ineffective communication. This translates to US\$75 Million at risk due to communication problems (Project Management Institute 2013). The PM profession has deep roots in the construction industry. However, as a profession that prides itself on being innovative, Project Management is not innovating its way into the 21st century. The last great innovation in project management was the precedence diagramming method, developed by John Fondahl in the 1960's (Harrin, Social Media For Project Managers 2010). Researchers have noted that Internet is the technology that can best facilitate a collaborative working environment in a construction project (Nitithamyong and Skibniewski 2004, Alty 1993, Walker and Betts 1997). Recently, there has been a lot of interest generated surrounding the use of SM and Web 2.0 based tools for project management. A knowledge gap exists concerning the usage of SM in managing projects as there are no associated models with its use. The management of project communication requires more than just the confirmation of transaction. It is possible in this respect for SM to manage relationships, build trust and manage stakeholder expectations (Remidez and Jones 2012). Communication and collaboration have a significant effect on project success and is very important to PMs. This thesis aims to investigate the practicality of SM adoption and how it can be integrated within construction projects. 


\subsection{Research Question and Scope}

The initial research question that underpins this thesis is;

"How can Social Media be used by Project Managers to support communication management and collaboration in construction projects?"

Given the breadth of this initial research question, it has been deconstructed to present three fundamental questions for this dissertation.

TABLE 1: Research question matched against proposed research methods

\begin{tabular}{|c|c|c|c|}
\hline Research Question & LR & $\mathbf{S}$ & SR \\
\hline (1) What is the current state of IT use in the construction industry? & $\bullet$ & $\bullet$ & \\
\hline (2) Is there a need for Social Media in construction projects? & $\bullet$ & $\bullet$ & \\
\hline (3) How can SM be used for construction project management? & • & & • \\
\hline
\end{tabular}

The thesis employs the use of three tools of research; a Literature Review ( $\boldsymbol{L R})$, Survey (S) and a Software Review (SR). Table 1 demonstrates how the research methods is mapped onto the research questions that they are aimed at answering.

\section{Question 1}

The first question is aimed at gauging the collaboration and communication tools being used by construction industry professionals through a literature (LR) exploration and an online Survey (S). This question is fundamentally used to frame the questionnaire of the Survey as well.

\section{Question 2}

The need for SM in construction project is addressed through a review of literature that explores the communication and collaboration tools that are currently being used by PM in the construction industry. The literature discussed in this dissertation focusses on web-based technology. Furthermore, a Survey for industry professionals is intended to also gauge current levels of SM use in the NZ construction industry while also evaluating the respondents' use of IT and web-based technologies.

\section{Question 3}

The second research question directs the LR towards exploring Web 2.0-based collaboration technologies and the relative ideologies. This focuses much of the research on web-based project management software (WPMS) and Social Software. It is intended that a product of the LR and SR will be the synthesis of a conceptual web-based software that can be used by PMs for 
managing construction projects while simultaneously facilitating a collaborative virtual project space for all project stakeholders on the Web. It is important to note that this dissertation delivers an overview of core collaborative functions and tools of the concept platform and outlines how it could be used for CPM. The concept platform, Gantt 2.0 is based from two precedent platforms that will also be presented. 


\section{Thesis Outline}

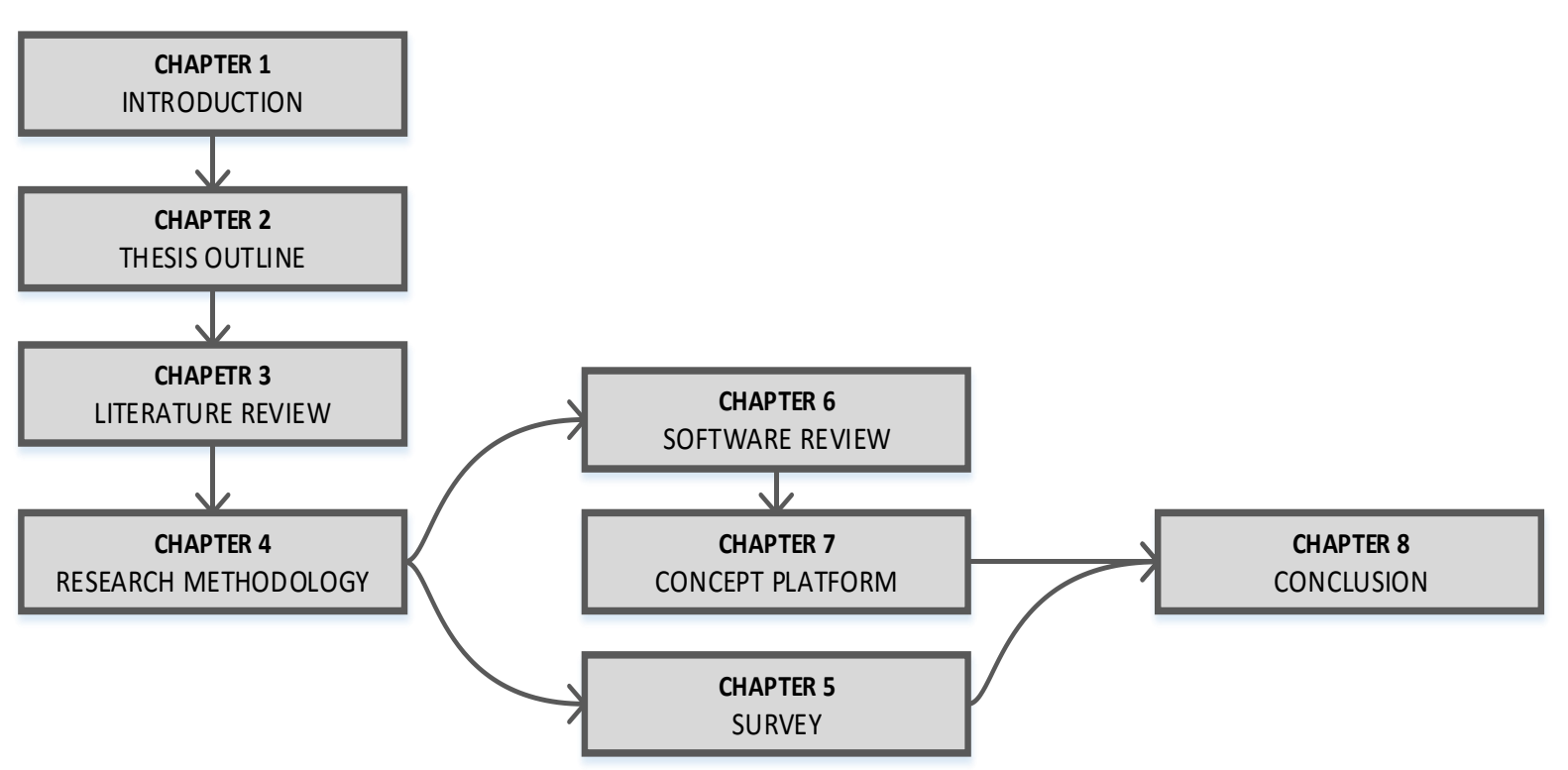

FIGURE 4: Thesis structure

The thesis outline in Figure 4 shows the structure of the dissertation. The chapters and headings assigned above reflect the actual table of contents of this thesis and how the chapters relate to each other. The proceeding sub-chapters and gives a brief overview on what is discussed within them.

\subsection{Introduction}

This Chapter introduces the thesis question and sets the direction for the Literature Review. The scope and research questions underpinning the thesis is also discussed to provide the reader with more insight as to what is going to be discussed and researched in the main body of the dissertation. In addition, the significance of this study is also discussed in this chapter.

\subsection{Literature review}

Chapter 3 of this dissertation is effectively divided into two parts. The first part of the literature (Chapter 3.1) looks at IT use in the construction industry and web-based software use for PMs. The second part of the Literature Review (Chapter 3.2 - Chapter 3.6) delves into the emergence of Social Media, its role in today's workplace and its implications for the project management methodology used by PMs in the construction industry. 


\subsection{Research Methodology}

This chapter describes in detail, the two research methods used in this dissertation. The research methodology also looks at the research parameters that were set for each method and why they were chosen.

\subsection{Survey Analysis}

This chapter looks at the analysis of the Survey. Topics that are discussed in this Chapter include IT use in the workplace and SM use for personal and professional purposes. Apart from this, the Survey is essentially aimed at answering the first research question.

\subsection{Software Review}

This chapter gives a review of 10 chosen web-based project management software which exhibit characteristics of what is termed in this thesis as Social Project Management (SPM) software. The review collates information on the tools and services that are offered by these web-based software in this Chapter. The information gleaned from the review is then used to describe a conceptual platform for construction project teams.

\subsection{Concept Platform}

This chapter bring together the findings from the Literature Review and the Software Review and uses the information that was gained to describe a conceptual platform that could potentially be utilised in construction projects.

\subsection{Conclusion}

This chapter presents the entire research in a summarised format and discusses the limitations of the research methods that were used. This chapter also discusses the impact of this research and the lessons learnt that can be used to direct future research. 


\section{Literature Review}

\subsection{Background}

\subsubsection{The Construction Project}

A typical construction project contains a series of phases and brings together construction firms of diverse disciplines. Project managers (PMs) typically adopt the CDEF lifecycle model to illustrate the relatively linear progression of the project.

\section{CONCEIVE Inception \\ Client identifies need \\ Feasibility \\ Can it be done \\ within proposed constraints? \\ DEVELOP \\ Design \\ Drawings prepared

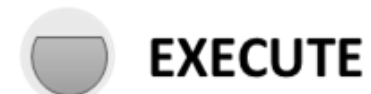 \\ Tender \\ Quotes sought \\ Construction \\ Work completed \\ FINISH \\ Final testing and handover}

FIGURE 5: A generic project management overview of a construction project from concept to the final built phase of the project adapted from (Young 2008)

The CDEF model in Figure 5 gives an overview of a typical project lifecycle. The Concept phase sees the commencement of the project. At this stage, the feasibility of the project is checked, key stakeholders appointed, and an approved Project Charter/ project brief/proposal is published. The Project Charter is a document that formally acknowledges the approved project, appoints the Project manager and provides planning guidance. Develop phase outlines the details for the implementation of the project, beginning with the development of a work breakdown structure (WBS) and ending with a comprehensive workable project plan that can be implemented. Execute phase of the project is where the actual work is done. Resources procured, work is assigned, progress monitored, corrective actions taken, and the final deliverable produced. At the Finish stage, the project is handed over to the project sponsor or client. A post implementation report is also prepared and a review of the initial benefits of the project is done. Other lifecycle frameworks exist that differ in terms of terminology used and number of project phases; the fundamental concepts are still the same (Young 2008). 


\subsubsection{Information Flow}

Stephen Mak in his analysis of information flow in construction projects surmises that much of the information integral to a project is drawn from Tender documents. When referring to the CDEF model, the tendering process occurs during the Execute phase. Many of the contractors and construction firms, solicit jobs through the tendering process. Information in the Tender documents typically include Bill of Quantities, Specifications, Drawings and so on. Other types of information used in construction include detailed drawings and photos, cost analysis sheets, budget reports, risk analysis charts, contract documents, planning schedule (Tam 1999).

The design phase of the project involves the sharing of drawings and other documents between project participants' Essential information gathered through the concept and development phase of the project is collated in the tender documents which is where the bulk of the information arrives at the contractor. During the enduring stage, there is an exchange of tender documents between clients, contractors and subcontractors. The construction stage mainly involves the buying and selling of building materials take place over the Internet (Forcada, Casals and Roca, A model for Construction Project Management extranets 2003).

When a tendered project is won, the Quantity surveying department takes over the tendered project and a Project Team is assembled. At this point, a site office is set up and the Purchasing Department is given a schedule of material requirements. The Accounting and Personnel Departments then set-up appropriate files/databases for project accounting/financing and human resource administration. A general office team is charged with the responsibility of duplicating the Tender documents for distribution to the relevant parties of the project team. Even if a Tender is not won, the tendered project will still have to be archived for record and analysis (Mak 2001). It is the responsibility of each and every member of the project to prepare the necessary information for the other stakeholders of the project. The PM is responsible for developing the communications plan for the entire project team with input from both the task managers and the project team development team (PDT) (Caltrans- Office of Project ManagementProcess Improvement 2007). Table 18 in Appendix D, lists some of the IT that is currently available for PMs. The use of such computer-based and networked IT has substantially made the work of the PM easier. 


\subsubsection{Web 1.0}

Use of computer in the construction industry can be traced back to the 1970s' and 1980s' when Finite Element analysis programmes (FEAP) and computer aided drafting (CAD) software were developed. Today there are 7 categories of software currently used in the construction industry. The categories reflect the different disciplines that are typically involved in the building industry and is used to manipulate and process data and information relevant to building projects. The research landscape concerning the use of IT in the construction industry is very broad. Published papers that have tried to collate and determine trends in the direction of IT research include (Amor, et al. 2002), (Boddy, et al. 2006) and (Turk and Cerovsek 2003).

The application of IT in the construction industry come with associated benefits and challenges. While most of the IT research has been focussed on rationalising design and production, collaborative communication and its supporting technology have been reduced to a secondary priority in the construction industry (Wikforss and Lofgren 2007).

Since its inception in the 1990s, the Internet and its associated technologies was touted to have a great impact on the AEC industry and a facility to support open collaboration in construction projects (Walker and Betts 1997, Al-Reshaid and Kartam 1999). There has been an extensive amount of research in its application in construction projects following the aforementioned research papers. Research on the use of the web range from:

1) Creating websites for construction sites (Nuntasunti and Bernhold 2002)

2) Developing web-based information systems for collaboration between individuals and organisations (Rezgui, Zarli and Bourdeau, Inter-enterprise Information Management in Dynamic Virtual Environments: The OSMOS Approach 2000) (Deng, et al. 2001) (ElTayeh \& Gil, 2005) (Roh, et al. 2006)

3) Creating collaborative search engines for discovering construction information on the Web (Bakis \& Sun, 2000)

4) Collaborative knowledge management systems (Dave and Koskela 2009).

Research concerning Internet use for construction projects is more extensive than this. On the other hand, research by (Klinc, Dolenc and Turk 2008) and (Dave and Koskela 2009) have started to look towards the incorporation of Web 2.0 technologies in the construction process to support more collaborative approaches to information sharing and communication. 


\subsubsection{Intranets Vs Extranets}

Intranets and Extranets are the most powerful applications of Internet technology. Early Intranet systems usually had an extended electronic document management system (EDMS) which was used to manage distribution, storage, and retrieval of drawings and documents. Intranets were also used with enterprise resource planning (ERP) software by construction companies/projects to manage its various functional activities such as, material procurement, human resources, finance, plant hiring etc. The introduction of the Internet afforded external collaboration for intranets and the emergence of web-based software such as Microsoft SharePoint. These web-based platforms were easy to customize and were widely adopted by Small to Medium enterprises (SME) (Lam, Wong and Tse 2010, Onyegiri, Nwachukwu and Jamike 2011). Extranets allow access to external collaborators via virtual private networks (VPN) and the Internet. Access to Extranet systems can be attained through any standard web browser. Users/organisations who do not possess their own in-house IT expertise are able to use the equipment and services of an application service provider (ASP) for their project management and information depository needs (Lam, Wong and Tse 2010). The different types of networking offer varying degrees of security for information exchange. VPN is considered to be the most secure of the 4 types of networking (refer to Table 19 in Appendix D).

\subsubsection{Internet-based Communication Model}

The use of computer, networking technology and the Internet has revolutionised the traditional communication model. Traditionally, interactions between the various project participants is typically modelled in Figure 7 below. The organisational chart for a typical construction project is typically hierarchical and multi-layered and is a useful tool for management. It does not necessarily show how project participants interact with each other.

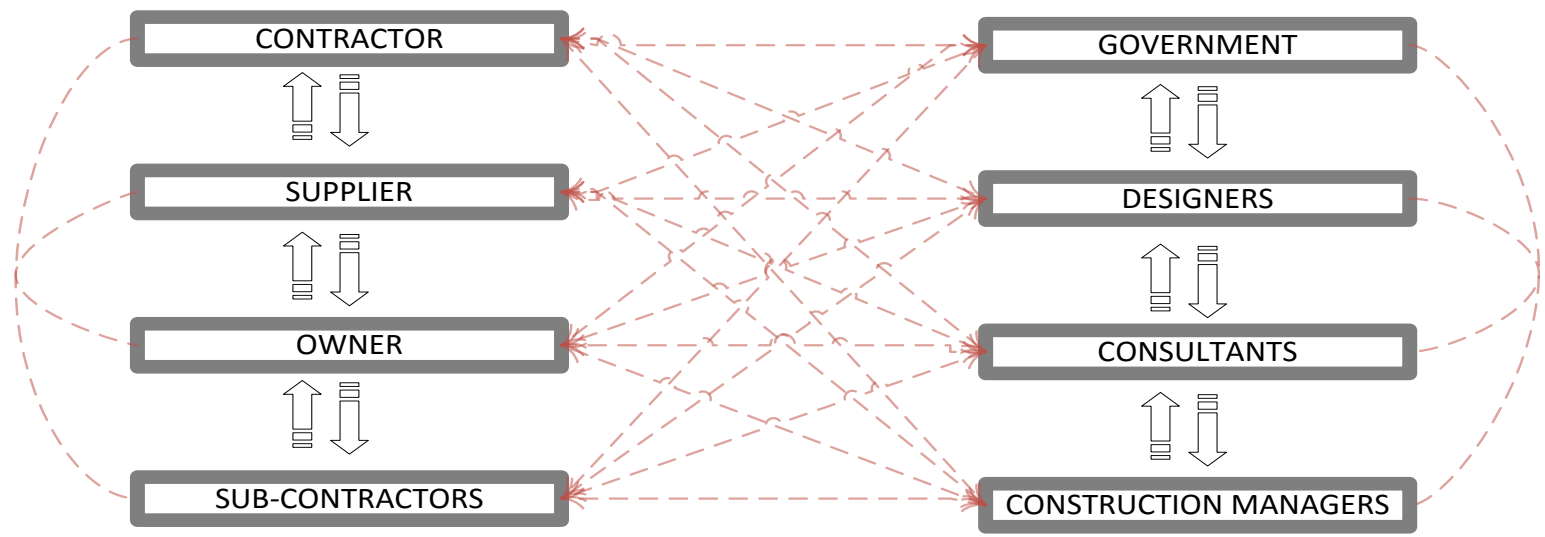

FIGURE 6: The conventional communication model adapted from (Shami and Elzarka 2000) 
The conventional communication model in Figure 6, illustrates the interaction between stakeholders involved in a typical construction project. In the instance where a message must be communicated to different parties involved, the message will have to be communicated many times e.g. the communication of change orders. Typically, a team of 100 participants could be generating up to 4,950 channels of communication, which can be chaotic. The traditional communication model is quite stringent and hierarchical, only allowing for direct communication channels and restricts the standardisation of messages. This ultimately results in misunderstandings and confusion, causing potential claims and cost or schedule overruns.

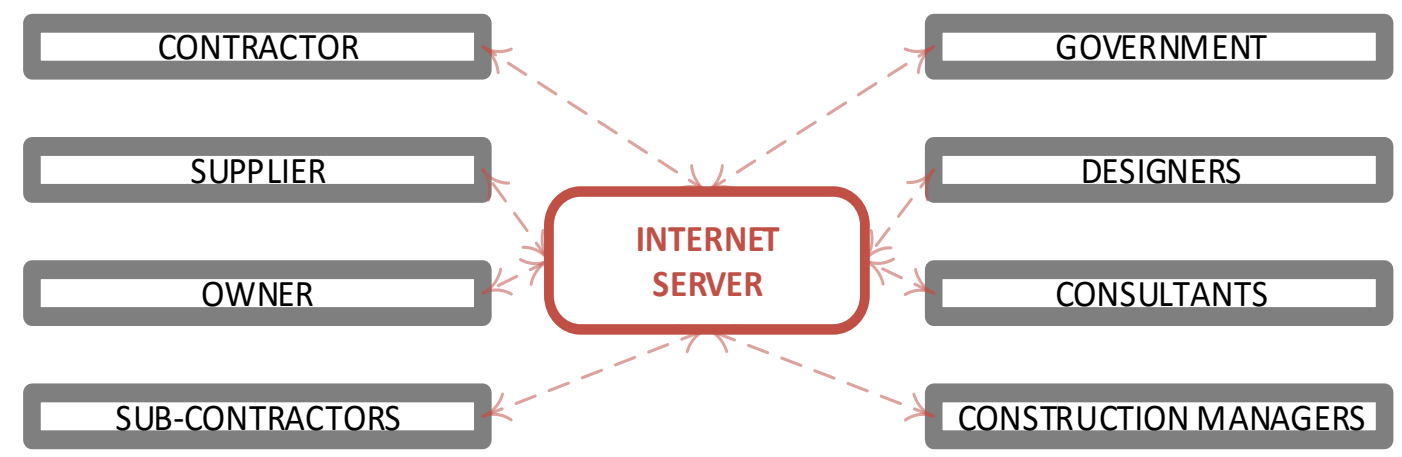

FIGURE 7: Internet-based communication model adapted from (Shami and Elzarka 2000)

In comparison, the Internet based model only generates 100 channels of communication as all participants have access to the same information located on the project server. The Internet model is much more efficient at managing large projects as it reduces the number of communication channels while improving the quality of communication by standardising the content of the messages (Shami and Elzarka 2000).

\subsubsection{Project Management Software}

Project management software is an umbrella term that refers to a variety of software. Such software is utilised by PMs; for estimation and planning, scheduling, cost control and budget management, resource allocation, as collaboration software, for communication, quality management and documentation or administration systems. The first use of project management software dates to the 1950s through the development and application of two methods which are quite popular tools in PM. The Critical Path Method (CPM) of network scheduling and the Project Evaluation Review Technique (PERT). PM software can be categorised into desktop applications, web-based Applications, personal or single user applications and collaborative applications (Kundu, et al. 2015). Construction project extranets (CPE) is an umbrella term that is used to describe web-based software hosted by ASPs excluding web-enabled software. CPEs also include web-based project management software that enhanced collaboration and communication (Becerik 2004). This dissertation looks towards the 
use of web-based collaborative applications for PMs. Cloud computing has made it easier to provide software over the Internet some of the definitions regarding cloud computing is discussed below.

\subsubsection{Cloud Computing}

Cloud computing is the delivery of computing services over the Internet. Social networking sites and webmail are perfect examples of cloud services. Cloud computing enables data access and storage, and web-based software over the Internet. It also encompasses hardware, systems software and applications which are all delivered over the Internet. There are two types of clouds, Private Cloud is used when the cloud infrastruture is operated solely for a business or an organisation. A Public Cloud on the other hand is made available in a pay-as-you-go manner to the general public. A composition of the two types (private and public) is called a Hybrid Cloud. A Hybrid Cloud is one where a Private Cloud can maintain its high service availability by supplementing or scaling up their system with externally provisioned resources. These resources are provisioned from Public Clouds when there are rapid workload fluctuations or hardware failures in the Private Cloud (Antonopoulos and Gillam 2010).

\subsubsection{Software as a Service (SaaS) and Application Service Provider (ASP)}

There are three types of services that can be proved via cloud computing. This dissertation focuses on software as a service (SaaS). SaaS is the provision of software over the web by application service providers (ASPs). The user can subscribe to the software service from the manufacturer through the Internet. The ASP supplies software via a standard web-browser, and charges according to the quantity of software and using time. Examples of such services include Salesforce.com, Google Doc, Google Apps and Zoho Office etc. (Zhang, Yuan and Chen 2012). Application Service Providers (ASPs) are third party software providers that manage and distribute software-based services and solutions to customers across a wide area network (WAN) from a central data centre. In essence, ASPs are a way for companies to outsource some or almost all the aspects of their IT needs.

\subsubsection{Web-enabled vs Web-based Software}

Web-enabled or stand-alone software may use the Internet to exchange data, however they require initial instalment of application-specific software on all workstations that needs to run the tool. Alshawi and Ingrige (2003) provide more insight into the subject of web-enabled PM software in their study. In comparison web-based software only require an Internet connection and a web-browser to gain access to the tool. Web-based tools are more efficient as they mean a 
reduction in IT staff and maintenance related costs while being easily accessible (Verheij and Augenbroe 2005)

\subsubsection{Web-based Project Management Systems}

Web-based project management system/software (WPMS) is an:

Electronic project management system conducted through the Extranet, which is a private network that uses Internet protocols to transmit information

(Nitithamyong and Skibniewski 2004)

WPMS is an outsourced Internet-based project information and workflow management service. WPMS platforms typically have document management, team communication, collaboration, and business process automation services built into them (Matheu 2005). There are three options regarding how WPMSs are made available.

1) Develop a customized WPMS in-house by hiring either a consulting company or programmers to create a system.

2) Develop a WPMS by purchasing commercial web-enabled software and installing it on a company's internal server.

3) Rent/lease a completely developed WPMS from an ASP for a usage fee which is charged per project, per the amount of computer storage space required and or per user.

The third option is also referred to as a "Project Management-Application Service Provider" (PM-ASP). The PM-ASP option is generally adopted as it requires minimal technical, financial and human resources to develop and maintain. The initial investments and overhead costs are also quite low for this option. PM-ASPs specific to the construction industry can be further divided up into three categories, Project Collaboration Network (PCN), Project Information Portal (PIP), and Project Procurement Exchange (PPE). In addition to the three types of PMASPs (refer to Table 20 in Appendix D), there are also 'Full Service Portals' which integrates functionalities of all three types of PM-ASPS in a single system. Team members can track and manage project documents online, communicate and share information, search online catalogues for needed resources, and conduct electronic bidding and procurement using PMASPs (Nitithamyong and Skibniewski 2004). 
TABLE 2: Software review websites with the number of available PM software compared to Software specific to PMs in AEC industry

\begin{tabular}{llll} 
Website & URL & $\begin{array}{l}\text { PM } \\
\text { Software }\end{array}$ & $\begin{array}{l}\text { Construction } \\
\text { Specific PM } \\
\text { software }\end{array}$ \\
\hline Software Insider & http://www.softwareinsider.com/ & 391 & 167 \\
\hline Capterra & http://www.capterra.com/ & 388 & 165 \\
\hline Trust Radius & https://www.trustradius.com/ & 199 & 104 \\
\hline G2 Crowd & https://www.g2crowd.com/ & 224 & 169 \\
\hline Software Advice & $\begin{array}{l}\text { http://www.softwareadvice.com/nz/proje } \\
\text { ct-management/ }\end{array}$ & 157 & 174 \\
\hline
\end{tabular}

A simple online search was conducted as at March 2016, within five separate software review websites for web-based/ cloud-based PM software. The results are shown in Table 2. There is a plethora of web-based software for PMs. Software Insider lists about 391 different types of software, of these just over $40 \%$ of are specific to the construction industry. This is still a high number of software. These software differ in the range of services that they offer their users. Project management software can be specific in terms of:

- User types (Architect, PM, Engineer etc.)

- Software delivery type (web-based or web-enabled, Mac or windows operating system, mobile device compatibility etc.)

- Size of the organisations (small, medium, large etc.)

- Project type (residential, commercial, public infrastructure, engineering etc.)

- Services offered by the software (document management, project management, task management, calendaring, email integration, calendaring capabilities etc.)

Competition between rival software which are quite similar in functionality and target similar customers mean that some software often falls into obscurity and obsoleteness against more popular tools. Software companies also often undergo re-branding which results in a change of software name or design. This usually occurs if a new company or developer takes over the rights to a software. This results in fluctuations in the number of software available in the market at any given time. 
TABLE 3: Top 10 web-based construction project management (CPM) software from (Software Insider n.d., Capterra n.d.)

\section{Software}

Procore

Aconex

Viewpoint

NewForma

Builder TREND

PMWeb

Co-Construct

E-builder

SimpleBuild

Projectmates
URL

www.procore.com

www.aconex.com

www.viewpoint.com

www.newforma.com

www.buildertrend.com

www.pmweb.com

www.co-construct.com

www.e-builder.com

www.simplebuild.com

www.projectmates.com

Table 3 shows a list of the top 10 PM software identified from review sites Software Insider and Capterra. The 10 identified software are construction industry specific and they differ in the services they offer, size of organisations and the targeted user of the software. These software solutions are often scalable and can be configured to suit different projects. Different types of WPMS offer certain services for its users. PM-ASPs are quite useful, but adoption and implementation are still hindered by many factors. Implementation requires readiness not only in one organisation but in all organisation involved in the project (Alshawi and Ingirige 2003). Some of the barriers against the implementation of PM-ASPs identified by (Nitithamyong and Skibniewski 2004) are listed in Table 22 in Appendix D. PM-ASPs are not specifically designed to be a complete communication and information handling solution. The PM-ASP system is lacking in that it is not designed to interact with the standard tasks of individual project team members. The collaborative maturity of project teams need to be at a certain level as well for successful PM-ASPs implementation. In this respect, collaborative maturity means the level to which team members are willing to work together and share information and experience to make a project succeed. Furthermore, there hasn't been an empirical study carried out on a large scale for the use of PM-ASP software in the construction industry which would be able to benefit from PM-ASP systems in projects. In addition to that PM-ASPs are more practical to be used in Small to Medium Enterprises (SMEs) (Nitithamyong and Skibniewski 2007) 


\subsubsection{Social Software}

Groupware is a term used to describe computer-based systems that are used to support groups of people that collaborate on common tasks. Other terms that hold similar meanings include Office Automation (OA), Social Software and Collaborative Software. Disagreement with the use of either terms still exist amongst researchers in the field of computer supported collaborative (or cooperative) work (CSCW) (Allen 2014). CSCW is the scientific discipline guiding the design and development of collaborative software (Penichet, et al. 2007). This dissertation uses the term Social Software and Collaborative software instead of Groupware. Social software is defined as terminology that encompasses:

...all uses of software that supported interacting groups, even if the interaction was offline

(Boyd 2007)

CSCW in the construction industry focuses on the use of tools such as centralised databases, systems for workflow management (WFM) and electronic document management (EDM) (Leeuwen and Fridqvist 2006).

TABLE 4: List of team collaboration software (Capterra n.d.)

\begin{tabular}{|c|c|c|}
\hline Software & Developer & URL \\
\hline Chatter & Salesforce & www.salesforce.com/eu/chatter/overview/ \\
\hline Slack & Slack Technologies & www.slack.com \\
\hline Confluence & Atlassian & www.atlassian.com/software/confluence \\
\hline Yammer & Microsoft & www.yammer.com \\
\hline SharePoint & Microsoft & www.sharepoint.com \\
\hline Wrike & Wrike & www.wrike.com \\
\hline $\begin{array}{l}\text { Facebook at } \\
\text { Work }\end{array}$ & Facebook & https://work.fb.com/ \\
\hline $\begin{array}{l}\text { IBM } \\
\text { Connections }\end{array}$ & IBM & www-03.ibm.com/software/products/en/conn \\
\hline Podio & Citrix & www.podio.com \\
\hline Jive & Jive Software & www.jivesoftware.com \\
\hline Dropbox & Dropbox, Inc & www.dropbox.com \\
\hline
\end{tabular}

Table 4 gives a list of the top collaboration software on the software review website Capterra. The software ranges from applications with single specific functions e.g. file and document handling, instant messaging, video and voice calling etc. to more extensive systems that include features that can be found across all four categories of collaborative software. Furthermore, most of the platforms above can integrate third-party applications within them. 
Bafoutsou and Mentzaz's in their study reviewed 47 different collaborative software which were available commercially or as research prototypes. The different services offered by these types of software were listed and divided into four main categories below.

TABLE 5: The four categories of collaboration services adapted from (Bafoutsou and Mentzaz, Review and Functional Classification of Collaborative Systems 2002)

\section{Categories of collaborative tools}

Group file and document handling

Computer conferencing

Electronic Meeting Systems (EMS)

Electronic Workspace

\section{Description}

This category of tools is mainly involved with documents and files and deals with information storage, retrieval, data exchange, individual editing, collecting authoring and revision of documents as well as synchronous work on documents. In addition, email notification and e-mail is also provided

Space for asynchronous and threaded discussions as well as realtime text talk and discussions is provided. File and document sharing capabilities. Audio and video conferencing is quite common.

Meeting conduction is the basic functionality of the EMS category. Meetings can either be regular (same time, same place), synchronous (same time, different place), or asynchronous (different time, different place)

This category of electronic workspace has the primary purpose of providing teams with a common space to coordinate and organise their work. Groups can essentially store documents and files, work with, solve problems through discussion, keep to-do lists and a directory of information about group contacts and can even be used to track project milestones and project interactions. Users may be members of several workspaces depending on the number of projects that they are involved with.

Social software can contain varying combinations of the collaborative tools identified in Table 5.

There are numerous web-based software described as 'team collaboration software' or 'social software'. These types of software are typically delivered on a SaaS basis by software vendors and require only a standard web browser to be able to access them. Furthermore, it is important to note that some of these software also have PM tools integrated within them and are also generally classified on Software Review websites as Project Management software. In this sense, there is a blurring between PM software and Social Software on a technological level, where ASPs offer an amalgam of the two software types. 


\subsubsection{Summary}

To summarise, typical construction projects create a very dynamic and complex environment for communication. The CDEF project lifecycle simplifies the construction project into four distinct phases (Young 2008). Most of the useful information essential to a typical project is contained in the Tender documents which is generated during the Execution Phase (Mak 2001). Applications of IT in the industry has tried to resolve the communication problems surrounding the industry (Becerik, A review on past, present and fututre of web based project management \& collaboration tools and their adoption by the US AEC industry 2004). More recently there is a growing body of literature aimed at using the Internet to facilitate a virtual collaborative working environment amongst the project participants. The traditional communication model is inefficient at managing the communication process, where the communication channels increase exponentially relative to the size of the project and the number of stakeholders involved. The server or Internet-based model ensures that everyone has access to the same information (Shami and Elzarka 2000). Cloud computing has enabled the provision of software as a service (SaaS) over Internet by ASPs. Software offered by ASPs can either be web-based or web-enabled. Today there are many ASPs who offer software catering towards the AEC. Two web-based software (WPMS and Social Software) for PMs were discussed. There is a growing amalgam of the services offered by both WPMS and social software in current state-of-the art software options.

The next half of the Literature Review delves into the evolution of the Internet into Web 2.0, its role in the corporate context through the emergence of Enterprise 2.0 and in Project Management in the emergence of the terms Project Management 2.0 and Social Project Management (SPM) theory. 


\subsection{Web 2.0}

Web 2.0 can be defined as;

...the business revolution in the computer industry caused by the move to the internet as a platform, and an attempt to understand the rules for success on that new platform. Chief among those rules is this: Build applications that harness network effects to get better the more people use them.

(O'Reilly and Battelle 2009)

Differentiating between Web 2.0 and Web 1.0 by describing technology is difficult so the two terms are usually presented as comparisons. Such a comparison is presented below.

TABLE 6: Key differences between Web 1.0 and Web 2.0 adapted from (Han 2012)

\begin{tabular}{ll} 
Web 1.0 & \multicolumn{1}{c}{ Web $\mathbf{2 . 0}$} \\
\hline DoubleClick & Google AdSense \\
Ofoto & Flickr \\
Akamai & BitTorrent \\
Mp3.com & Napster \\
Britannica Online & Wikipedia \\
Personal websites & Blogging \\
Evite & Upcoming.org and EVDB \\
Domain name speculation & Search engine optimisation \\
Page views & Cost per click \\
Screen scraping & Web services \\
Publishing & Participation \\
Content management systems & Wikis \\
Directories (taxonomy) & Tagging (folksonomy) \\
Stickiness & Syndication \\
\hline
\end{tabular}

While Web 2.0 does not in fact refer to any specific detail in the update of the Internet, three of the basic functionalities inherent of Web 2.0. The first, Adobe Flash is a popular method for adding animation, interactivity, and audio/video streams to web pages. RSS (Really Simple Syndication), is a family of web feed formats used to publish frequently updated content, such as blog entries or news headlines, in a standardized format. It is an XML document format that alerts subscribers, via a feed, to new web content such as media headlines, blog postings, and podcasts available for download. Thirdly, AJAX (Asynchronous Java Script), a technique to retrieve data from web servers asynchronously, allowing the update of web content without interfering with the display and behaviour of the whole page (Kaplan and Michael 2010). Apart from the characteristics of Web 2.0 outlined above, Tim O'Reilly also gives seven guiding principles (1) The web as a platform, (2) Harnessing collective intelligence, (3) Data is the next 'Intel inside', (4) End of software release cycle, (5) Lightweight programming models, (6) 
Software above the level of a single device, and (7) Rich user experience (O'Reilly 2005). These principles essentially articulated how the Internet changed from static brochure like web pages to support a more participate web in Web 2.0

\subsection{Social Media}

Social Media, began with the rise of social networking sites (SNS) Facebook and Myspace between 2003 and 2004. This dissertation uses an amalgamation of two definitions for SM such that;

Social Media refers to a group of Internet-based and mobile applications/services that builds on the ideological and technological foundations of Web 2.0, and that allow the creation and exchange of user-generated content (UGC) or join online communities.

(Kaplan and Michael 2010, Dewing 2010)

UGC is the sum of ways in which end-users utilise SM to create the various media content that is available publicly online. To be considered as UGC the media content needs to be published either on a publicly accessible website or on a social networking site accessible to a selected group of people. The content needs to show a certain amount of creative effort and created outside of professional routines and practices (Kaplan and Michael 2010).

\begin{tabular}{|c|c|c|c|c|}
\hline & \multicolumn{3}{|c|}{ Social presence/ Media richness } \\
\hline & & Low & Medium & High \\
\hline \multirow{2}{*}{$\begin{array}{c}\text { Self- } \\
\text { presentation/ } \\
\text { Self- } \\
\text { disclosure }\end{array}$} & High & Blogs & $\begin{array}{c}\text { Social networking sites } \\
\text { (e.g., Facebook) }\end{array}$ & $\begin{array}{l}\text { Virtual social worlds } \\
\text { (e.g., Second Life) }\end{array}$ \\
\hline & Low & $\begin{array}{c}\text { Collaborative } \\
\text { projects } \\
\text { (e.g., Wikipedia) }\end{array}$ & $\begin{array}{l}\text { Content communities } \\
\text { (e.g., YouTube) }\end{array}$ & $\begin{array}{l}\text { Virtual game worlds } \\
\text { (e.g., World of Warcraft) }\end{array}$ \\
\hline
\end{tabular}

FIGURE 8: Classification of Social Media by social presence/media richness and self-presentation/selfdisclosure adapted from (Kaplan \& Michael, 2010)

The list of SM available today is virtually non-exhaustive. Figure 8 shows a classification scheme that uses two schools of thought found in the field of media research (social presence, media richness) and social processes (self-presentation, self-disclosure). Using these criteria, 6 types of SM are identified by Kaplan and Michael (refer to Table 7 in the next page). Current SM platforms integrate different tools in one platform. This can be attributed to the evolving user requirements and enabling technologies that make it possible. Accessing SM platforms over the 
Internet is far easier to do today with wireless networking technology and powerful mobile devices.

TABLE 7: The six different types of social media platforms that are available adapted from (Kaplan and Michael 2010)

\begin{tabular}{l|l} 
TYPE OF SOCIAL DESCRIPTION & EXAMPLES
\end{tabular} MEDIA

\begin{tabular}{|c|c|c|}
\hline $\begin{array}{l}\text { Collaborative } \\
\text { projects }\end{array}$ & $\begin{array}{l}\text { Collaborative projects enable the joint and } \\
\text { simultaneous creation of UGC. Within } \\
\text { collaborative projects, one differentiates } \\
\text { between Wikis that is, websites which allow } \\
\text { users to add, remove, and change text-based } \\
\text { content and Social Bookmarking applications } \\
\text { which enable the group-based collection and } \\
\text { rating of Internet links or media content. }\end{array}$ & $\begin{array}{l}\text { Wikipedia, Wiki, } \\
\text { Ask.com, Google } \\
\text { Docs, Dropbox, } \\
\text { Pinterest, } \\
\text { TripAdvisor, Trivago, } \\
\text { Yelp, Delicious, } \\
\text { StumbleUpon, Reddit, } \\
\text { etc. }\end{array}$ \\
\hline Blogs & $\begin{array}{l}\text { Blogs are special types of websites that usually } \\
\text { display date-stamped entries in reverse } \\
\text { chronological order. They are the equivalent to } \\
\text { personal web pages and are available in a variety } \\
\text { of forms. }\end{array}$ & $\begin{array}{l}\text { WordPress, Penzu, } \\
\text { Blogger, Tumblr, } \\
\text { Squarespace, Wix, } \\
\text { etc. }\end{array}$ \\
\hline $\begin{array}{l}\text { Content } \\
\text { Communities }\end{array}$ & $\begin{array}{l}\text { Content communities allow the sharing of media } \\
\text { content between users. They are also known as } \\
\text { media sharing sites. Content communities exist } \\
\text { for a wide range of different media types, } \\
\text { including text, photos, videos, and PowerPoint } \\
\text { presentations. Users on content communities are } \\
\text { not required to create a personal profile page; if } \\
\text { they do, these pages usually only contain basic } \\
\text { information, such as the date they joined the } \\
\text { community and the number of videos shared. } \\
\text { Examples of such platforms on the Internet } \\
\text { include YouTube, }\end{array}$ & $\begin{array}{l}\text { YouTube, Spotify, } \\
\text { Instagram, Flikr, } \\
\text { Vimeo, Meetup, } \\
\text { Dropbox, Revver, } \\
\text { Veoh, Snapfish, } \\
\text { Photobucket, } \\
\text { Imageshack, } \\
\text { Photobucket, etc. }\end{array}$ \\
\hline $\begin{array}{l}\text { Social Networking } \\
\text { Sites (SNS) }\end{array}$ & $\begin{array}{l}\text { Social networking sites are applications that } \\
\text { enable users to connect by creating personal } \\
\text { information profiles, inviting friends and } \\
\text { colleagues to have access to those profiles, and } \\
\text { sending e-mails and instant messages between } \\
\text { each other. These personal profiles can include } \\
\text { any type of information, including photos, video, } \\
\text { audio files, and blogs. }\end{array}$ & $\begin{array}{l}\text { Facebook, Myspace, } \\
\text { YouTube, Twitter, } \\
\text { LinkedIn, Google } \\
\text { Plus+, ask.fm, } \\
\text { Classmates, Reddit, } \\
\text { Instagram, etc. }\end{array}$ \\
\hline Virtual game worlds & $\begin{array}{l}\text { Virtual worlds are platforms that replicate a 3D } \\
\text { environment in which users can appear in the } \\
\text { form of personalized avatars and interact with } \\
\text { each other as they would in real life. The first, } \\
\text { virtual game worlds, require their users to } \\
\text { behave according to strict rules in the context of } \\
\text { a massively multiplayer online role-playing } \\
\text { game (MMORPG). }\end{array}$ & $\begin{array}{l}\text { World of Warcraft, } \\
\text { Minecraft, Kingdom } \\
\text { Warriors, etc. }\end{array}$ \\
\hline
\end{tabular}




\begin{tabular}{lll}
\hline $\begin{array}{l}\text { Virtual social } \\
\text { worlds }\end{array}$ & $\begin{array}{l}\text { As in virtual game worlds, virtual social world } \\
\text { users appear in the form of avatars and interact } \\
\text { in a three-dimensional virtual environment; } \\
\text { however, in this realm, there are no rules } \\
\text { restricting the range of possible interactions, } \\
\text { except for basic physical laws such as gravity. }\end{array}$ & $\begin{array}{l}\text { Second Life, Smeet, } \\
\text { Virtual World for } \\
\text { Teens, Wee World, } \\
\text { InWorldz etc. }\end{array}$ \\
\hline
\end{tabular}

\subsubsection{Social Media in the AEC}

A study by Azhar and Abeln on medium-to-large construction companies in Southeast United States of America (USA), focussed on the use of Facebook, LinkedIn and Twitter in different construction companies. The graph below shows the various uses for SM as identified by survey

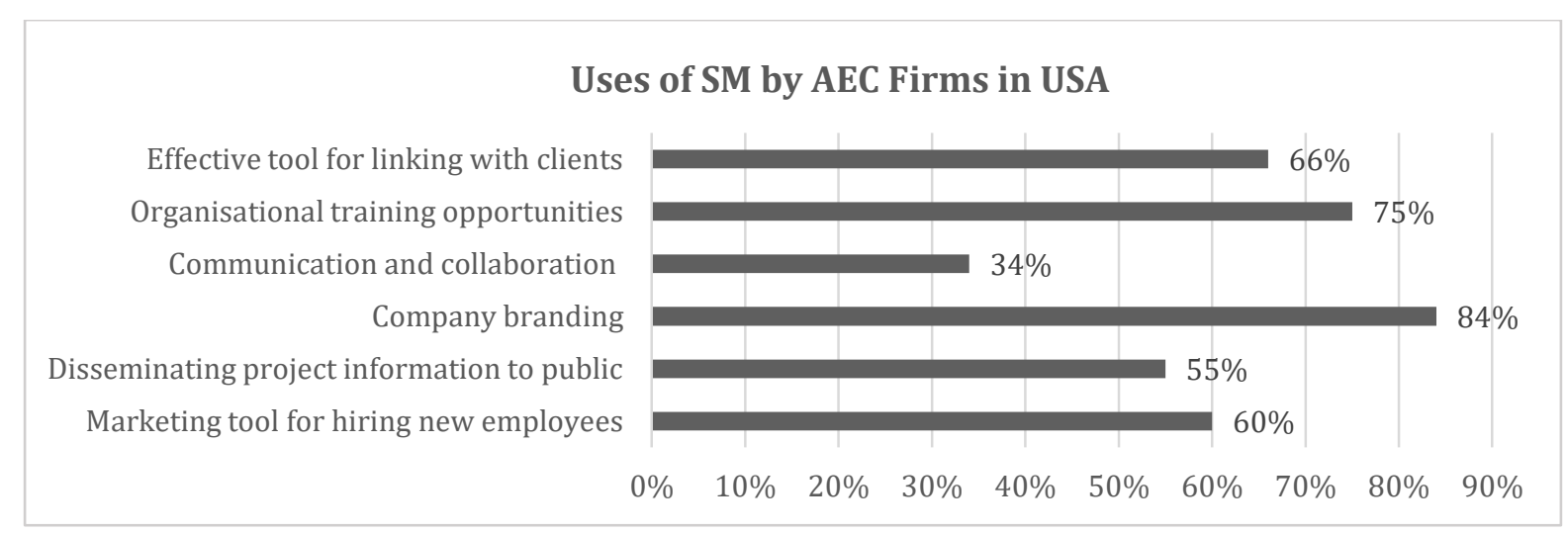

FIGURE 9: Summary of survey findings for social media use adapted from (Azhar and Abeln 2014)

Figure 9 shows that SM is largely used for external, one-way communication such as advertising, company branding, dissemination of project information to the general public etc. Overall, the study revealed that $80 \%$ of the respondents cited benefits for using SM for external communication, while only $50 \%$ of the respondents used SM for internal collaboration and communication. Despite these positive results on the use of SM, there is still a general mistrust of SM preventing it from being adopted industry wide for communication and internal collaboration. Three notable issues associated with SM use were security, privacy and lack of understanding. Azhar and Abeln suggest that these can be mitigated through the following three avenues:

1. Allocating sufficient time and funding for the daily operations, maintenance and security of SM resources

2. Information and dissemination on SM platforms should be regular and consistent to maintain social presence among individuals and organisations 
3. Employees should be provided with adequate training to better orient themselves with the resources SM provides and be able to use these resources to best represent their organisations.

Azhar and Abeln's study acknowledges that while SM is being adopted at a small scale in the AEC industry now, the benefits of SM is being acknowledged. Similarly, a study by the Australian building and construction industry identified that while 72 percent of the businesses surveyed were unsure as on how to create a SM strategy to engage their followers on SM platforms (Trenchless International 2014).

\subsubsection{Social Media in Project Management}

Harrin's study focussed on the use of Facebook, Twitter, LinkedIn, Wiki, Podcast, Video Podcast, Instant Messaging (IM), blog and other social networks by PMs. Of these SM platforms the most widely used were LinkedIn and Facebook. The survey had a total of 181 participants from 32 different countries (Harrin 2011).

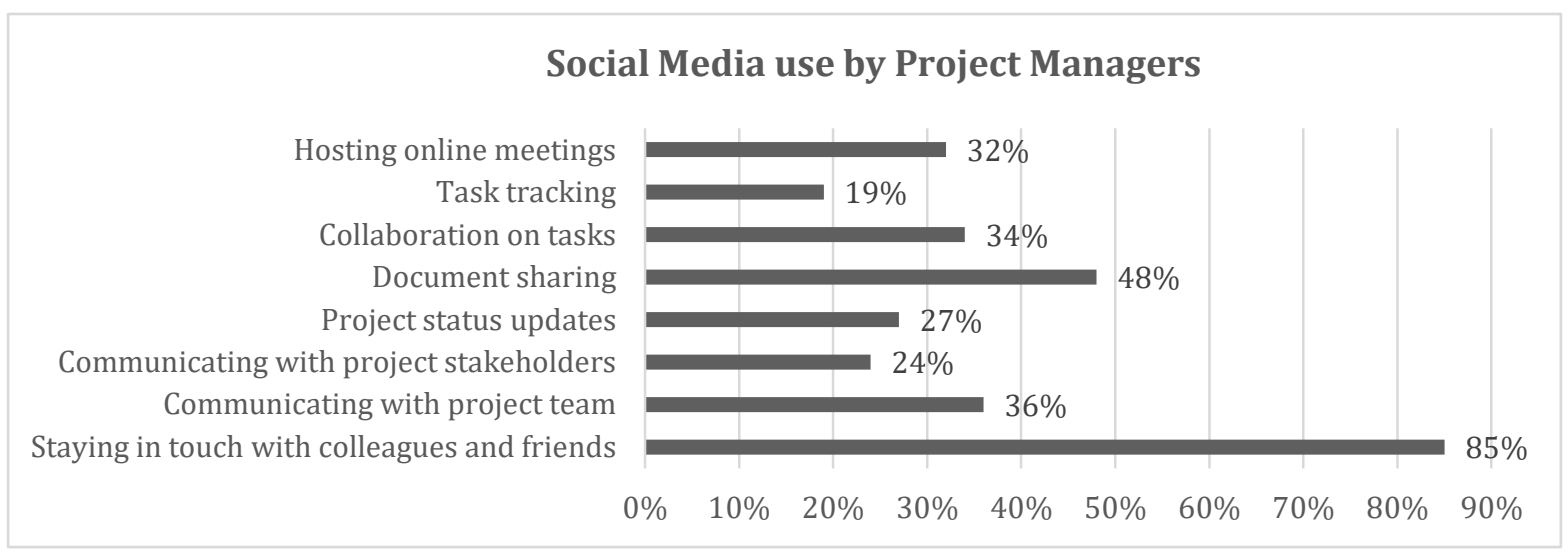

FIGURE 10: graph showing the 9 ways in which survey respondents used social media for project work adapted from (Harrin, Social Media In a Project Managment Environment 2011)

Figure 10 shows how the SM platforms were being utilised by PMs. Facebook and LinkedIn were mostly used for professional and personal networking purposes. For this reason, Figure 10 shows that staying in touch with colleagues and friends is the most common use of SM by PMs. However, more project relevant tasks such as task tracking, collaboration, document sharing, and hosting of online meetings is used less by PMs. This was mainly attributed to the technological challenges and security risks associated with the use of SM. In addition to this, SM and their integrated tools existed on distributed platforms which made it harder to work collaboratively.

While the survey by Harrin did not focus mainly on PMs who were involved with projects in the AEC sector, the results however point to the fact that PM have a use for such tools and its 
neglect would be unwise. A deeper exploration of the matter is needed. For this reason, a study of SM and associated tools/technologies/ideologies and its use in the construction industry particularly by PMs would be a step in the right direction in trying to shed light on the practicality of using SM or SM enhanced platforms in supporting project management. 


\subsection{Enterprise 2.0}

The affinity of the 'modern employee to using SM, has been encouraged by the 'consumerisation of IT' (Basset 2013) or 'Technology Populism' (Klinc, Turk and Matevz 2009). This use of SM in the workplace was later adopted by organisations and the emergence of Enterprise 2.0. Enterprise 2.0 is a term that was introduced in 2006 by MacAfee and is defined as,

Use of emergent social software platforms within companies, or between companies, and their partners or customers.

(McAfee 2006)

Other terms that have been identified through literature that hold similar meanings include Enterprise social collaboration platform (Li, et al. 2012), Enterprise Social Media (ESM) (Leonardi, Huysman and Steinfield 2013) and Enterprise Social Network (ESN) (Casanova and Bellifemine 2012). All these terms are pretexts for the use of tools, technologies, software as well as business theories that are inherently derived from Web 2.0, hence the addition of the '2.0' suffix in Enterprise 2.0. Comparisons between Enterprise 1.0 and Enterprise 2.0 are presented in Table 23 in Appendix D.

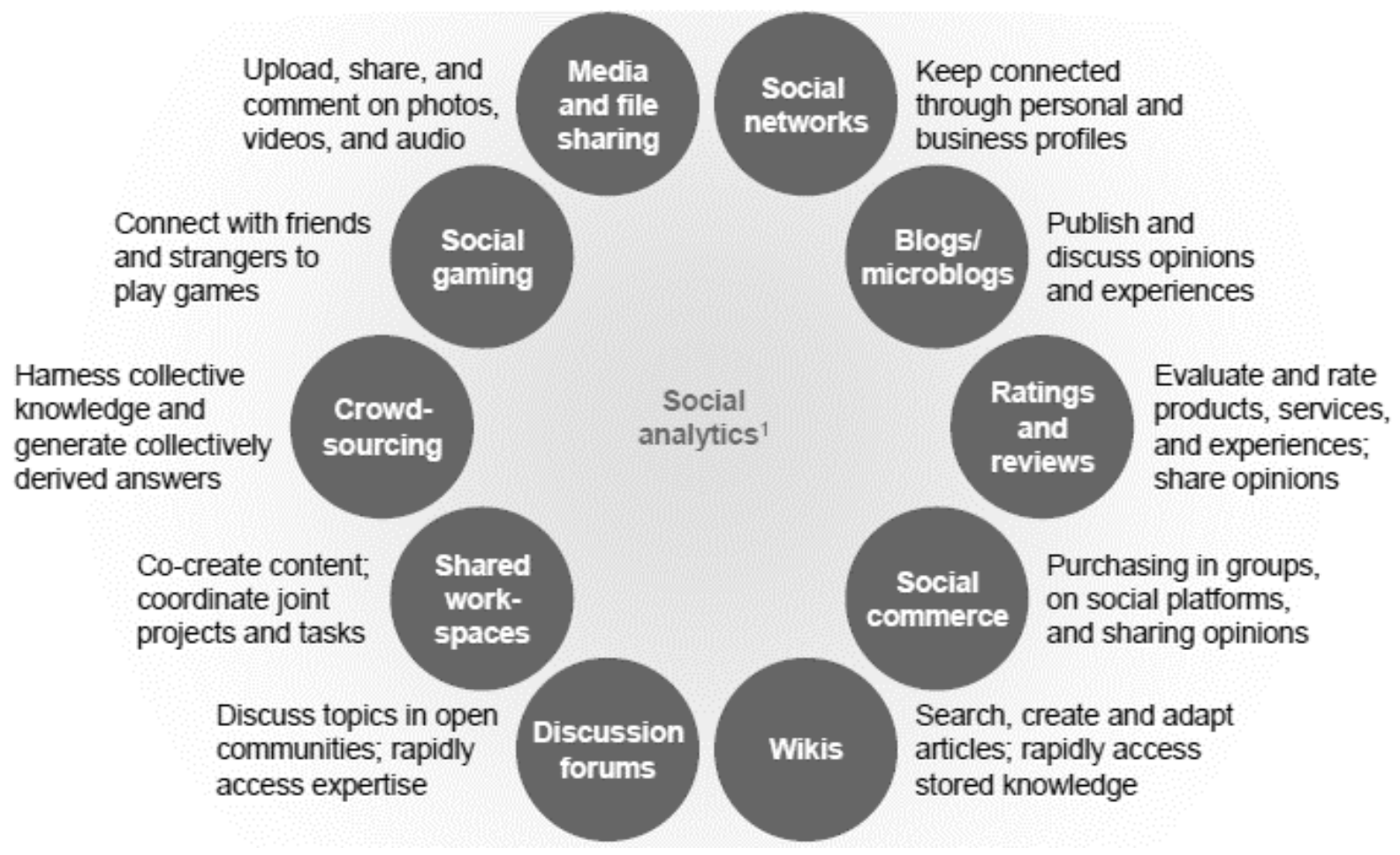

FIGURE 11: Social technologies that can be used by consumers and Enterprise by (Chui, et al. 2012)

Figure 11 lists some of the social technologies that are being used by both individuals and Enterprises. Initially organisations used $S M$ for external communications to other companies, vendors, customers, and the general public. Organisations that used SM for external 
communication typically adopted a multipronged approach to SM use. For example, a company may maintain a company profile on Facebook, post status updates using Twitter and create blogs on Blogger (Leonardi, Huysman and Steinfield 2013). This strategy is inefficient for internal communication as it required the maintenance of profiles across many different platforms and only allowed for one-way external communications (one-to-many communication model). Enterprise 2.0 software suites facilitate internal communications and collaboration by integrating multiple social technologies under a single interface.
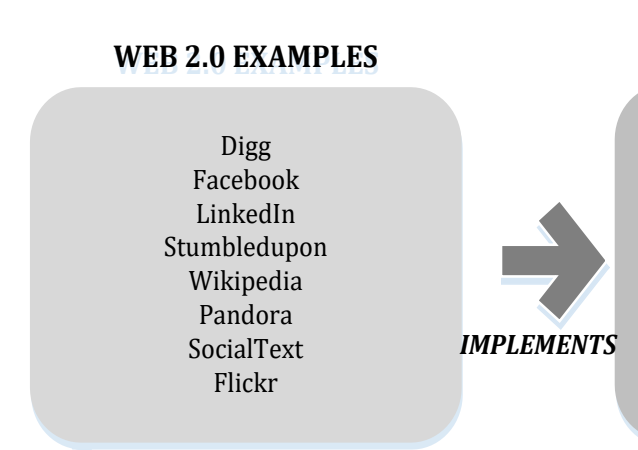

\section{COLLABORATION}

PARADIGMS

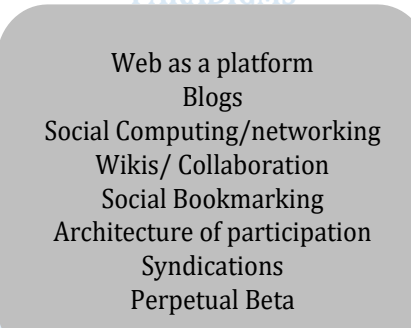

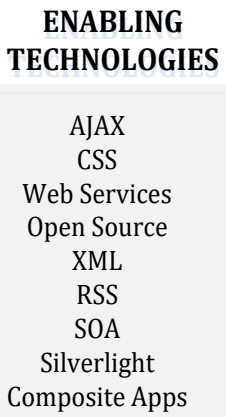

FIGURE 12: Enterprise 2.0 and its collaborative paradigms and technologies adapted from (Polaschek, et al. 2012)

Figure 12 shows the synthesis of collaborative paradigms from Web 2.0 and the enabling technologies. The technologies used to implement these are listed on the left with the enabling Web 2.0 technologies listed on the right. The paradigms and technologies listed in Figure 13 above were later integrated in Enterprise 2.0 software. Examples of such integrated enterprise social software services include Salesforce's Chatter, Microsoft's SharePoint, Yammer, IBM's Connections, Jive from Jive Software, Oracle's Social Network, Cisco's WebEx Social, BlueKiwi from Atos, Cynapse's Cyn.in, Tibbr, Telligent, MangoApps, Socialtext, Socialcast, and Ingage Networks (Leonardi, Huysman and Steinfield 2013).

Most, if not all of these platforms are offered on a SaaS basis by ASPs and can be accessed via a standard web-browser. Some of these platforms also offer the option of being installed on an organisations own server which is a more secure option. The latter option is commonly referred to as the 'On-premise' option. More recently Enterprise 2.0 is evolving towards Social enterprise (Casanova and Bellifemine 2012) 


\subsection{Project management 2.0}

The Internet was first introduced in 1993 and as a crucial IT in the construction industry, the Internet has had many application and prompted a variety of research directions. It wasn't till 1995 when WPMSs began to be used in the US (Becerik, A review on past, present and fututre of web based project management \& collaboration tools and their adoption by the US AEC industry 2004). PMs in the AEC were using WPMSs and Social Software. Social software use dates to the 1980's and was known under the term 'groupware' before being superseded in the 1990's (Allen 2014). Web 2.0 saw the re-birth of the Internet and the extensive adoption of SM platforms. Widely used for personal consumption, SM was later adopted by enterprises through Enterprise 2.0 signalling a paradigm shift which recognised the role of Web 2.0 technologies for internal collaboration within organisations.

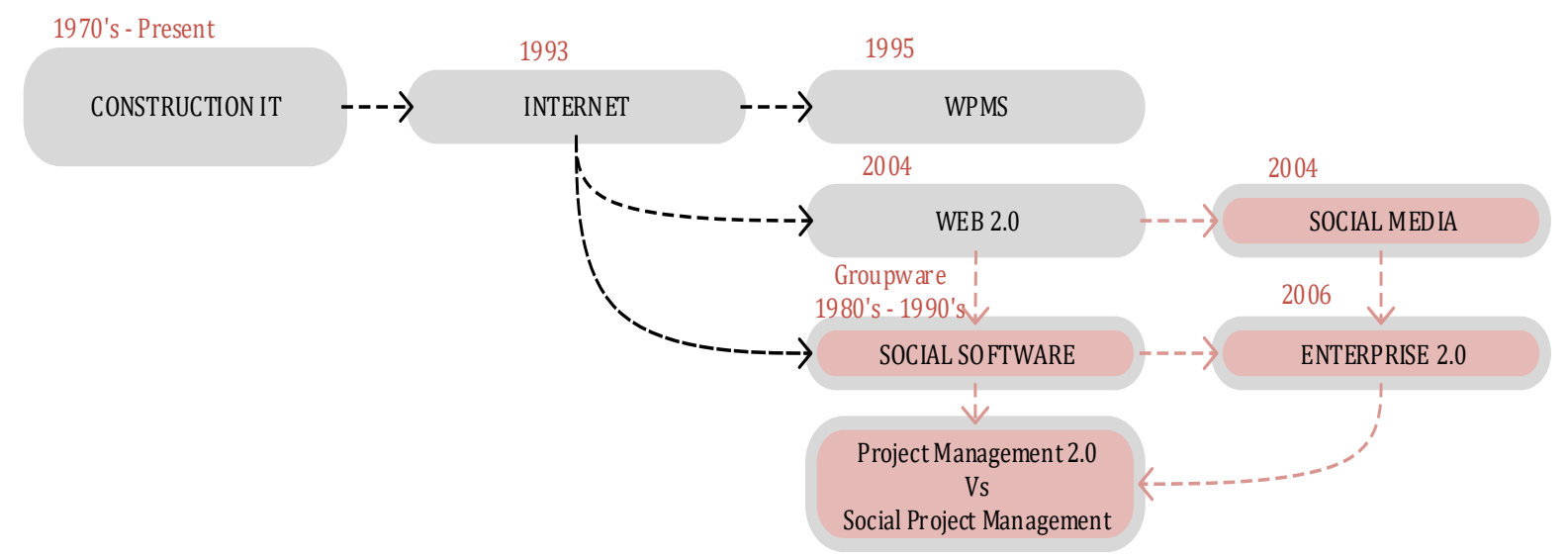

FIGURE 13: The emergence of PM 2.0 and tracing the Web 2.0 influence on project management 2.0

Figure 13 shows the development of Web 2.0 and how it influenced the emergence of SM, social software, Enterprise 2.0 and its adoption for projects in Project Management 2.0 (PM2.0). The main aim of this dissertation is in understanding the role of SM for projects in the construction industry. The study by (Harrin, Social Media In a Project Managment Environment 2011)-, indicates that PMs across different sectors are in fact using SM and Web 2.0 based tools to help complete project tasks. Casanova and Bellifemine refer to this use of Web 2.0 and SM as Social Computing, where social computing is defined as

\section{A social structure in which technology puts power in communities and not institutions.}

(Casanova and Bellifemine 2012)

Social computing is a central component in the concept of PM 2.0, and it advocates the use of Web 2.0 technologies in facilitating the project teams need for, better information sharing, increased collaboration and empowerment for teams to get things done. PM 2.0 effectively 
weakens the traditional PM role of acting as proxy in all project-related communication and increases productivity using collaborative tools to support bottom-up planning (Casanova and Bellifemine 2012). The idea for PM 2.0 initially came from PMs in the IT industry who associated the "2.0" to project management out of necessity for the different tools and different project needs that had arisen over the years (Kerzner 2014). Two definitions of PM 2.0 are given below;

...the use of Web 2.0 Technologies to enhance project collaboration and coordination, assisted greatly in enabling teams, especially virtual teams, to collaborate and share information, problem-solving and best practice (Andres 2013)

...It is web 2.0 technologies enabling project teams to better share information, increase collaboration and empower teams to get things done

(Casanova and Bellifemine 2012)

Kerzner adds to this definition suggesting that PM 2.0 is more than the explicit use of Web 2.0 technologies in projects. PM 2.0 focuses on new project management tools, better project governance, improved collaboration with stakeholders and more meaningful information reporting using metrics, key performance indicators (KPIs) and dashboards. Kerzner (2014) in his definition implies that PM 2.0 is an evolution of 'traditional' project management or PM 1.0 (Kerzner 2014).However, PM 2.0 must not be confused with social project management (SPM). While both terms infer the application of the social networking (SN) paradigm to a project ecosystem, they differ somewhat in their definitions. PM 2.0 initially manifested in the use of disparate SM platforms, Web 2.0 technologies for various functions in projects. Harrin's (2011) study had already highlighted the interest amongst PMs who used SM in their projects. 


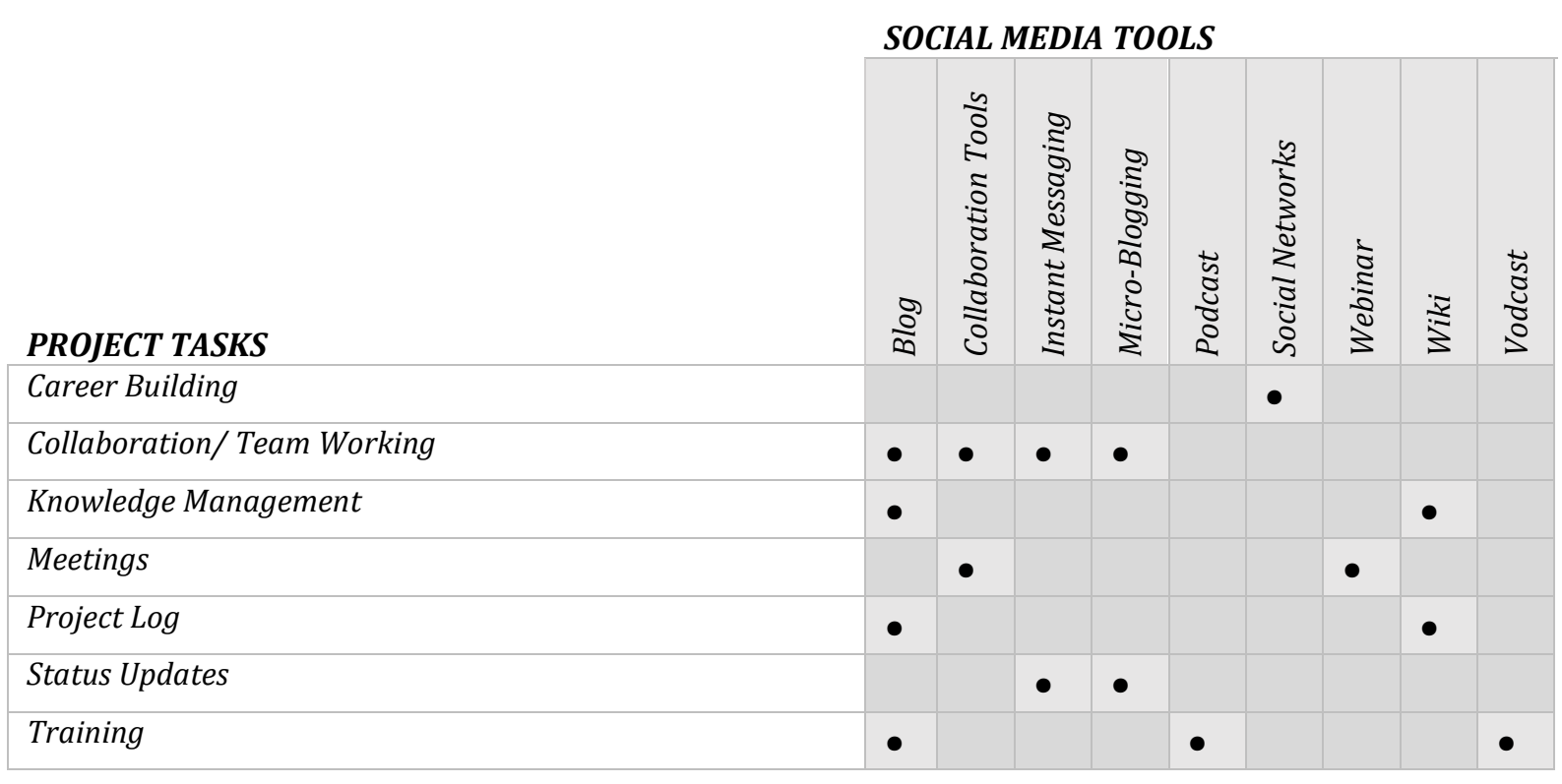

Some of the project tasks matched against Web 2.0 tools is shown in Table 8. These tools were used in isolation from each other on separate platforms. The use of these Web 2.0 tools while providing opportunities, also had associated challenges for the PM to deal with. SM use for projects can affect five project parameters

(1) Interest of the target group,

(2) Investment,

(3) Resources (material, human, technological),

(4) Creativity, and

(5) Uncertainty (Gerogescu and Popescul 2015)

The interest of the group is positively affected with the use of more informal communication channels. In terms of investment, savings can be noticed in the use of Skype-like technology which cuts down on travel costs and the need for the team members to be co-located. Resource use is not impacted as much, however information contained within SM can be used to collate lessons learned throughout the project. The ease of and user-friendliness of Web 2.0 makes it easier to build and nurture relationships amongst team members. Despite the positive impacts of SM use, uncertainty and risk is increased and represent the largest barrier to the adoption of SM in projects. Risks associated with SM can be divided into three categories reputational, legal and related to the work force vacancy and information security. These risks need to be attended to by the PM when implementing SM (Gerogescu and Popescul 2015). 
Initial use of Web 2.0 tools/platforms often were "Islands", project participants had to establish accounts on a number of SM platforms to be able to communicate with other users on the same platform and to set-up a collaborative community. Lack of Regulatory, privacy and limited security measures surrounding the use of SM in the workplace meant that companies were not able to use these free Web 2.0 tools. PM 2.0 helped in streamlining project team processes through increased collaboration, however the distribute nature of the Web 2.0 technology did not help solve the core challenges of project management and made it more difficult for the PM to assess progress and status of projects (Andres 2013).

In terms of project management in the construction industry, Levitt (2011) refers to new forms of contracts, lean construction principles together with agile project management methodologies that are being currently utilised in the construction industry. He refers to the integrated product delivery (IPD) (Levitt 2011). The IPD approach drives the key concept of integrating stakeholders with project teams, with the aim of meeting the owner's requirement using the best collaborative tools to reduce time and cost. The BIM approach is a current focus of the IPD delivery method in the construction industry (Valsson 2012).

PM 2.0 is a very recent development in the way that PMs manage projects, therefore it invites a lot of criticism. Some argue that PM 2.0 is not relevant term as it is just a variation of the project management and that it is only applicable to IT projects, especially those requiring the use of agile and scrum techniques. Others view that while PM 2.0 advocates increased collaboration within projects, there simply is no guarantee that it will elicit more open communications between project participants. Moreover, the size of a project dictates the usefulness of PM2.0 implementation as open communications can become more chaotic and distributed collaboration is harder to achieve given the numerous participants involves. However, it is certain that PM 2.0 is being put into practice and that it works. More recently, the term PM 2.0 is developing more towards 'socialised project management ' (Kerzner 2014) or social project management (SPM) (Casanova and Bellifemine 2012, Andres 2013). PM 2.0 is essentially the use of Web 2.0 technologies. Internet video and voice calling, wikis, blogs, search engines and even Wi-Fi technology have been put forward as Web 2.0 technology. However, these are more general-purpose tools and their use in project management 2.0 can be hard to identify. 


\subsubsection{Social Project Management}

Social project management (SPM) methodology and by extent, SPM software aims to leverage the full SN of the project community. Where project community is defined as;

...the entire social network related to a project including the team, stakeholders, management, and other interested parties

(Trilog Group 2012)

SPM is a term sometimes used in equivalent to PM 2.0, however while the two terms share similarity in that they both seek to apply the Social Networking paradigm in a project context, they are slightly different concepts (Casanova and Bellifemine 2012). Table 9 below show a comparison across three types of project management methodologies.

TABLE 9: Project management comparison adapted from (Andres 2013)

\begin{tabular}{|c|c|c|c|}
\hline & $\begin{array}{l}\text { Traditional } \\
\text { Project } \\
\text { Management }\end{array}$ & $\begin{array}{l}\text { Project Management } \\
2.0\end{array}$ & $\begin{array}{l}\text { Social Project } \\
\text { Management }\end{array}$ \\
\hline Type of Project & Large & Small & Large and Small \\
\hline Leadership style & $\begin{array}{l}\text { Top Down, } \\
\text { Macro }\end{array}$ & Bottom up, Micro & Top Down Macro + \\
\hline Communication & Hierarchical & & $\begin{array}{l}\text { Streamlined communities } \\
\text { within larger social fabric } \\
\text { promotes strong tie and } \\
\text { weak tie communication }\end{array}$ \\
\hline Execution speed & Slow & Fast & Fast \\
\hline
\end{tabular}

Table 9 shows that PM 2.0 is more applicable to smaller projects whereas SPM can be applied to both small and large projects. Both the PM 2.0 and SPM approach are viewed to have a faster execution speed than traditional project management as they are both enabled by more collaborative technologies. In comparison, Table 24 in Appendix D shows a comparison between Social Network-based project management and traditional project management. Andres defines SPM as the collaborative process of guiding a project from Concept to Finish. SPM applies the 'social networking' paradigm to the core business process where SPM software makes the project process visible to everyone allowing teams to achieve transparency to project progress and status and increase collaboration. Furthermore, SPM also applies the 're-tweet' paradigm which engages the wider corporate (and external) networks allowing for interested stakeholders to engage socially with the project team and help accomplish the project goals (Andres 2013). The work of (Andres 2013) and (Casanova and Bellifemine 2012) both try to 
define SPM by comparing it with 'traditional' project management theories and proposing SPM alternatives.

Traditional project management theory according to PMBOK postulates that projects are heavily dependent on project plans, the dispatch of planned tasks and the control of project progress through the thermostat-method of control. Casanova and Bellifemine proposes SPM theory replacements for these three fundamental approaches to traditional project management which is described in the table below.

TABLE 10: Three paradigm shifts of project theory for Social Project Management adapted from (Casanova and Bellifemine 2012)

\section{Theory shift towards SPM}

\begin{tabular}{|l|l|}
\hline $\begin{array}{l}\text { Management-as- } \\
\text { planning }\end{array}$ & $\begin{array}{l}\text { Management-as- } \\
\text { organising }\end{array}$ \\
\hline & \\
\hline Dispatching model & $\begin{array}{l}\text { Commitment model } \\
\text { (language/action } \\
\text { perspective) }\end{array}$ \\
\hline
\end{tabular}

Thermostat model Scientific experimentation model

\section{SPM Theory Description}

Assumes that human activity is inherently a response to the situation in question. Human agents are sub-units capable of sensing, planning and acting. Communication is nonhierarchical, based on interaction between subunits. In this approach, management involves design, co-ordination and enabling of otherwise autonomous activities. The leadership model is coaching with a purpose of fostering an organisational environment conducive to building trust among people for collaborative learning and innovation.

Work in organisations is coordinated through making and keeping commitments in a two-way communication between controller and executors. The model assumes that a job will be started and completed only if the executor is committed to realise it. The commitment cycle begins with an offer or a request, followed by a promise, performance and declaration of completion. Thus, an action is coordinated by the commitments people make rather than by central control acting through commands

Each project can be considered as an experiment in which there is a phase of the formulation of hypotheses (requirements), a run of experiment (construction) and a phase of hypotheses testing (testing). By making explicit hypothesis, the root cause for problems can be found and performance can be improved.

Casanova and Bellifemine go a step further and introduce the CNOS platforms that can be used to support SPM methodology. Enabling technologies are present to support collaboration within project teams. It is the procedural and organisational changes that need to be made to ensure implementation of true SPM methodology within projects. Table 10 shows the three paradigms shifts of project management that is proposed by SPM that is supported by the CNOS platform. 


\subsection{Summary}

In summary, Web 2.0 represented the fundamental change in the way that users utilised the Internet. It also foreshadowed the advancement of Internet technology that made it possible for the emergence of SM. Wide adoption of SM platforms, saw its adaptation for use in the workplace and by organisations. At first for external communication and later for internal collaboration and communication purposes. This paradigm shift was known as Enterprise 2.0 and presented collaborative paradigms that were fundamentally driven by Web 2.0 technology.

Following the emergence of Enterprise 2.0, PMs using SM and Web 2.0 for project management and collaboration began to refer to it as Project Management 2.0. Since PM 2.0 is a recently evolved terminology, there is little literature on the subject. PM 2.0 refers to the use of Web 2.0 technology which also includes SM platforms. Kerzner (2015) refers to PM 2.0 as the evolution of traditional project management methodology or PM1.0 to PM 2.0. This is further being evolved towards social project management (SPM) methodology which is still a very inceptive area of knowledge concerning the application of social methodologies to the management of projects. SPM software is used to support SPM theory by providing a platform that is integrated with Web 2.0 based tools. However, Casanova and Bellifemine infer through their study of CNOS, (a SPM software) that procedural and organisational change is paramount to the implementation of SPM.

Levitt (2011) notes that there isn't much evidence pointing to the emergence of PM 2.0 or SPM in the construction industry. He instead implies that Lean Construction Techniques such as BIM and IPD methodologies are a precursor to PM 2.0 and SPM methodology in construction. At this point it is too early to draw any conclusion of PM 2.0 and SPM applicability in the construction sector as there are no empirical studies undertaken that concludes this. This dissertation instead looks at the current WPMS that are referred to as PM 2.0 or SPM software and explores the tools and services that are offered by them in a Software Review. 


\section{Research Methodology}

\subsection{Survey}

Literature has highlighted the use of SM in Project management (Harrin, Social Media In a Project Managment Environment 2011) and in the AEC industry (Azhar and Abeln 2014). In addition to his, it was also identified the use of Social Software and the emergence PM 2.0 gave rise to the development of 'Social Project Management' (SPM) methodology. SPM methodology advocates the use of Web 2.0 technology to enhance project collaboration and information sharing. In addition to this, there are project management software that are developed to support and SPM. This dissertation employs a Survey as a research tool to investigate how these emerging theories are being manifested in the New Zealand construction industry. The following section presents the survey method and how it was administered. A framework for analysing the data gained form the survey is also discussed in this section.

\subsubsection{Survey Method}

The survey comprising of 27 questions was administered online and contained a mixture of question formats including, multiple choice, single/multiple answer, matrix table of single and multiple choices, and Likert matrix tables etc. Ethics approval had to be sought before the distribution of the survey (Ethics ID Number: 0000021894). The survey was approved by the Human Ethics Committee (HEC) based on the assurances that the information provided by the participants would be adequately protected and the responses were anonymous. A copy of the questionnaire (Appendix B) as well as the Survey information sheet (Appendix C) can be found attached in the Appendices.

The survey entitled “COLLABORATION IN THE NEW ZEALAND AEC INDUSTRY” is divided into 5 categories.

(1) Participant background

(2) Project information and communications technology (ICT)

(3) Personal Social media use

(4) Social Media use in the workplace

(5) Social Media influenced collaboration software

The survey is distributed through mixed methods of invitation via emails and over telephone calls made directly to potential survey participants. A number of companies were contacted and invited to submit up to a maximum of 5 to 8 participants' responses to the survey. This is to 
avoid a redundant response set and ensures that a viable and dynamic sample of the company that is being approached is represented in the survey analysis. It is intended that the 5-8 participant response from each organisation will consist of a mixture of different types of construction industry professionals to give a more dynamic response set on each organisations IT use.

The participants were given a period of two weeks to complete the survey online. At the end of this period the data was collated and analysed. The results are presented in this written work.

The survey is aimed at construction industry professionals. However, it is important to note that the primary survey participants being targeted are PMs who play a big role in supporting and managing collaboration and communication between the other stakeholders involved in building projects. Overall it was anticipated that a sample of at least 30 to 50 participants from several different organisations would be needed to be able to draw viable data from. Examples of respondents' types that were excluded from this survey included project client/ sponsors, subcontractors, authorities/local government/ government etc., suppliers, public, facilities managers etc.

\subsubsection{Analysis Framework}

The survey is directly aimed at answering the two research questions stated below.

A. What is the current state of IT use?

B. Is there a need for Social Media in the AEC?

The two first question fundamentally investigates the participants' use of SM and Web 2.0 technologies. This research question also aims to takes account of the respondent's stance on the use of social media for project management and team collaboration. The literature noted the use of WPMS (Matheu 2005), Construction project extranets (CPEs) (Becerik 2004) and social software (Bafoutsou and Mentzaz, Review and Functional Classification of Collaborative Systems 2002) otherwise known as groupware (Poolvoralaks 1996). The second research question firstly gauges the awareness of the respondents as to the use of web-based software and affinity to IT use. It also asks the fundamental question of whether industry professionals are aware of web-based software that have integrated SM/ Web 2.0 technologies within them.

The results of the respondents are grouped under four different headings

1. Participant Background

2. IT use in the Workplace (B)

3. Social Media Use (A, B) 
4. Social Software Awareness (A, B)

The four groupings above are matched against the research questions that they are aimed at answering in the list above

\subsection{Software Review}

PM 2.0 and SPM theory is based on the use of Web 2.0 technologies to enhance collaboration and information sharing within project teams through the use of Web 2.0 technologies (Casanova and Bellifemine 2012). PM 2.0 and SPM methodologies were developed as a response to the concept of Web 2.0 use in a project context to support collaborative working amongst the participants. Using SM platforms presents too many problems for the PM. Currently there are project management information systems that integrate SM elements within them (Remidez and Jones 2012). This dissertation uses the term PM 2.0 software and SPM software to describe these software. Remidez gives examples of these types of software such as AtTask, CentralDesk, Liquid Planner, MangoProjects, ProjectPlace, Sprintr, Teambox, and Zoho Projects as examples of project management software that have integrated Web 2.0 technologies.

To investigate how these platforms, differ from the WPMSs/ PM-ASPs described in Nitithamyong and Skibniewski' work, a review of eight PM 2.0 software was undertaken. Some of the software were already identified from the list of software by Remidez and Jones (2012).

\subsubsection{Software Criteria}

As the number of web-based PM software is too great to be all included in this study, a total of eight software were chosen to be reviewed. The chosen software were selected based on a list of criteria that is listed below.

$\checkmark$ Web-based software

$\checkmark \quad$ PM 2.0 or SPM software

$\checkmark$ Integrates Web 2.0 and SM-like functionalities

$\checkmark$ Integrates Web 2.0 tools and technologies as well as adopting a SM-like functionality

$\checkmark$ SaaS delivery

$\checkmark$ For Small to Medium Enterprise (SMEs)

$\checkmark$ Free-to-trial option

All platforms that were chosen above have the free-to-trial option which made it possible to be able to see the features and functions that each provided. Overall a total of eight software were chosen for review. 


\subsubsection{Analysis Framework}

The 10 software for reviewed provided a large amount of information which had to be processed and summarised. This section describes the method of analysis that was utilised. Figure 13 below summarises the analysis framework into five steps.

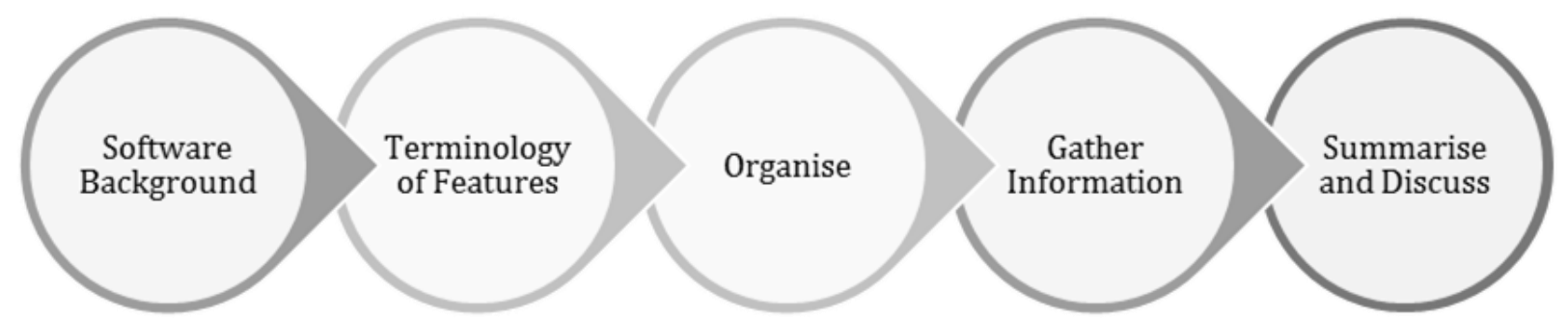

FIGURE 14: Steps taken to deconstruct the terminology of software features across all 10 software

Figure 14 demonstrates the semi-structured approach that was adopted in reviewing the 10 platforms. The steps are further explained below

\subsubsection{Software Background}

The 10 software that were reviewed offered a wide range of tools and services for its users. Reviewing each software on a case-by-case basis would have generated a massive amount of information that would have been impractical and impossible to include in this report. A summary paragraph of each platform is provided in Appendix C.

\subsubsection{Terminology of Features}

To deconstruct each software and collate information for analysis, a list of all collaborative and project management tools contained within each of the eight platforms was composed. This list of software features was sourced from each software's website which already gave a categorised list of features. In addition to this software review websites were also used to give an insight from the users' point of view regarding tools that were used within each software and how effective they found them to be.

\subsubsection{Organize}

This list of tools was then shortened to only include common tools found across all eight platforms. This was due to the fact that various software would use different terminology for the same tool/service/ feature. This final list was then further divided into two categories of Project Management and Social Networking features. A third category of Integrations was added to include features that could not be classified into the previous two categories. 
Figure 15 (refer to page 44) shows the derivation of the identified features that is discussed in Chapter 5. The lists to the left contains all the terminology that was gathered referring to the features/tools that was integrated within each software.

\subsubsection{Gather Information}

To gain more information and a better understanding of how each feature functioned, the author had to establish user accounts within each software. Hence the specification in the criteria for a free-to-use option. In addition to this information regarding each of the tools was gathered from the Software website. It was commonly found that the software companies typically provided wide-ranging information on their websites regarding the use of their software by projects, project team members as well as Project Managers. This information was available and retrieved form the software websites in the form of webinars, YouTube tutorials, and training videos, frequently asked questions (FAQs), PDFs, Resource webpages, Help sections etc. Apart from this, some of the platforms also offered support for project teams newly implementing the software in their teams.

\subsubsection{Summarise and Discuss}

The summary and discussion basically represents the work that is presented in Chapter 5 where after going through the previous processes, the identified tools are identified and then a summary of the identified features found across all 10 platforms is discussed. 


\section{Terminology of Software Features}

Kanban Boards

Gantt charts

Project planning and coordination

Workflow management

Change request and case management

Web forms and project templates

Task management

Resource management

Document management

Project portfolio Management (PPM)

Time tracking

Employee directory

Calendaring

Email integration (App, Task and activity

stream)

Reporting Tool

Project and financial reporting

Personal to-do list

Budget and expense management

Online conferencing

Synchronous working

Desktop application

Workspaces

\section{Push Notifications}

User tagging

File and media sharing

Activity streams and news feeds

Status posts

Likes

Commenting

Instant messaging

Video and audio calling

File storage integrations

Extensions (third party add-ons)

Project Forums

Project Pages

Personalisation

Customization and branding

ESN

Video conferencing

Gamification

\section{Integrations}

Extensions and add-ons

API

Reporting tools

\section{PROJECT MANAGEMENT TOOLS}
A. Project scheduling
B. Calendaring
C. File versioning
D. Document management
E. Workflow management
F. Project directory
G. Advanced searching
H. Threaded discussions
I. Mobile access
J. Time tracking
K. Project Portfolio Management (PPM)

L. Email integration

\section{SOCIAL COLLABORATIVE TOOLS}
A. Social Networking
B. Instant Messaging (IM) and chat

C. Shared workspaces

D. Push notifications

E. News feeds

F. User tagging

G. Hash tagging

H. Audio and visual calling capabilities

I. Wikis

J. Blogging and microblogging

K. File and media sharing

L. RSS feeds

M. Forums

N. Bookmarking

0. Rating and reviews

P. Gamification

\section{Integrations}




\section{Survey}

This chapter of the thesis discusses the results of the survey that was conducted as part of the research into SM and collaboration software use in the construction industry. The survey questionnaire is appended to this document in Appendix A. In addition to this, the survey information sheet for the survey participants is also included in Appendix B. The survey analysis clusters the survey responses into four categories in the proceeding sections.

\subsection{Results}

\subsubsection{Participant Background}

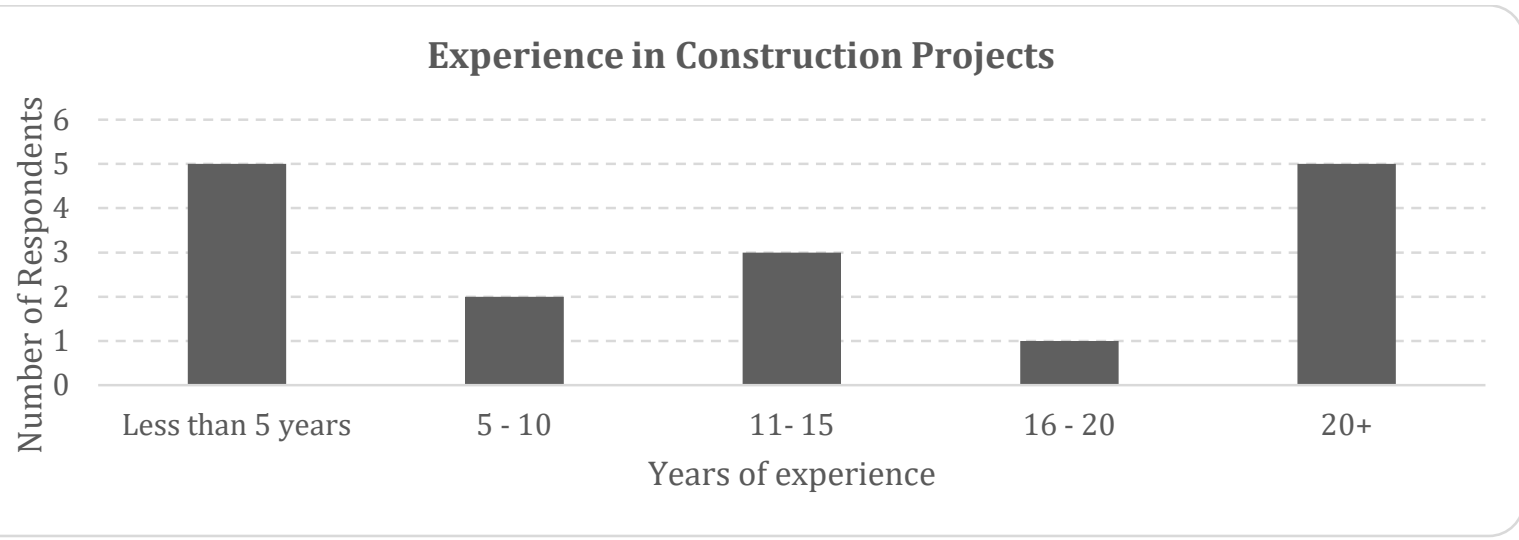

FIGURE 16: Graph showing the years of experience of the survey participants

Many of the respondents have less than 20 years in the industry. This represents a younger participant demographic with the respondents divided up into 11 males and 6 females. Overall there were 30 survey invitations sent out to potential participants. Out of the 30 invited participants only about 17 participants completed the online survey within the allocated time given to them. However due to the limited time allowed for the completion of the survey and because participation for the survey hinged on candidates' anonymity and their willingness to participate, the survey had to be closed despite the low participation rate. The background of the survey participants is analysed in this section. Moreover, two respondents did not complete the survey, so their results could not be used in this analysis. In terms of the participants most of the respondents were architects with lower number of participants being PMs. It is important to note that the survey gave the option of choosing more than one option as their job description. The highest number of participants were Architects with 7 respondents. A breakdown of the respondents is given in figure 18 in the next page. 


\section{Respondents Roles}

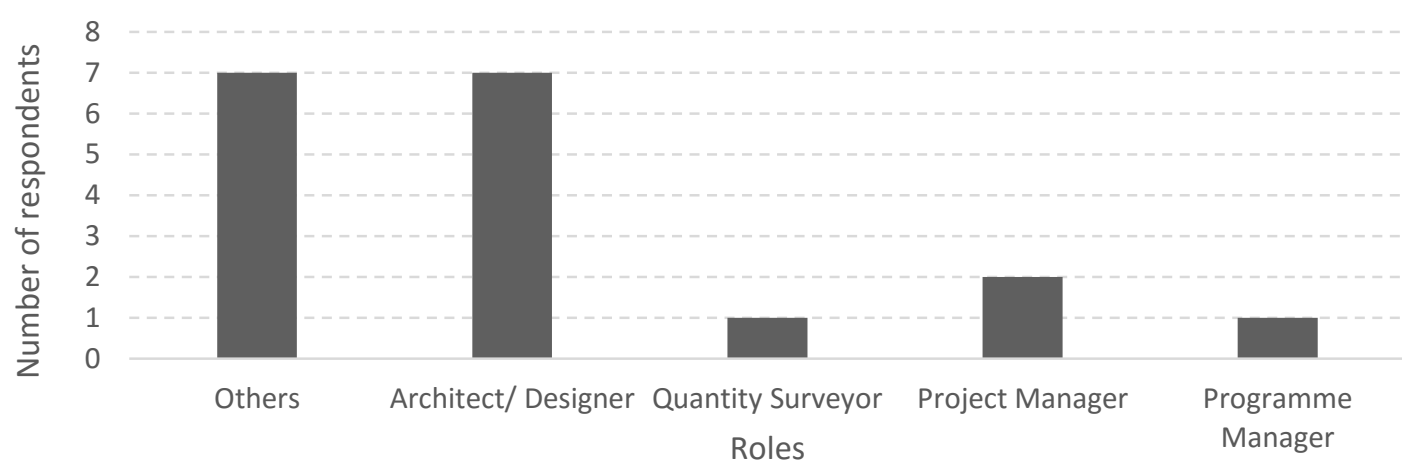

FIGURE 17: The chart above shows the respondents roles that participated in the survey.

Apart from the job descriptions graphed above, many other construction industry professionals and consultants also put down the following as their job descriptions

- $\quad$ Marketing manager

- HR manager

- General manager

- Health and Safety Manager

- IT manager

- BIM manager

- Structural Engineer

The survey shows that the IT adoption of the respondent is quite high with workplaces providing tools such as work laptops and PCs. Smartphones are also quite ubiquitous amongst the participants who utilise it for both personal and professional use. The next sections of the survey analysis look at the IT with a specific focus on software used in the workplace by the respondents. This could be because a large proportion of the respondent sample group are below the age of 40 . The age bracket of the respondents largely lies between 25 and 45 years with a majority of the respondents having project experiences of 10 years and more. This gives a picture that the participants would have a much wider knowledge of IT adoption in the construction given the number of years they have in construction project work. This age bracket between 25 and 45-year olds is commonly referred to as the ' $\mathrm{Y}$ ' generation or Millennials. According to Ferrara, there are currently four generations of employees in the workplace. They are known as the Millennial generation (born 1981 - 2001), Generation X (1965 - 1980), Baby Boomers (1946 - 1964) and the oldest generation Silent Generation (1928- 1945). The Millennials in today's workplace have a competitive advantage due to their affinity for technology. And this is because Millennials have been growing up with the ICTs of today compared to the older generations who have had to deal with technology only in an educational 
or work setting. Farrar carried out a study that revealed that Millennials in the construction industry viewed the adoption and implementation of new technology to be less of a barrier than their older counterparts. Millennials also displayed some higher affinity then older generations for the use of social technologies (instant messaging, texting, social networking such as Facebook etc.) (Ferrara 2015).

\subsubsection{IT use in the Workplace}

This section of the survey focussed on the information technology (IT) that was being utilised in the workplace of the respondents. The questions revolved around the use of software and webbased software that the respondents were either aware of or currently using for project related tasks.

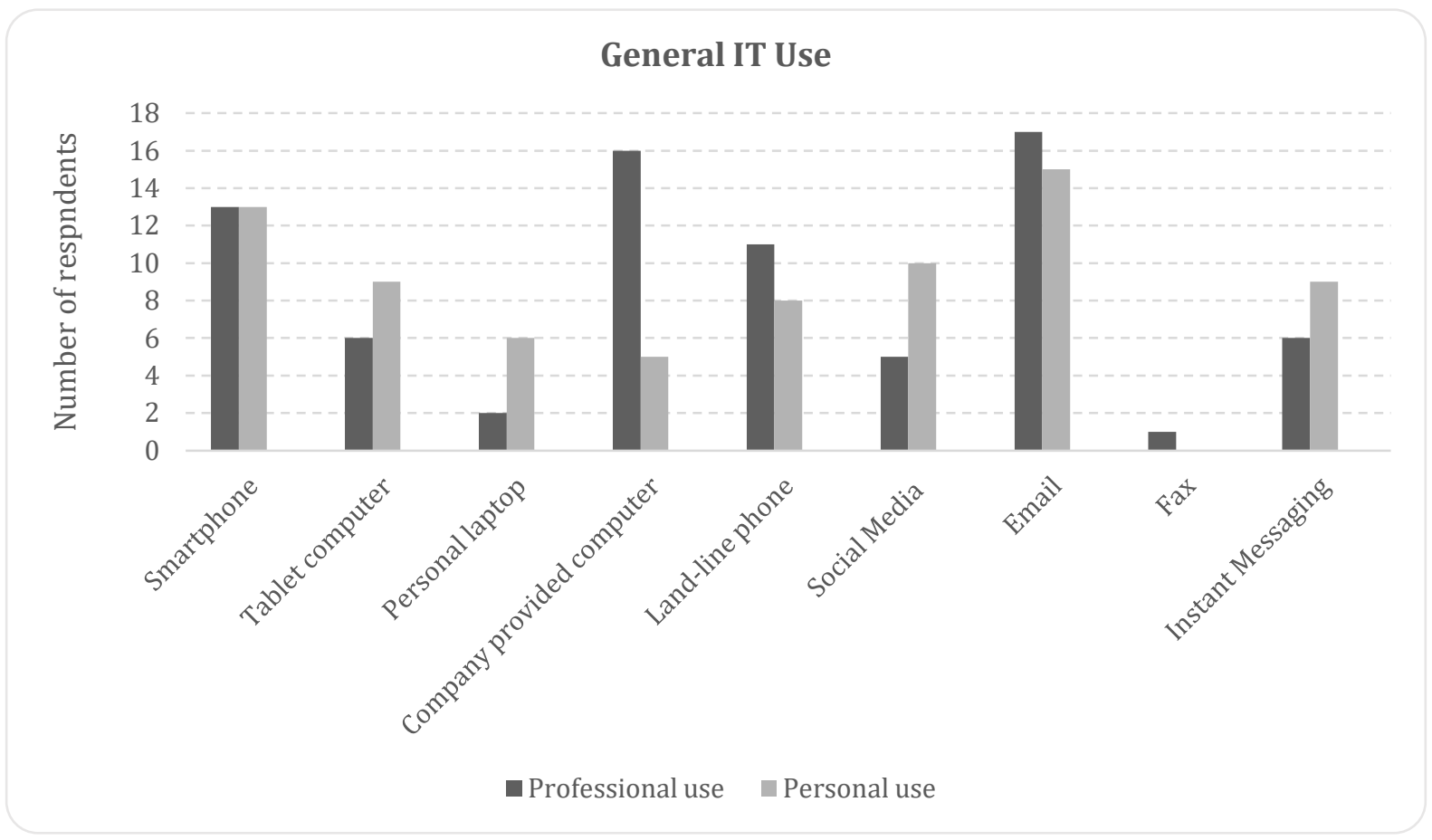

FIGURE 18: What IT do you use and for what purposes?

Respondents were given a range of options in terms of the software that they were currently using or have used in the past for projects. The figure below shows the popular responses of the respondents in terms of the software that they use. In terms of specific ICT use by respondents, email is still the most popular form of communication for many of the respondents who utilise it for both personal and professional communication purposes. The fax machine is viewed by most respondents as an obsolete piece of technology with only one respondent indicating that they actually use it in the workplace. In comparison SM is utilised more. The respondents when asked to rank their favoured mode of communication responded with the following. The results 
below are based on the majority of respondents who indicated which form of communication they used more than the others with (1) being the most used and (6) being the least used.
(1) Email
(2) Phone (landline + mobile phone use)
(3) Face-to-face (Non-CMC)
(4) Instant messaging
(5) Social Media
(6) Fax machines

Email is the most favoured method of communication while only one respondent indicated that they used fax machines at all. The use of PDF technology is perhaps to blame for the fax machine being made obsolete as it has made it easier for users to send and receive documents electronically. Instant messaging (IM) is used more than SM which is interesting as most SNS offer IM in their tools. In addition to this, the Facebook messenger mobile application also offers voice calling and video calling as well in their services. Most of the technology in Figure 27 can be considered to be general purpose and while most of them are being used in the workplace, IT such as IM, SM, personal IT such as tablets computers and personal computers are of course used more for personal reasons rather than professional purposes. Generally, all the listed IT are used both in the workplace and for personal reasons. 


\subsubsection{Software Use}

The following section of the survey analysis discusses the respondents' answers to questions regarding the use of software. The questions relating to the use of web-based software for project collaboration. The questionnaire asked specific examples of software that they had access to. The results are graphed below.

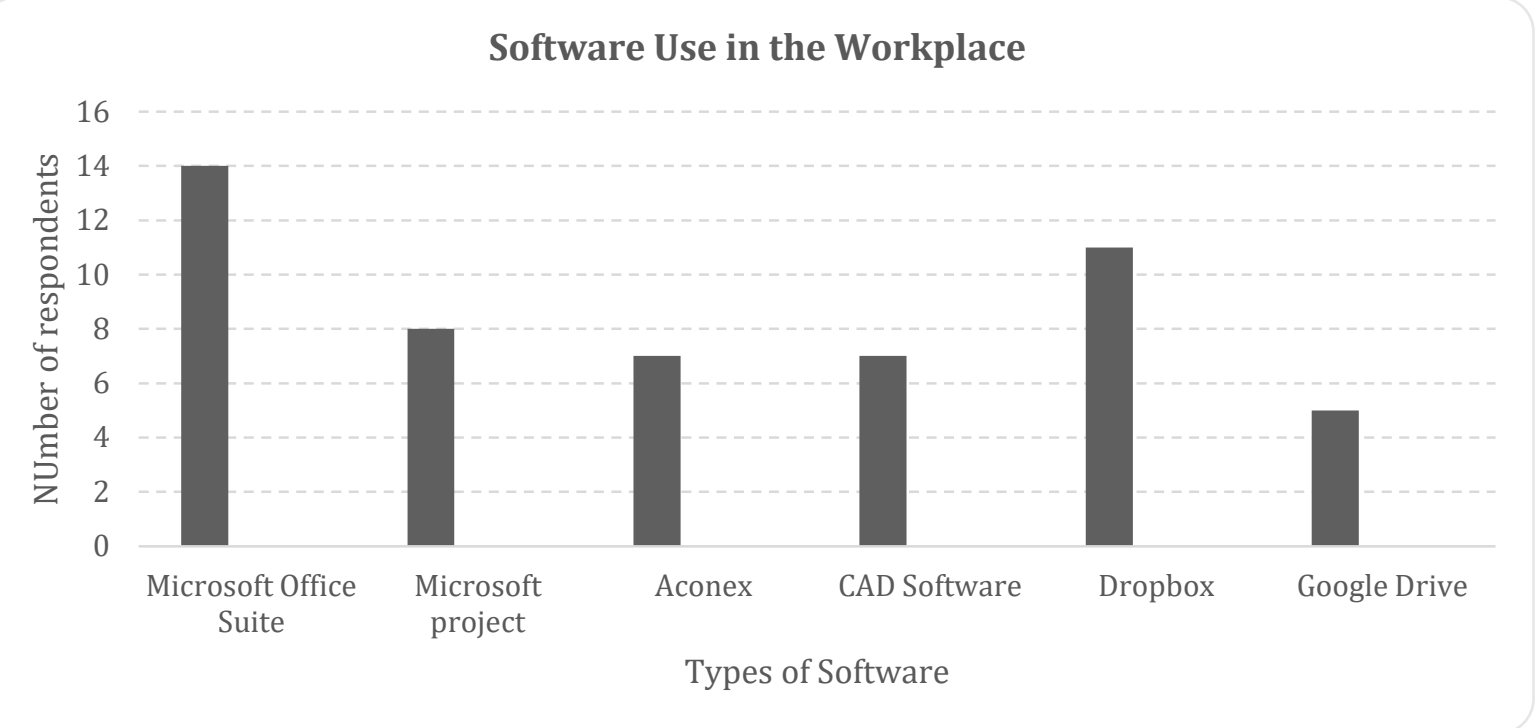

FIGURE 19: What types of software do you use currently or have used in the past in projects?

The most commonly used software of course is the Microsoft Office suite which includes the use of Word, Excel etc. and is commonly used in just about every workplace. The second most used tool was Dropbox. Google Drive was also included in the question but is not used as much as Dropbox even though they basically provide the same services to their users and are provided on a SaaS basis. MS project is the third most used software. Of course, CAD software is a staple platform for the construction industry as well in the survey questionnaire specific software options were given for the respondent to choose from. Aconex is a popular construction project management platform used for document management and collaboration. The platform features BIM collaboration, workflows, interface management, quality and safety etc. Other project software which were used included BuildTools, Procore and Basecamp which are collaborative software used for project management. BuildTools and Procore are construction industry specific software while basecamp is a more general-use platform that is used for group work, or projects work. 
TABLE 11: A summary table of colaborative software and tools that were identified by respondets in the survey

\begin{tabular}{ll}
\hline SOFTWARE & DESCRIPTION \\
\hline Microsoft SharePoint & $\begin{array}{l}\text { This is a collaborative platform which integrates enterprise social } \\
\text { networking with document management, workflow management } \\
\text { and other functions together for better communication and } \\
\text { collaboration. SharePoint also has add-in which can be added to the } \\
\text { platform to extend its features and capabilities which also includes } \\
\text { social media integration. }\end{array}$ \\
\hline SplashTop streamer & $\begin{array}{l}\text { A mobile application by SplashTop software that allows users' } \\
\text { remote access their PC (windows and Mac compatible) via their } \\
\text { mobile devices. }\end{array}$ \\
\hline Project NewForma & $\begin{array}{l}\text { A cloud-based construction information management system. The } \\
\text { system has built-in solutions for BIM management, Collaboration } \\
\text { document management, email management, project teams etc. }\end{array}$ \\
\hline QDMS & $\begin{array}{l}\text { A document and transmittals system for construction projects. } \\
\text { An internal package delivery tracking system. It is available as a } \\
\text { mobile application that can be used for routing packages, and } \\
\text { automatically sending emails and or text notifications via mobile } \\
\text { phone. }\end{array}$ \\
\hline ETRAK & $\begin{array}{l}\text { Email management platform. } \\
\text { Microsoft outlook }\end{array}$ \\
\hline
\end{tabular}

Aconex, Project NewForma, and QDMS software are all software that are purpose built for the construction industry. In comparison Dropbox, Microsoft SharePoint, SplashTop Streamer and Microsoft outlook are general purpose collaborative tools that can be used by project teams. The SharePoint platform is the closest software in use at the time of writing this thesis, which has elements of social media integrated. The platform itself is advertised as Enterprise social network (ESN) platforms, which is modelled after the Social Networks that are currently available in SM. This is interesting to note as participants do not recognise the terms associated with social media use in the enterprise. In terms of delivery the software mentioned in the table above can be purchased from commercial software developers and installed on company owned servers. The other method of software delivery is through the SaaS method which is the common deployment mode for web-based (cloud based) platforms. In the SaaS method, a piece of software is rented/leased from an Application Service Provider (ASP) for a usage fee. The usage fee is normally charged per project per amount of computer storage space requires and/or per user. 


\subsubsection{IT Management}

A majority $56 \%$ of the respondents noted that their IT systems are managed in-house by a dedicated IT department. In comparison only 38\% respondents indicated that they utilise a third-party organisation who is responsible for maintaining their company's IT. The remaining respondents either do not have a structured IT management plan or deal with IT related issues on an ad-hoc basis. This indicates that respondents' companies already have mechanisms in place that would be able to support the adoption and implementation of new software.

About $67 \%$ of the survey respondents have set policies in their workplace to ensure that software is reviewed and up-to-date. This is a large response and indicates the priority of the respondents' companies in terms of making sure that their IT offered to their employees is upto-date. This directly translates to $88 \%$ of the respondents indicating that they have adopted and integrated software in their company in the past 1- 3 years. While this is a significant response, only $56 \%$ of the respondents have software installed that they use for internal and external communication, information sharing and general collaboration purposes on projects. Most of these software are web-based. The software mentioned by the respondents are tabulated in Table 11.

\subsubsection{Software satisfaction}

The participants were asked how they felt about the current software that they were using for collaboration and communication purposes. The results are tabulated below

TABLE 12: How do you feel about the following statements?

Statement...

I find it easy to use the software provided at work

Current software is up-to-date

Current software solution is adequate

Improvements are needed for the software

\section{Response}

Agree

Disagree

Neither agree or Disagree

Agree

A Likert chart was used to gauge the respondents' satisfaction with their current set of communication and collaboration software used in their workplaces. The results show that while respondents generally agree that the software that they are currently using for communication and collaboration purposes is easy to use, they also recognise that there are improvements that can be made to them. In comparison respondents neither disagree nor agree that their collaboration software is up-to-date or if it is effective and efficient for communication and collaboration. This points to the lack of or limited knowledge and awareness of the 
participants in terms of tools that are currently available that can be used to support collaborative work

\subsubsection{Social Media Use}

A study carried out by Dell in 2011 revealed that up to $90 \%$ of their employees were using their personal laptops, tablet computers and mobile phones for work related tasks. The use of ubiquitous technologies such as these in the workplace meant that users had greater access to the Internet and Social Media associated technologies (Turban, Strauss and Lai 2016). When asked how many hours a day they spend on SM, eight of the respondents indicated that they spend less than an hour a day and four respondents said that they spent between one and three hours on SM.

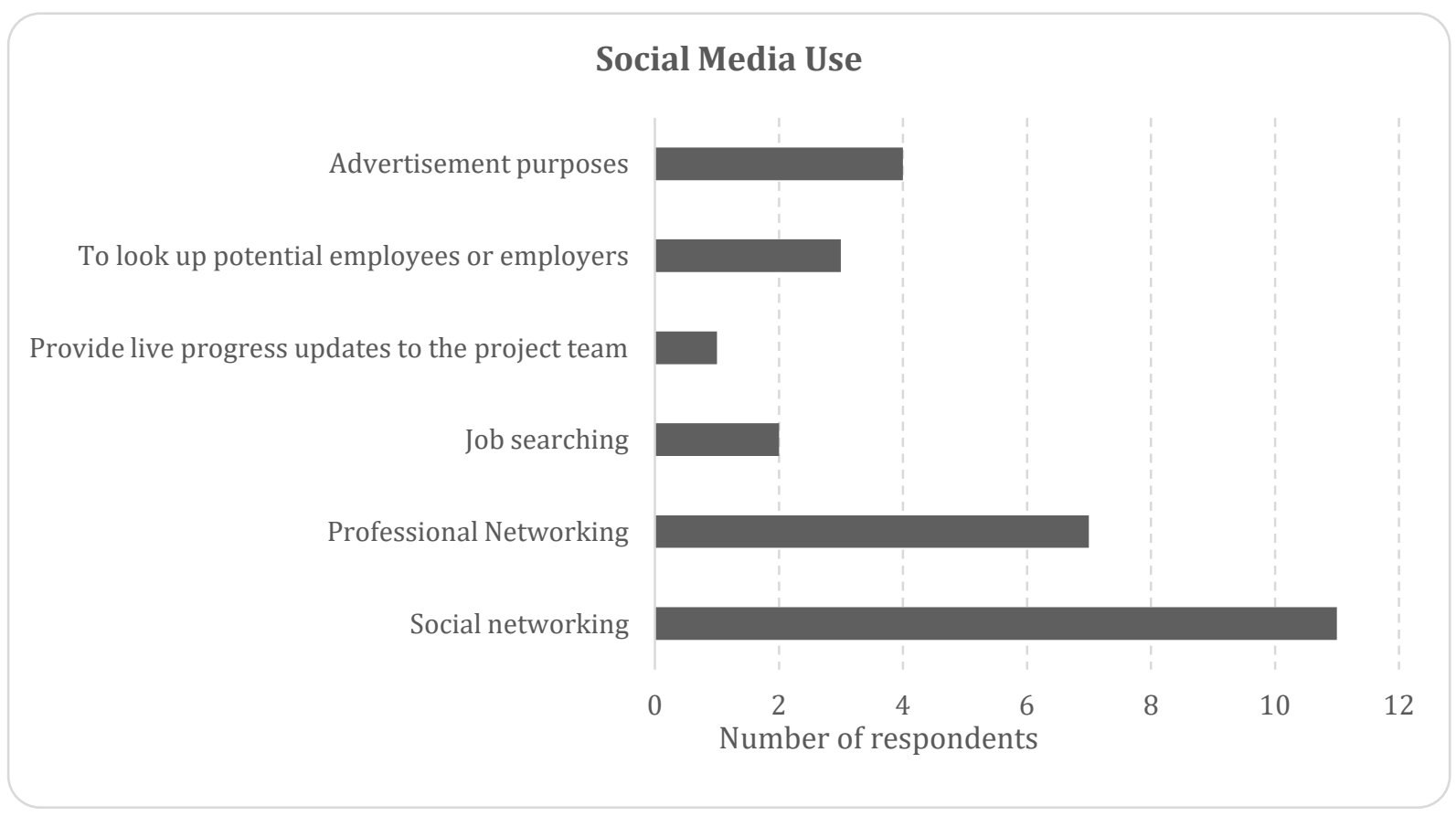

FIGURE 20: The above graph shows the purposes for which respondents use social media.

As can be seen from the graph above the, majority of the respondents use SM for both personal and professional networking. Apart from the uses graphed above, respondents also indicated that they were using SM for advertising jobs as well as managing the SM profile of their organisation. When asked how they accessed SM, respondents ranked the following IT in the order they used the most to access SM:

(1) Smartphone

(2) Tablet computers (iPad, tablets etc.)

(3) Personal laptop

(4) Company provided PC 
(5) Public computers

It was seen that mobile devices were being used the most to access SM platforms. It was found that $70 \%$ of the respondents did not have a policy in their workplace concerning the use of SM. The remaining $30 \%$ of the respondent were split in half indicating they either did not have a policy concerning SM use or that they were not allowed to use SM at all in the workplace. In general SM was not being utilised in projects as well, however there was an interest on the use of SM tool to support project related tasks. When respondents were asked how they would utilise SM if given the choice, the top three uses for SM identified by the respondents were (1) establish a company profile on SM, (2) Advertising, and (3) file transfer and exchange. When asked if they would consider using SM or have used in projects the following responses were given by the respondents.

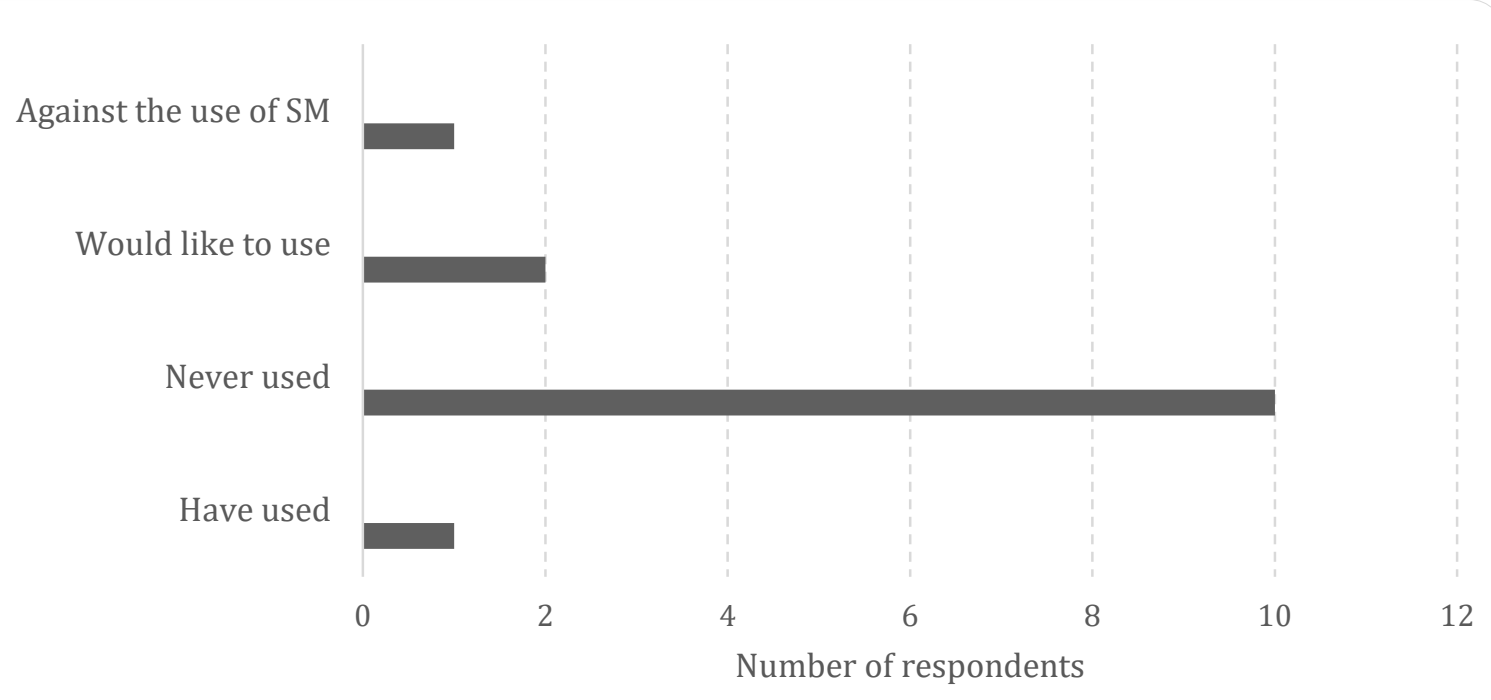

FIGURE 21: Have you ever used SM for project work?

Most of the respondents indicated that they had never used SM for any project related purposes. On the other hand, only two participants said that they would be interested in using SM for project work. This is perhaps due to a lack of knowledge in the use of the Sm tools and platforms for collaborative working. Apart from this, there are also a few issues with regards to the use of SM in organisations. As noted by (Azhar and Abeln 2014) three notable issues associated with SM use by AEC companies were security, privacy and lack of understanding. Generally, there is a mistrust with the openness of the technology. Moreover, according to a study conducted by the Australian building and construction industry identified that while 72 percent of the businesses surveyed were unsure as on how to create a SM strategy to engage their followers on SM platforms (Trenchless International 2014). These reasons coupled with 
the AECs adverse IT adoption approach, is making it hard to allow for structures and strategies to emerge that would be able to allow for SM use. However, it is recognised form literature that SM use is only applicable to external facing communication and not internal project collaboration. Internet collaboration requires looking at Web 2.0 technologies and Web 2.0 centric Social software (groupware).

\subsubsection{Social Software Awareness}

Social software in this dissertation is used as an overarching term that encompasses nonspecific software used to support group collaboration and may or may not offer Project management functionalities as well. This definition effectively includes the terms WPMSs, Enterprise 2.0 software and SPM software which are essentially Web 2.0 influenced software. In terms of awareness for Web 2.0 while some of the respondents indicated that were aware of the term Web 2.0, they were not aware of the other terms that were identified through literature which have been directly influenced by Web 2.0. These terms include Enterprise 2.0, project Management 2.0 and Social Project Management (SPM). In addition to this, none of the respondents were aware of any project management software that have been influenced by SM. This is contradictory to the results of the question that tested the respondents' knowledge of web-based project management software. When given a list of web-based software and to identify software that they either recognised, had used in past projects or did not recognise at all. Respondents indicated that they recognised the following software.

\section{Zoho Projects}

2. SharePoint

3. Yammer

4. Project Place

Out of the four platforms mentioned above, respondents point out that they had also used Teambox, SharePoint, Trello, Box, Dropbox and Google Drive in the past. While this list is small it does give the indication that respondents were aware of these software. It is important to note that these types of software are web-based collaborative software which are fundamentally built on the technologies and principles of Web 2.0 which is the underlying technology of SM platforms. Dropbox and Google Drive are general purposes tools which are largely used for online file and document. Apart from storage capabilities the two platforms also support synchronous collaborative work on documents. 
Teambox, Trello and SharePoint are social software which offer collaborative tools for its users. Teambox which has changed its name to Redbooth and is one of the software that was also reviewed in Chapter 6 of the thesis. 


\subsection{Limitations of Survey}

This section looks at some of the limitations of the survey that affected the results and analysis of the data.

\subsubsection{Survey duration}

The survey which was initially planned to take only two weeks to complete took longer than expected due to the low survey completion rates. This meant that the survey timeframe had to be extended which affected the data collection and analysis. Due to the limited timeframe the final number of participants which was lower than anticipated had to be settled for to be able to complete this dissertation.

\subsubsection{Distribution}

The survey distribution method was a significant limiting factor as it meant that the participants had no associated responsibility to complete survey when they had already started. This meant that there was a higher rate of survey participants dropping out without completing the entire survey.

\subsubsection{Survey target group}

The survey was generally aimed at construction industry professionals with construction PMS being the intended primary target. This study would have provided a more dynamic analysis by including PMs from other industries to give a better indication of how construction PMs compare in terms of collaborative software and SM adoption. Also, widening the participant net to include survey participants outside of New Zealand would have given a wider ranging response set to analyse as well as a larger data that would have increased the reliability of the results. 


\subsection{Summary}

In summary, the survey was carried out with the aim of answering the question of; Is there $a$ need for SM in the construction? Participants mainly used SM for personal communication and used it less for professional purposes. However, it is important to note that all the participants owned a smartphone and it was the main way in which they accessed their SM accounts from. Participants' also noted that they would spend on average less than 3 hours a day on SM platforms. This could mean more as it does not consider 'push notifications' that smartphones are susceptible to receiving which essentially increases the SM use-time for respondents. In terms of software use in the workplace, the participants had access to basic software for the construction industry such as CAD software, Microsoft Office tools, email management and MS Project.

When asked, participants had no knowledge or were not aware of what the terms Enterprise 2.0, Project Management 2.0 or Social Project Management meant. However, they were aware of and using web-based collaborative software such as Google Drive and Drobox. The survey questionnaire did not define these terms but just asked the participants if they recognised them. It would have been better to define the terms in the survey for a better understanding of the question which may have given a different response set. While survey participants were somewhat satisfied with their current collaboration software, they admit to it needing some improvements as well. Survey respondents were also open to incorporating features found in SM platforms into improved collaborative systems.

In conclusion, the industry professionals surveyed had access to a lot of IT software and hardware that supported communication and collaboration. While they did not agree with the use of SM for internal team collaboration and communication, they were open to the idea of using features and tools that were adapted from SM platforms in a web-based software. The next Chapter of the thesis examines 10 state-of-the-art SPM software currently available that incorporate core PM tools while essentially functioning as an SNS for the project teams. These software offer a wide range of Web 2.0 collaborative tools that is aimed at supporting social interactions between team members on a virtual electronic workspace on the Internet. 


\section{Software Review}

The following section of the thesis summarises and discusses the various tools and services offered across 10 web-based project management software which were chosen based on a set of criteria. This chapter is divided into three chapters. Chapter 4.2 of the Research Methodology describes how the tools described in this Chapter were divided and Figure

The software were chosen through a list of criteria that had to be fulfilled. This list can be found in the Research Methodology section. It is important to note that in this study, the terms software and platform and application are used interchangeably to describe web-based software.

TABLE 13: List of Software chosen for review

\begin{tabular}{lll} 
Software & Developer & URL \\
\hline Project Place & Planview & www.projectplace.com \\
\hline Podio & Citrix systems & www.podio.com \\
\hline Zoho Projects & Zoho Corporation & www.zohoprojects.com \\
\hline Mango Apps & The Unified Collaboration Company & www.mangoapps.com \\
\hline Clarizen & Clarizen & www.clarizen.com \\
\hline Redbooth & Redbooth & www.redbooth.com \\
\hline Wrike & Andrew Filev & www.wrike.com \\
\hline ProjExec & IBM & www.triloggroup.com/projexec/ \\
\hline Liquid Planner & Liquid Planner, Inc & www.liquidplanner.com \\
\hline eXo Platform & Open source & www.exoplatform.com \\
\hline
\end{tabular}

Table 13 shows a list of software that was reviewed. All of the listed platforms are web-based and are deployed as software as a service (SaaS) type of cloud computing. SaaS option only requires the client to pay a usage fee and a standard web browser and Internet access to use the platform online. Some of the platforms also offer the on-premise option of software installation as an alternative or supplementary option. In comparison to the SaaS delivery method which only, the on-premise (traditional) option requires the client to have hardware and software installed in their own buildings. Compared to the on-premise option, the SaaS option is far more convenient and cheaper to adopt especially for small to medium enterprises (SME) who cannot afford to make the capital investments required for on-premise installations (Chung 2011). 


\subsubsection{User Accounts}
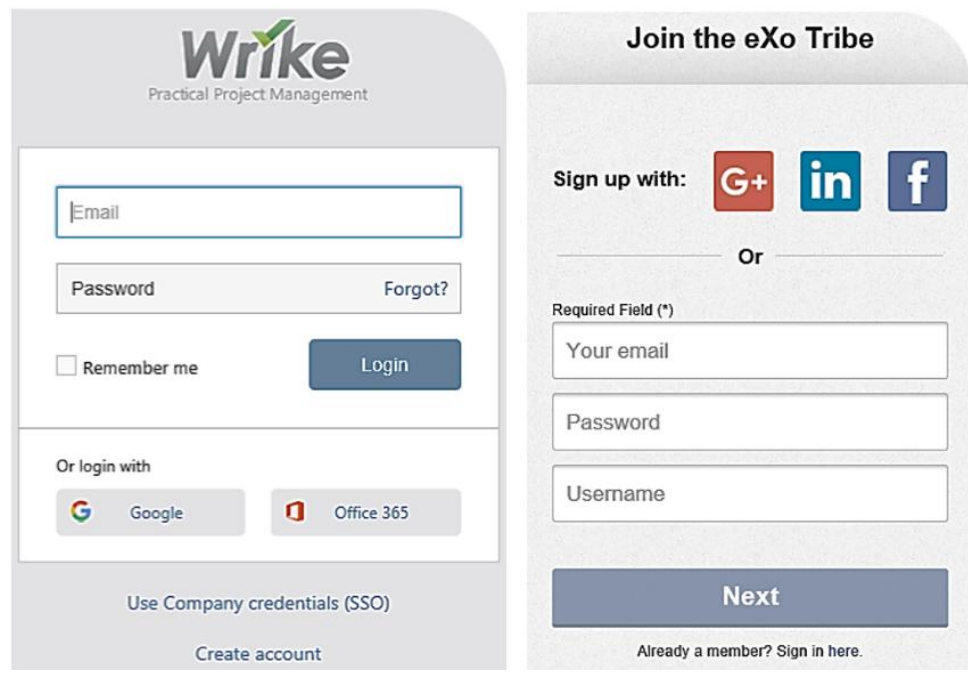

Sign in to your Zoho Projects account

FIGURE 22: Account creation page for platforms. From left to right Wrike, eXo Platform and Zoho Projects

SOURCE: 1. https://www.wrike.com/login/

2. https://community.exoplatform.com/portal/intranet/register

3. https://ww w.zoho.com/projects/login.html

Figure 22 shows the account creation option for Wrike, Exo Platform and Zoho Projects. Creating an account with these web-based platforms is easy. Users can either create an account using an active email address or through a SM account. Facebook, Google and LinkedIn are some of the commonly used SM login alternatives. Figure 15 shows examples of such account creation prompts across three separate platforms.

After choosing the method of signup/registration, users are typically prompted to fill in information about themselves and complete a short descriptive bio for their profiles much like a social networking profile set-up.

Several the platforms reviewed also employ the single sign on (SSO) option. SSO is a feature which allows a user to sign onto several integrated applications at once. A perfect example of this is when signing into Google. Google users when signing into Google are automatically signed into other connected Google applications such as YouTube, Gmail, Google Drive etc. This is useful feature for platforms that have integrated third party applications. 


\subsubsection{Graphical User Interface (GUI)}

The user interface or UI is how the user and the computer system interact. This is the way in which user navigate the platforms functions. A more appropriate term graphical user interface or GUI is used. The Podio GUI is used as an example in this study as it has a simple and highly customizable GUI. The GUI for Podio can be seen pictured in Figure 24 below.
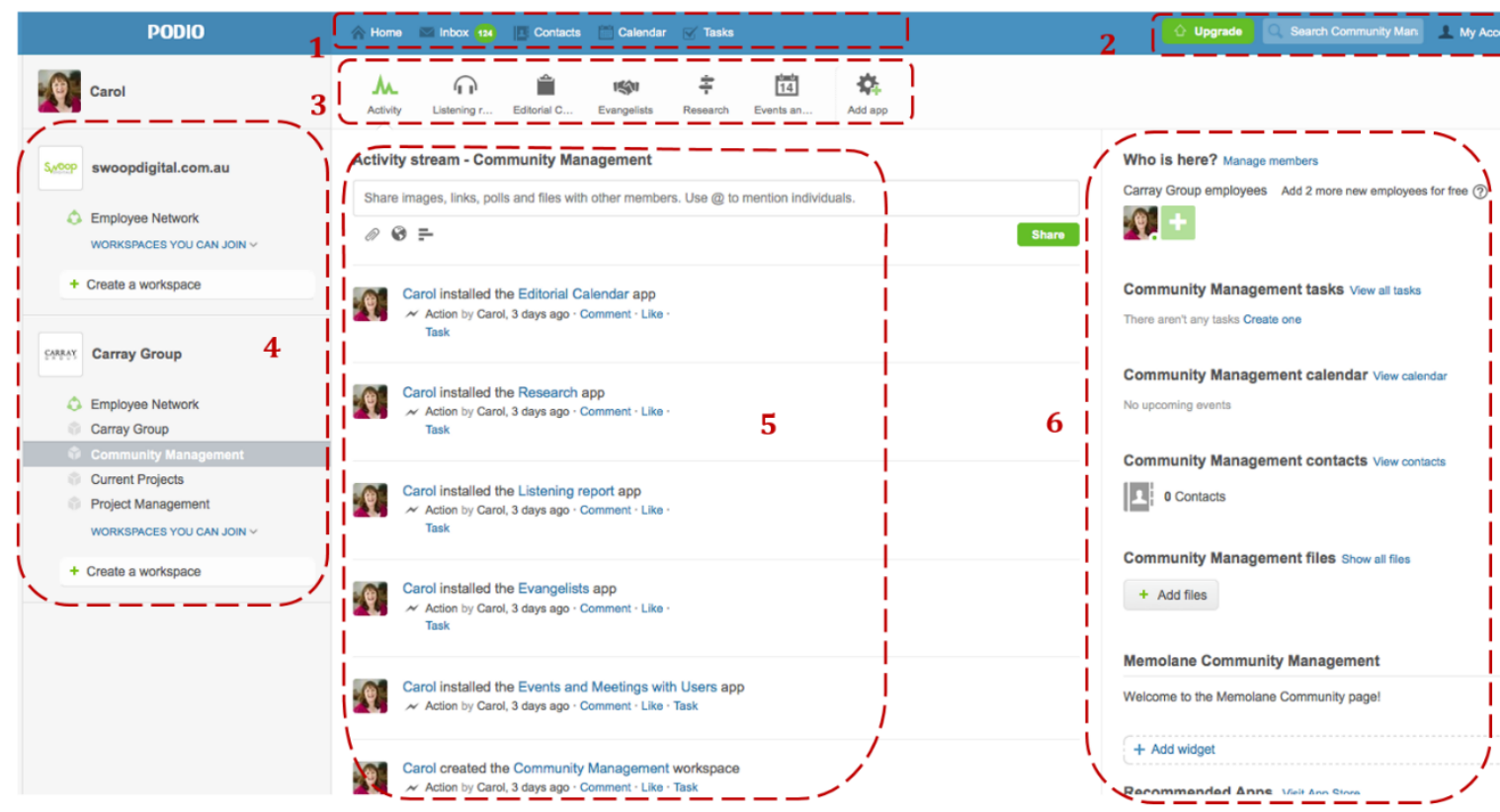

FIGURE 23: The workspace GUI for Podio

SOURCE: http://www.effortlessinternetmarketing.com/wp-content/uploads/2012/03/Screen-Shot-201203-08-at-12.47.55-PM.png

The Podio GUI is quite minimal and is reminiscent of popular SNS Facebooks in its colour scheme and layout. The functions for each section of the GUI is listed below for the workspace/ project view pictured above in Figure 23.

1. The horizontal toolbar on the very top of the page contains links to the Home page, Inbox, Contacts, Calendar and Tasks. This toolbar is always visible no matter what project or page the user is in the platform. This is the primary navigation toolbar and its location is never changing. Location of this platform varies across some of the other software.

2. To the right of the Primary navigation toolbar are three tabs Upgrade, Search bar and My account. The upgrade tab lets users change their subscriptions settings while the My Account tab contains all customizable settings such as security or personalisation settings to organise tabs, workspaces and what information can be displayed on the Secondary Toolbar

3. Just below the primary toolbar you have the Secondary tool bar. When a user is in the project or workspace that they have access to, the toolbar will contain tools that is accessible to group members. The Activity stream gives real-time updates on the activities 
of team members in a reverse-chronological order. Podio has several apps that can be integrated with it to extend its functions. SmartGantt is a Gantt chart tool that is not built into Podio but can be added as-needed.

4. This is the Workspace or project tab which contains a list of projects that a user is a member of. Users can click on a project and be directed to the project page to view specific information or interact with other members of the project. The administrators of these workspace pages are capability of setting privacy parameters and limit access to the project information as they see fit or as agreed upon by the group.

5. The Activity Stream/ Timeline feature is similar in functionality to those used in SNS and allows project team members to post questions, hold discussions, give updates or for file and media sharing purposes. Project team members can use User tagging to notify the relevant people of the information that are trying to share. The timeline gives a reverse chronological account of the team members' activities in the project group. It updates in real-time allowing for relevant information to be always be on top of the stack.

6. This widget contains all information relevant to the information such as project team members, project directory, documents and files, shared folders and calendars etc. this widget can be customised by team members to also include other information that they deem to be necessary for the whole team to have instant access to.

The GUI for each platform varies in layout, colour scheme and the types of tools that are available. Generally, GUIs are designed to simplify general navigation and browsing as well as making it easier to locate important tools, services and information. The Podio platform uses a GUI design that is strikingly similar to Facebook. This gives users a sense of familiarity and reinforcement in their innate ability to use the platform. Of course, this draws on the idea of 'technology populism' and 'consumerisation of IT' and placates to a generation of Internet users that have grown up with Web 2.0 technologies and have grown accustomed to adopting continually emerging Social Media platforms. However, the use of Social networking sites (SNS) is an overtly popular SM platform type. And this has seen its adoption within organisations under enterprise social networking (ESN). For this reason, most of the platforms GUI design is heavily influenced by SNS. 


\subsection{Project Management Features}

TABLE 14: Software features matrix matched against specific software.

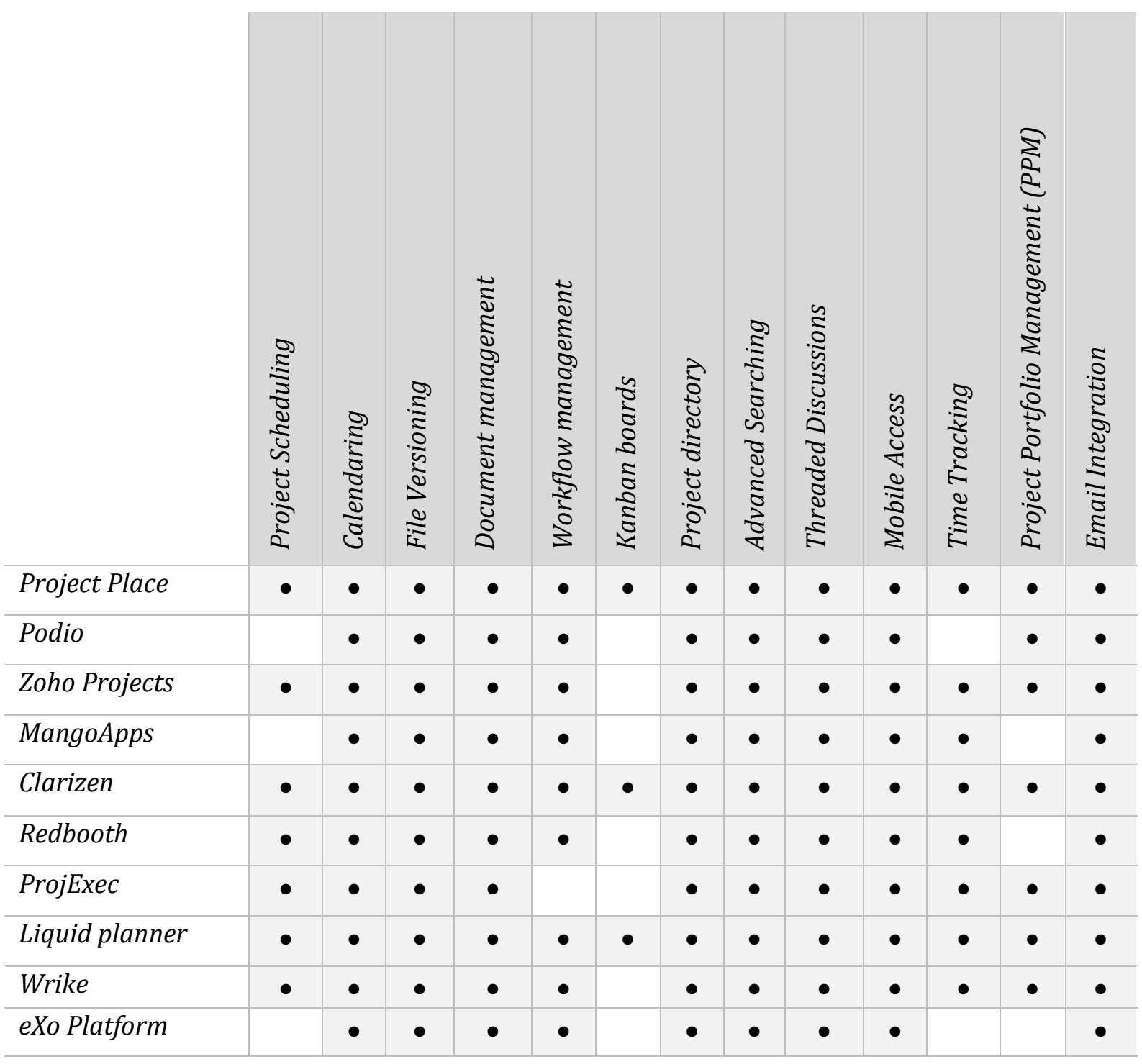

While the platforms that were reviewed demonstrated features that were similar to construction industry specific WPMSs, there were some features, that were either, not applicable found in the software review. These features are more construction industry specific. These features include, project camera, printing services, offline access, messaging outside the system, wireless integration, financial services and E-bidding and procurement. Offline access and messaging outside the system is a redundant feature for web-based platforms as they require constant Internet connection to access important information and interact with other users. Some of the platforms offer financial service but this is not a common feature amongst the reviewed platforms. However, financial services tools could potentially be included in the software though an integration of a third-party platform or by developing a dedicated application using the API of the PM 2.0 software. The project camera is potentially a useful tool 
that could be integrated into PM 2.0 platforms as well. Web 2.0 tools can only be effectively used if they are integrated together under a single interface (Polaschek, et al. 2012).

The next sections defines and discusses how these features function and gives example from the software that were reviewed of how they can be used. The Project Management list of features includes project and task management capabilities that are important for managing large teams and team work between departments. Examples of such features include, Workflow automation, document management, file versioning, scheduling with calendar integration and automated reminders and alerts, Gantt charts etc.

\subsubsection{Project Scheduling}

One of the Key tools and process for PMs is in scheduling and tracking progress of tasks. More common scheduling software include Microsoft Project and Primavera.

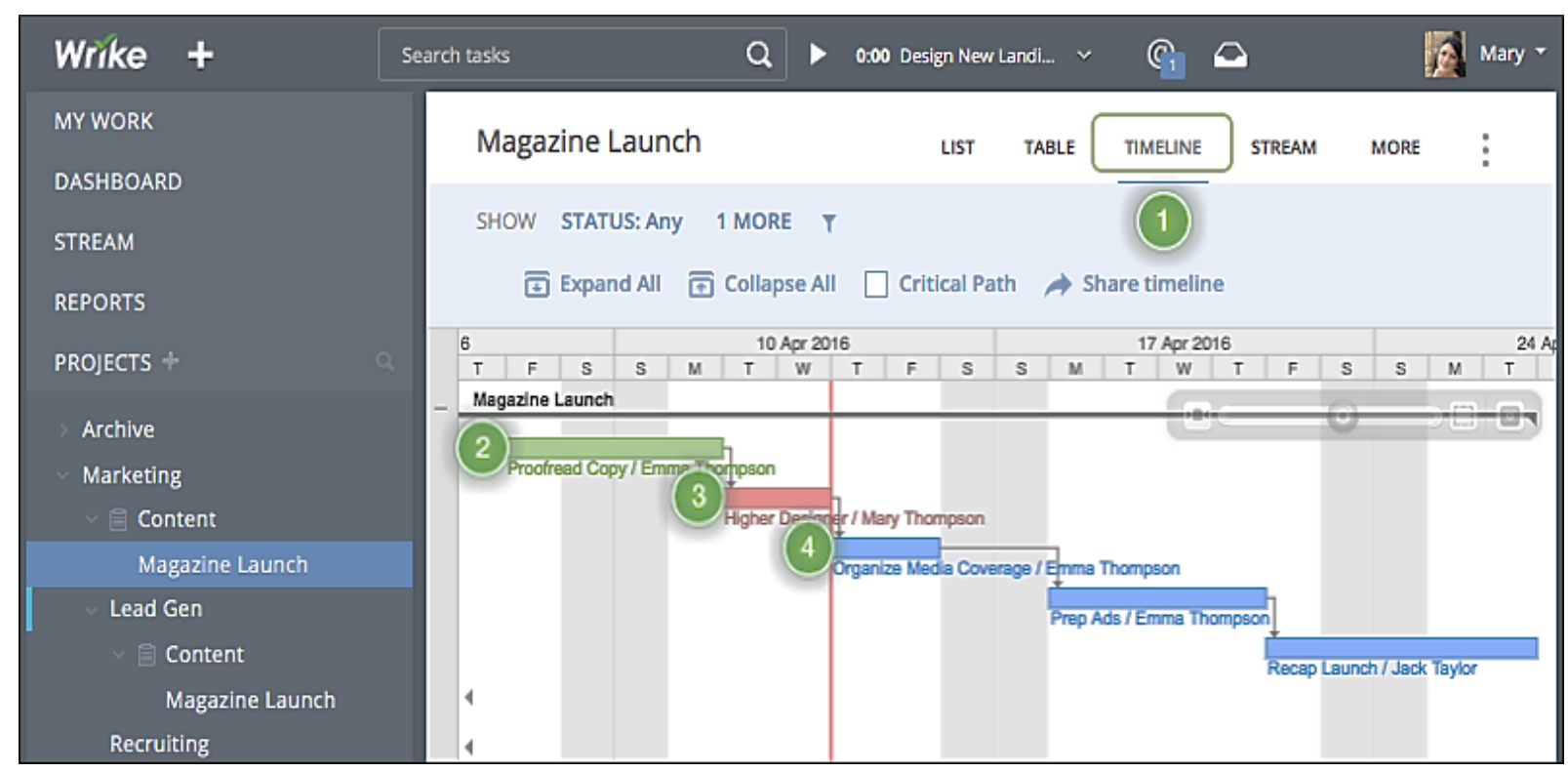

FIGURE 24: Wrike Gantt chart view.

SOURCE: https://www.wrike.com/help/project-schedule/

Gantt charts are a key tool in project planning, scheduling and progress tracking for PMs. The project scheduling features allows users and project managers to break down the project into its key milestones and tasks so that work can be assigned to team members. Typically, PMs would use disparate software suits such as MS project or Primavera which are software used for generating project timelines and provide progress reports for the project team. Scheduling software is crucial in monitoring progress and informing decision making. The Gantt charts allows users to monitor progress status as shown in Figure 24 where tasks on the Gantt chart are colour coded. Green indicates completed tasks. Yellow indicates minor setbacks which could affect project deadline. Red indicates the project is behind schedule, the deadline will be 
missed. The tasks highlighted in blue indicate active tasks which are yet to be completed but are on track. A unique feature which is used by the some of the platforms is the integration of email with Gantt charts, where email items can be directly turned into tasks in the project plan and updated in the project Gantt chart. Wrikes email integration does this by allowing users to send email to the project folders on Wrike and includes information such as task duration, which team member to assign the task etc.

\subsubsection{Calendaring}

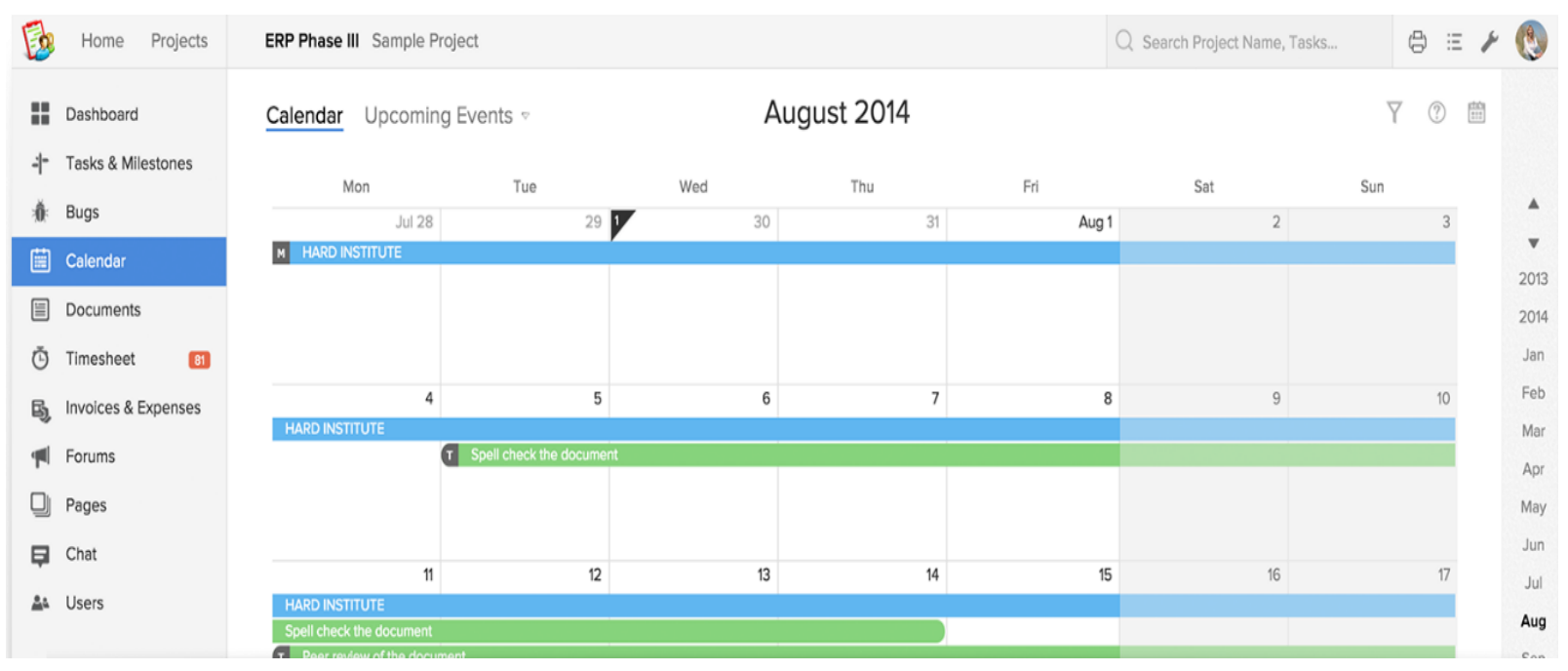

FIGURE 25: The calendar view for Zoho Projects.

SOURCE: https://www.zoho.com/projects/features.html

The calendaring features enables users to stay on top of their tasks by keeping a track of upcoming project deadlines, events, meetings etc. there are calendars for both individual and groups (project). This makes it easier. Functionalities of the calendar include:

a) Sending and receiving invitations for events, meetings etc.

b) Subscribing to and importing calendars

c) Sharing calendars with Individuals or groups

d) Accessing calendar through mobile devices

Calendars can also be linked up with the users' personal email account, so the user can get reminders and updates on any changes to the dates set in the calendar this includes date changes or any requirements or additional items or issues that need to be addressed for that set date on the calendar. 


\subsubsection{Document Management}

Web-based project management are mainly built as document management and information sharing platforms (Forcada, Casals and Roca, A model for Construction Project Management extranets 2003). This feature is used to establish a single point of location for storing general project related data. In terms of construction projects this refers to project photos, contract, drawings, specifications, cost data etc. it allows the management of files in a central location (Nitithamyong and Skibniewski 2004) . While this feature is typically built into web-based software, some of the platforms offer integrations with third party applications such as Dropbox, Google Drive, and Box etc. which are generally used for online storage space and offers documents management capabilities.

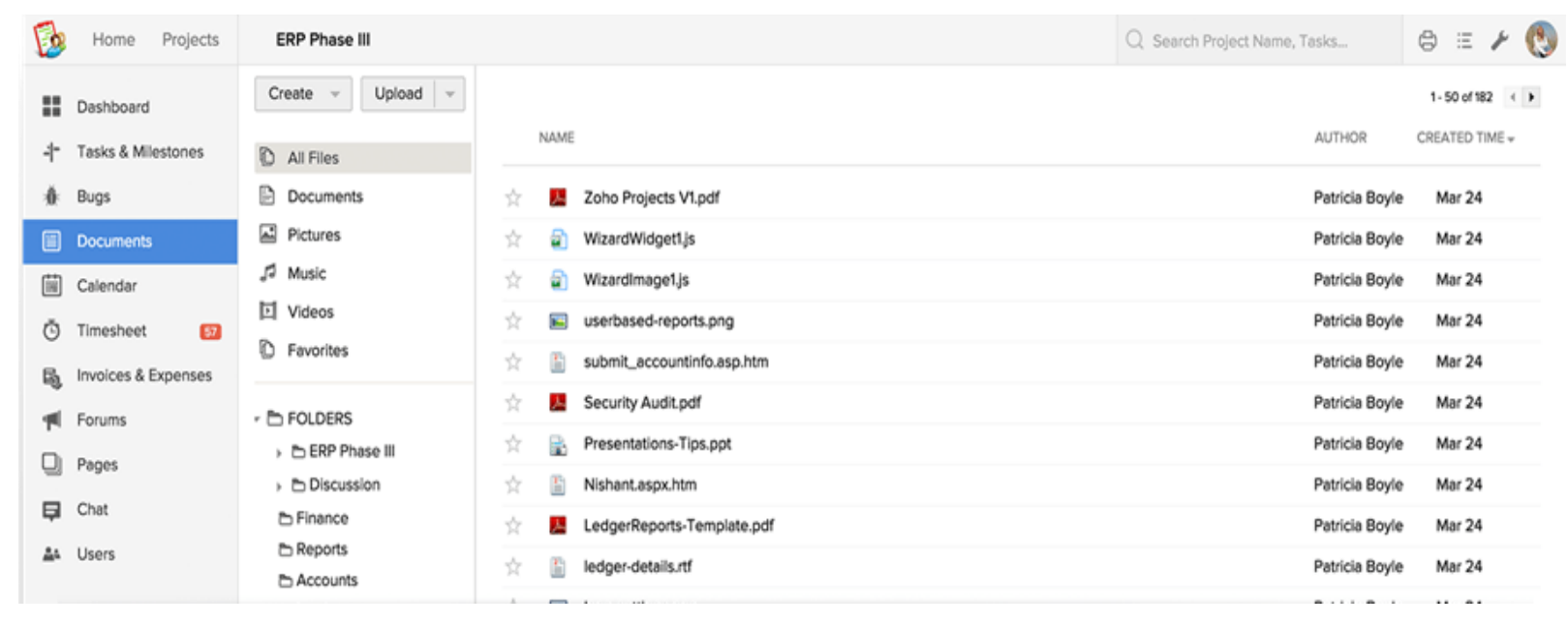

FIGURE 26: Document management system for Zoho Projects

SOURCE: https://www.zoho.com/projects/document-management.html

Figure 26 shows the format in which Zoho manages its documents. Users can see all files that they have access to while also having the option of going into individual project folders to view specific files and documents for a project. With file versioning users are also able to see if anyone has made any changes to the files and when.

Administrators can set access control on what files team members are able to view, modify, delete or add to the documents folder. This may vary and depends on the informational needs of the user. A further example in the Project Place platform is used to demonstrate how users can navigate typical documents folders. This is shown in Figure 27 in the next page. 


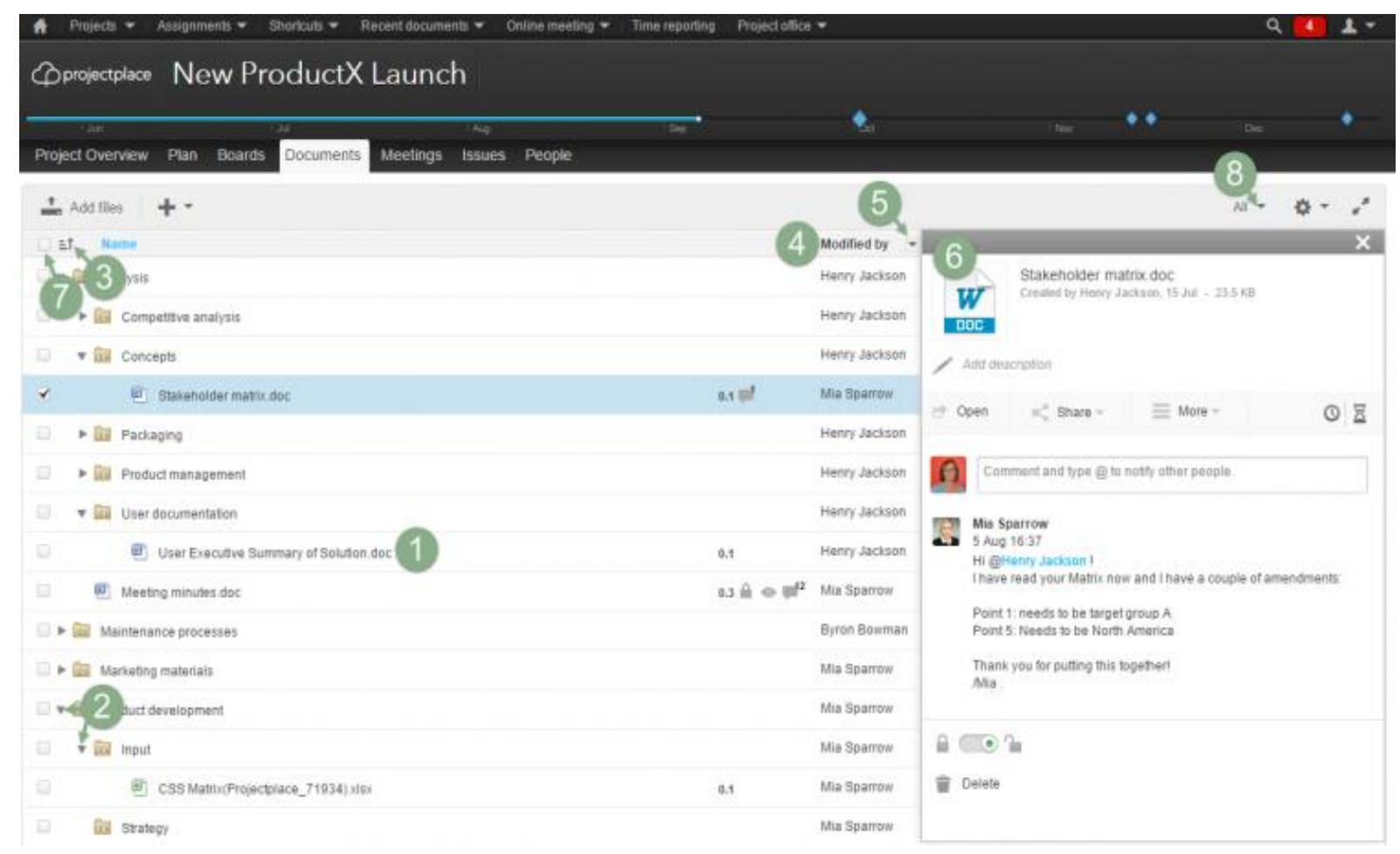

FIGURE 27: document management for Project Place software with important functions highlighted SOURCE: http://bit.ly/1VYhziS

To navigate the documents page users, have the following options. Click on a document name to open it (1). To expand or collapse a folder, click on the arrows (2). You can also collapse all folders at once (3). Click the column header (4) to change sorting and on the arrow next to it (5) to rearrange the order of columns.

To select a document or folder, click on the checkbox or anywhere except the name. The detail view (6) contains all related details and actions. Here you also can comment and discuss the document with other project members. If you select several documents and folders at once, the detail view will include only the applicable actions. Select all documents and folders listed with the checkbox next to the Name column header (7). In addition to the view listing all documents and folders, there are some special views (8)

\subsubsection{File Versioning}

The file versioning feature allows the project team members to keep track of who accessed file and any alterations that may have been made to the file. Digital signatures are used to identify and verify an individual before entering data or transmitting information (Nitithamyong and Skibniewski 2004). This feature is common across all the platforms studied except for the ones that do not have any file sharing or document management systems. Some platforms even allow for synchronous work to be carried out on shared documents where two people can modify and edit a document simultaneously. 


\subsubsection{Workflow Management}

Some of the workflow processes which are specific to construction projects include bidding and tendering, requests for information (RFIs), design reviews, change orders and variations, document review and approval, BIM collaboration, project correspondence, field inspections and issues management, and operations and maintenance (O\&M) handover etc. In the software that were reviewed, the use of web-forms and project templates is a tool in aiding workflow management and automation. It is important to note that these platforms are not designed towards managing construction project teams.

\subsubsection{Kanban Boards}

The Kanban board method gives the project team a highly visual overview of project tasks that needs to be done and their statuses as well.

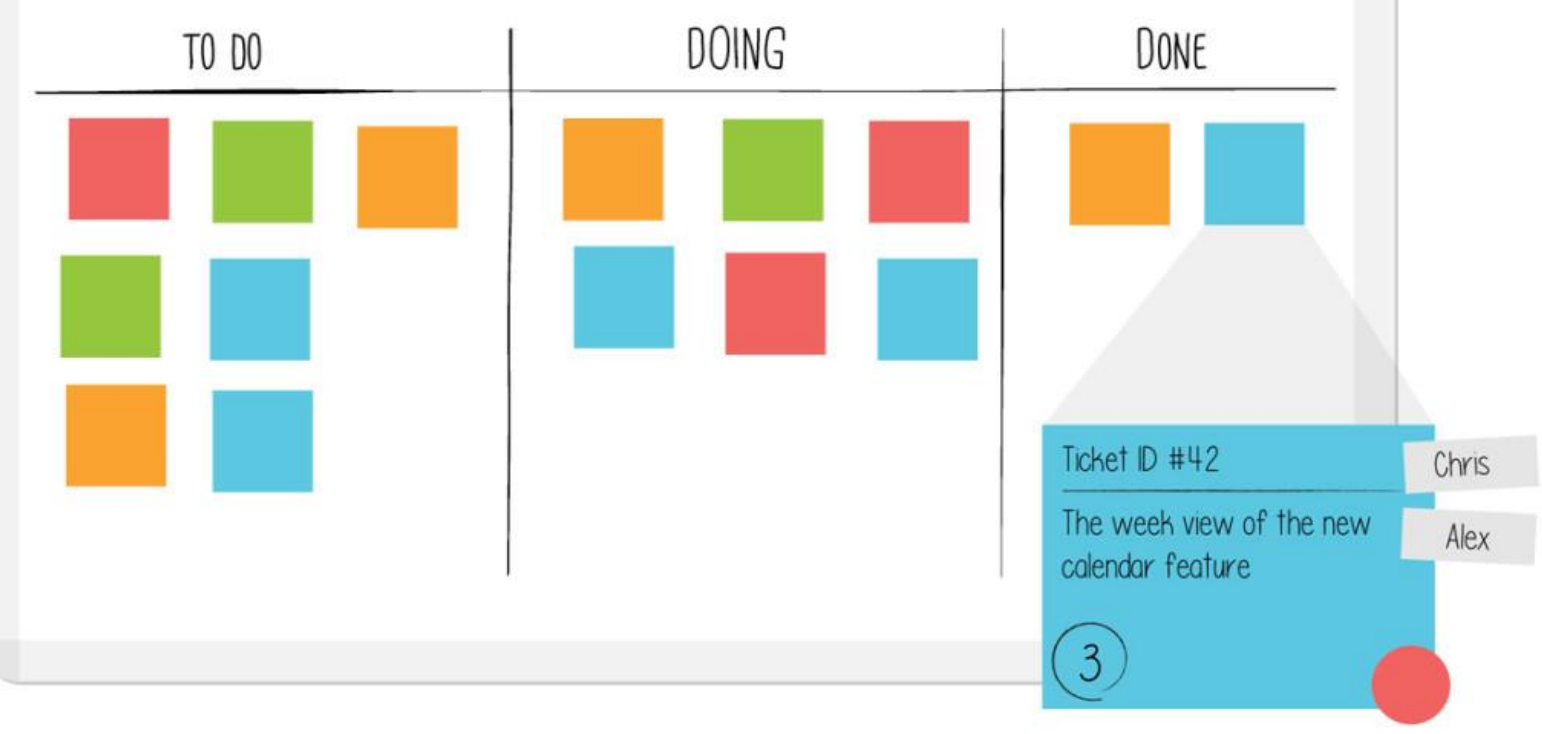

FIGURE 28: Example of a physical Kanban board.

SOURCE: http://leankit.com/learn/kanban/kanban-board/

Kanban boarding is method that is primarily used in lean project management. The Kanban bard is a work and workflow visualization tool that is used to optimise the flow of work. Traditionally physical Kanban boards utilised sticky notes on a white board for something akin to that depicted in Figure 28. In the platforms reviewed, the concept remains the same but is carried out in a virtual web-based setting. The example shown above is of a sample physical Kanban board with the sticky note details shown. The different colours refer to the type of work being done while the columns correspond to status of work. The information on the note includes who is working on that task, the task ID number (for easy reference all tasks may be 
given reference numbers) and who is responsible for the tasks. The tasks are then put into columns depending on their status.

The Kanban board gives all project team members a visual view of workflow and activities that still need to be done making it easier for decision making and resource allocation. The goal of the Kanban board is to limit the amount of work that are in process. So that the work flowing through the system matches the system's capacity. Work piling up columns show everyone where the project teams attention need to be focussed on (Leankit n.d.)

\subsubsection{Project Directory}

The project directory is a central repository for important contact information of everyone in the project team. This includes email, contact phone numbers etc. This project directory can even be downloaded and added to the users connected mobile devices for ease of access and archiving purposes. This makes it easier to access team members contact information while being offline.

\subsubsection{Advanced Searching}

The advanced searching feature allows users to search for important information available on the project. This includes items such as project documents, threaded discussions and project participants. Advanced searching enables the faster accessing of information. Customizable privacy settings enable users to protect sensitive information or information that is limited to a group, project or workspace. Another way privacy settings can be used would be to avoid other users from being able to view your profile from a simple search. Parameters such as allowing only people in the same network as you to be able to view your profile and content related to you is one way in which privacy options can be used.

\subsubsection{Threaded discussions}

This tool provides an open forum that displays a sequential record of messages and responses on or about a topic. Project team members can post questions, responses and comments and have a permanent record of the discussion and decision process surrounding an issue. For sensitive issues this can be secured by a password (Nitithamyong and Skibniewski 2004) 


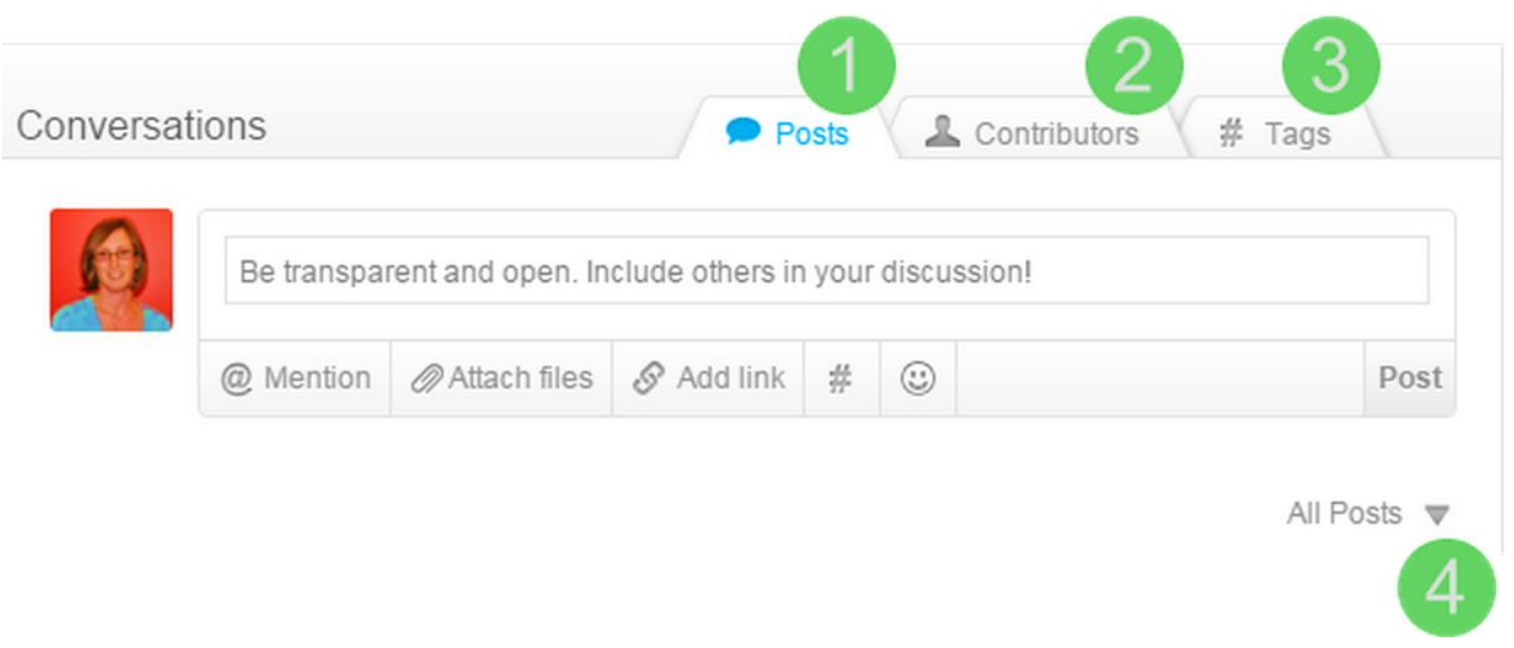

FIGURE 29: The Conversations Tab in Project Place

SOURCE: https://help.projectplace.com/wiki/index.php/Work_with_conversations

In the software Project Place, members can communicate with each other by informing, discussing or asking questions through the Conversations function as shown in Figure 19. All conversations are saved and available and can be followed by all project members. Whenever something happens in a conversation, the persons taking part or following the conversation will be notified via e-mail. Notifications for conversations can be turned on/off. Three tabs are available when using the conversations tools in Project Place. The first is Posts (1) which is used to view all conversations in the project. The Contributors tab (2) displays conversations that a member is involved in. Finally, the Tag tab (3) displays the tags that are used in the conversations. This is using the '\#' followed by a word to tag a word in a discussion. This makes it easier to search for discussions surrounding key words and helps to collate information that can be accessed later without too much hassle. The search tool which is a common tool in many web-based software easily picks up these tags to find information needed by the person searching for it. The tagging tools can also be misused by persons who tag discussions with irrelevant words. Moreover, users are also able to attach files to the post, add links to websites as well as tag other users in their post by using the @Mention tool.

\subsubsection{Mobile Access}

Collaboration platforms have this feature in the form of mobile applications. This allows mobile access to platforms across several devices including Android and iOS operating systems (OS) which are two of the most popular mobile operating systems currently available. These mobile applications can either mirror their web-based versions or only offer a limited set of functions and capabilities. With today's increasing computing power in mobile technologies, it is making it easier to access to gain access to web-based platforms through web browsers which can be commonly found in today's smartphones, tablets, iPhones and laptops etc. 


\subsubsection{Time Tracking}

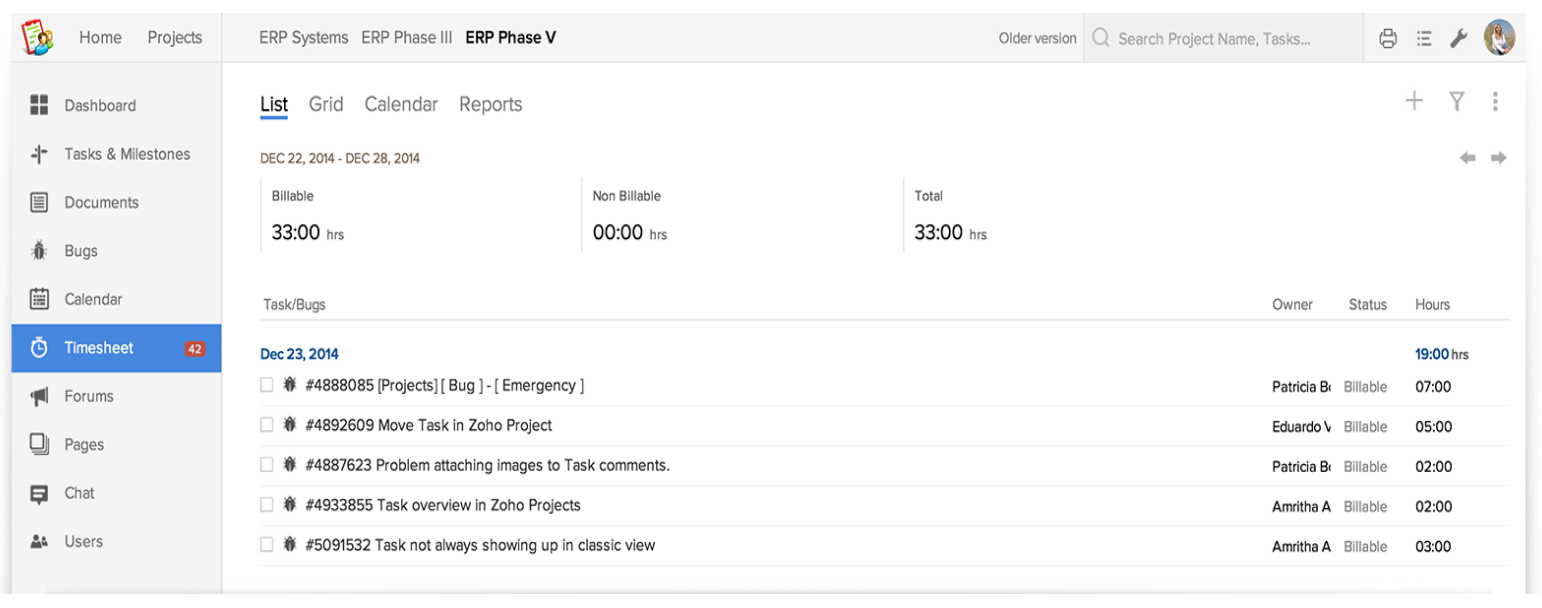

FIGURE 30: The timesheet view for Zoho Projects showing a breakdown of hours spent on tasks SOURCE: https://www.zoho.com/projects/features.html

The time tracking feature allows users to keep track of the amount of time spent on each task that they are assigned to. This also includes the capability for keeping track of billable and nonbillable hours for project participants. Figure 23 shows how Zoho users' timesheet view showing how it can be used to record their working hours spent on projects.

\subsubsection{Project Portfolio Management (PPM)}

When project participants work together on a project it is expected that they will not be working on only one project at any given time (Ahuja, Yang and Shankar, Study of ICT Adoption for Building Project Management in the Indian Construction Industry 2008) this feature allows PMs to monitor and manage several projects at any given time. This feature is particularly useful when working across multiple projects that have interdependent tasks and milestones.

\subsubsection{Email Integration}

The email integration feature is included in the project management features list as it is a recurring feature across all the platforms. Email technology is well established in the workplace today. It can be considered to be one of the more traditional enterprise technologies, its integration in these new web-based software highlights its importance. The Podio platform uses email integration in an interesting way. Tasks and project folders in Podio have assigned email addresses which users can use to email tasks and documents into. This allows the users to add or update tasks and project folders from their email accounts instead of logging into Podio. With such an extensive integration with emails such as the way in which Podio is designed, users run the risk of getting an overwhelming volume of emails. 


\subsection{Social and Collaborative Features}

TABLE 15: Software matched against social and collaborative tools

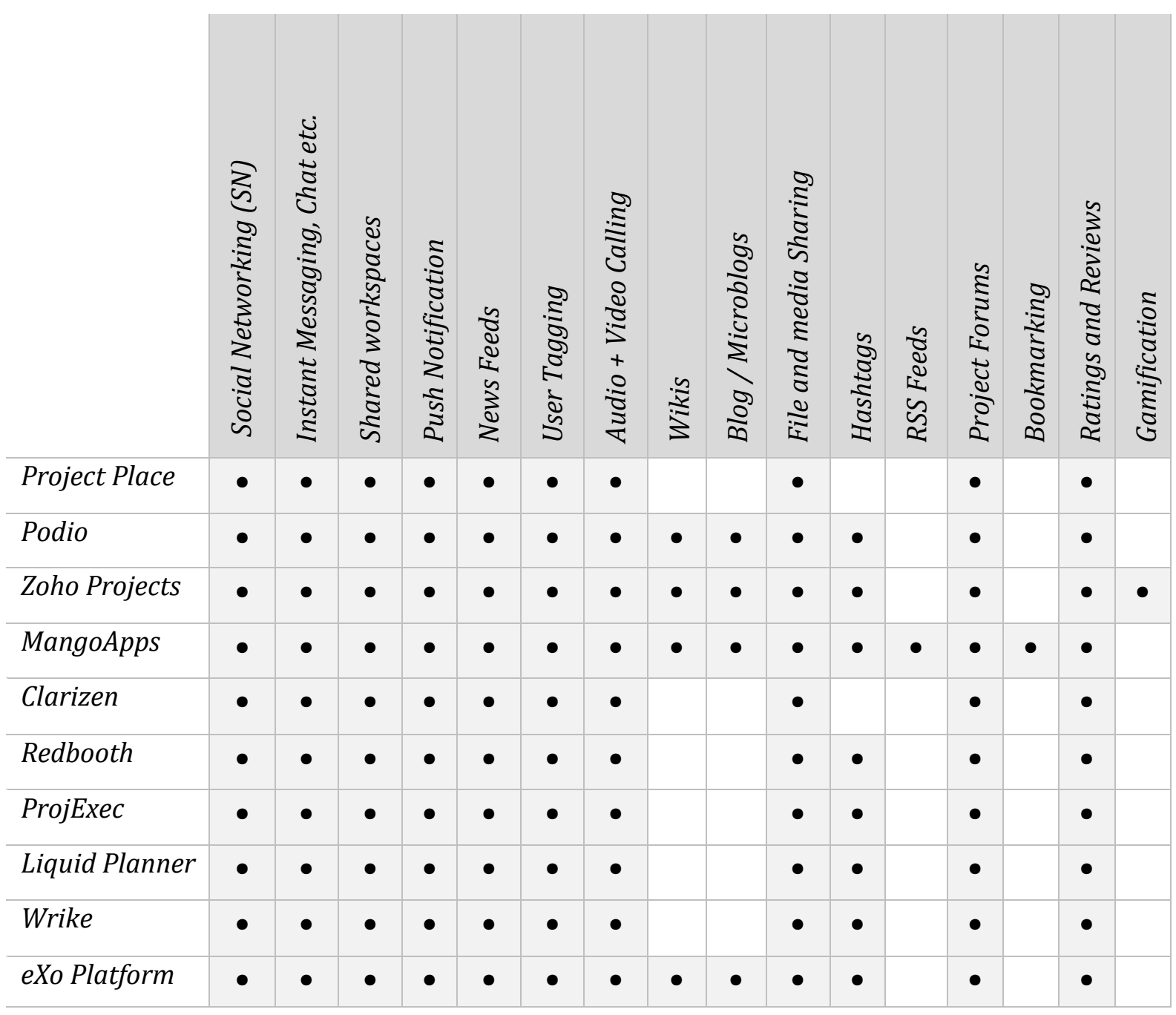

This Chapter comprises a short list of significant tools and services found across all 10 software that can be considered to be Web 2.0.

\subsubsection{Social Networking $(\mathbf{S N})$}

SN is not as much a feature but an inherent ability of the platform which allows for the platform to be used as a SN tool another term that has been used by platforms is Enterprise Social Networking (ESN). ESN allows for users to search and connect with other users of the platform and interact within projects on a more informal level. Like SNS users have account profiles which contains important information about the user including contact information, short biography, profile picture etc. SPM software must provide the ability for the project team to see the information that is most relevant to them. SPM theory and by extent software, applies the SN paradigm to the project core business process, software makes the project process visible to 
everyone both inside and outside the team. Further, using the "re-tweet" paradigm, project teams can publish issues, needs, and questions to the wider corporate (and external) social network, allowing for anyone who is interested to engage socially with the team to assist in accomplishing the project and organization's goal (Trilog Group 2012).

\subsubsection{Instant Messaging (IM)}

Also known as chat, IM is similar to emails except messages are short and the reply time is even shorter (Harrin 2010). IM or chat is a feature which is predominantly found in SM platform, but which is now also widely used in business software. Instant message can be accessed across various devices (over the Internet via a web browser, desktop applications, mobile devices etc.). Unlike emails, IM and chat systems enables the sender of a message to know when the message has been delivered and opened by the receiver. IM also allows the user presence detection and allows otherwise to know if the person they are trying to reach is at their desk or unavailable. This allows users to quickly ascertain appropriate and alternative channels of communication instead of wasting time waiting for the user to respond to messages.

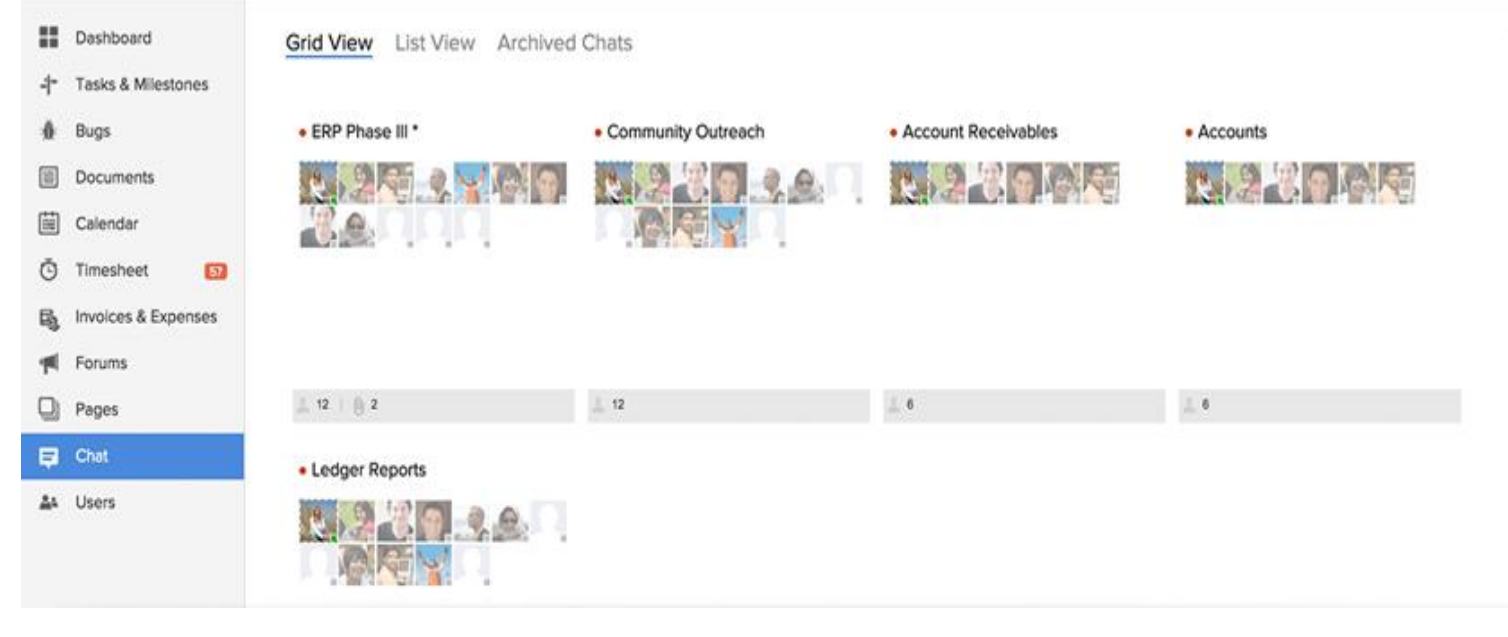

FIGURE 31: The timesheet view for Zoho Projects showing a breakdown of hours spent on tasks SOURCE: https://www.zoho.com/projects/features.html

The instant messaging feature is quite a common feature across the collaboration platforms studied and shows just how important and useful it is. The IM and chat feature can either be built into the platform or included as a third-party integration.

\subsubsection{Shared Workspaces}

The term electronic workspace is used by Bafoutsou and Mentzaz for a category of collaboration tools. This category of electronic workspace has the primary purpose of providing teams with a common space to coordinate and organise their work. Workspaces can be used to essentially 
store documents and files, work with, solve problems through discussion, keep to-do lists and a directory of information about group contacts and can even be used to track project milestones and project interactions (Bafoutsou and Mentzaz 2002). The reviewed software uses the terms workspace or projects to describe these dedicated electronic workspaces. Workspaces needs to be established at the start of project or any web-based collaborative work and the project team members added to the workspace to able to view, edit or contribute content. PM can assume an administrator role and is responsible for setting access parameters for members of the group and dictate who can be a member of a Workspace. This ensures that the relevant information contained within workspace document folders, can be viewed and modified only by authorised team members. Access need to be properly regulated to avoid misuse and inappropriate dissemination of information in the project workspace that is not relevant.

\subsubsection{Push Notifications}

A push notification is the delivery of information from a software application to a computing device without a specific request from the client/user. Push notification are also known as server push notification as it originates from the software server. Users can either opt-in or out of receiving notifications from particular items that users are following on the platform. For example, if you are part of a threaded discussion, group chat, shared file, comment etc. and do not want to receive notification updates you have the option of disabling receiving notifications for that item. This helps to limit information overload and ensures that the users only receive important information that they require. It is important to note that users cannot receive notifications while offline. Users must remain connected to the Internet server to receive up-todate notifications.

\subsubsection{News Feeds and Activity streams}

News feeds provide the user with real-time information on the activities of project participants. This allows users and PMs greater visibility on the project status and team members progress by showing real-time updates on the activities of project team members who are online. However, it is important to note that this feature only applies to users who are online to be able to see what's happening. Activity streams give a real-time update of everyone's activities on the platform in reverse chronological order. This is normally pinned to the side of the main view of the homepage or news feed page. 


\subsubsection{Audio and Video Calling}

Audio and video calling is a key feature for web-based collaboration and Web 2.0 services today. Allowing users to contact project members online. In project work this too is used to facilitate video conferencing with the added capability of screen sharing technology. Screen sharing technology allows everyone involved in a meeting or chat to view what is on a team member's screen in real-time (thus the terms screen sharing). This tool is useful for carrying out online presentations. In some instances, this can be used with compatible devices where users can be viewing the content using their PC or via mobile device such as a smartphone or a tablet.

\subsubsection{Wikis}

Wikis in SM platforms are used for a collection of web pages written by a group of people normally on a topic (Harrin 2010). The popular Wikipedia is an example of wikis being used successfully. The content is created and edited by the users (UGC). Zoho uses wiki pages to create a 'Social Intranet' for the project team through their page creation tool. Wiki Pages are a great way for team members to create, share and respond to project-related content like documents, spreadsheets, presentations, video clips and more. Build and update your own customized page in minutes with our complete set of drag and drop tools.

\subsubsection{Blog and Microblogging}

Short for web-log. It is like an online diary containing short posts (articles) which are viewed (usually) in reverse chronological order. People have the option of commenting on these posts providing feedback (Harrin 2010). While blogging is not really a standout feature in most of these platforms, microblogging can be associated with the status updates feature that many of the collaborative platforms have. The status updates is normally associated with news feeds.

\subsubsection{File and media sharing}

This feature allows users to share file and media as well. This feature is a well-established tool in social media and web-based enterprise platforms as well. The file/media sharing options allows users to share important and relevant information to other team member through comments thread, status updates. The file sharing feature is not to be confused with document management. The file sharing feature allows one to share images, documents, videos etc. anywhere on the platforms. This could be done through commenting on threaded discussions, blogs, project wikis etc. 


\subsubsection{User Tagging}

This feature allows users to tag other project participants in comments, status updates or in project tasks. The tagged user gets a notification which allows them direct access to the content that they are being tagged in. to tag a user the '@' symbol is used preceding the name of the person that you are wishing to share information with. This feature while useful in SNS needs to be controlled in context of use for the workplace as it gives high visibility to the information that is being shared to the tagged users. In this respect project team members need to be aware of the

\subsubsection{Hashtags}

This feature is a direct influence of social media such as Twitter and Facebook. The feature is quite like the user tagging, however instead to tagging users and groups, this feature allows users to tag information with associated descriptions for a specific topic of interest. The name comes from the use of hashtag '\#' preceding descriptive text or phrase. This makes it easier to search for information on a topic.

\subsubsection{RSS feeds}

RSS stands for Real Simple Syndication and is a tool used by a website to share content. Collaboration tools and blogs use RSS function and they appear as small icons on the bottom of a lot of web pages on the Internet. (Harrin, Social Media For Project Managers 2010)

The way in which RSS feeds operate is that they allow the user access to information from anywhere on the Internet given that the webpage or website has RSS enabled feature and capabilities. When clicking on the RSS button on a webpage the user is digitally subscribing to that page and will get any updates and changes on that page without having to revisit the same webpage repeatedly. This content can then be shared to other users as well. This automates your access to the information you want.

\subsubsection{Bookmarking}

Bookmarking refers to tagging a website and saving it for later. Instead of saving them to your web browser, you are saving them to the web. And, because your bookmarks are on-line, you can easily share them with friends or other users of your choice. This tool is oriented more towards social purposes rather than enterprise use. However, there may be instances where it can be useful in relaying project related matter to other project team members. 


\subsubsection{Ratings and Reviews}

Rating and reviews option enables other team members to provide feedback on anything that might posted up on the project page. This tool is commonly found in Social Media platforms. The Facebook like button is a simple example of this with the commenting feature as a means for users to express their views on topics, files, documents, video etc., being shared. Ratings and reviews can be used to for user tagging and hash tagging purposes as well. This feature helps generate interest in a topic which gets a lot of reviews and helps motivate users to generate project relevant information.

\subsubsection{Gamification}

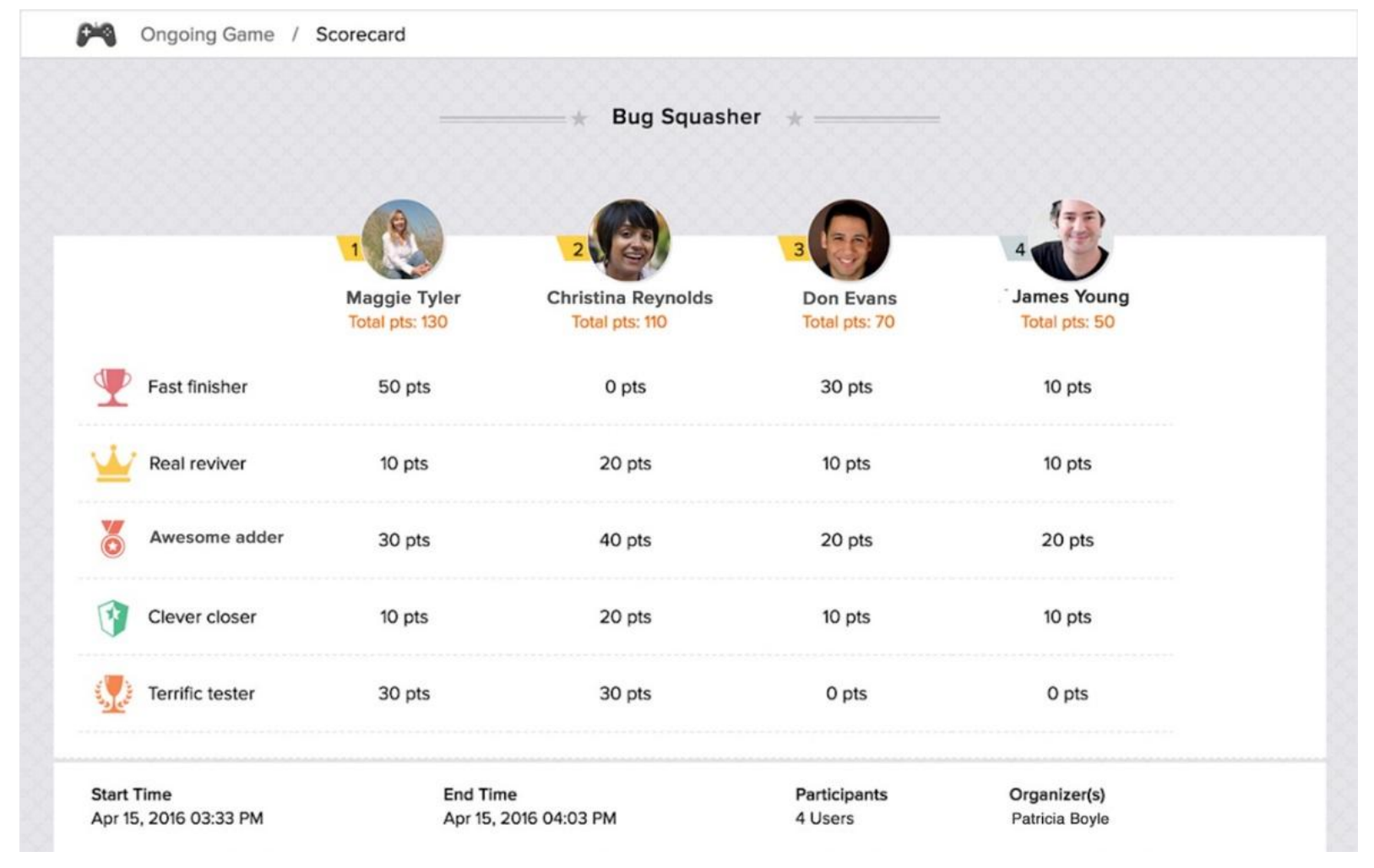

FIGURE 32: Gamification user interface for Zoho Projects Gamescope

SOURCE: https://www.zoho.com/projects/gamescope.html

Gamifications basically is the use of game design elements, game thinking and game mechanics to non-game context. Projects and games share some common traits which makes it easier to implement gamification theory in project management. Games are driven by goals, well defined player roles and measures in place to provide feedback on progress. Similarly, projects teams have a common goal/deliverable/objective where team members have delineated roles and measures which are put in place to measure the progress of the project. Figure 26 shows the Gamescope application which is used by Zoho Projects. Gamescope rewards users with badges, points and trophies based on their work performance, which is displayed on the users' profile 
and a dedicated scorecard for everyone in team to see. This generates a friendly competitiveness within project teams while increasing worker productivity and engagement. The gamification strategy is important to project management as one of the PMs Main priorities is in eliciting increased engagement and motivation within their teams. There are four main capacities under which gamification can be implemented in the workplace:

- points - something for 'players' to earn

- rewards - something for 'players' to spend their earned points on

- badges - something to show peers the achievements 'players' have unlocked

- Leader boards - a method of gaining some real-time feedback which is visible to everyone

It is important that everyone in the team can distinguish between the four areas mentioned above when implementing gamification in project teams. However, with the implementation of gamification methods there are associated benefits as well as risks which need to be considered. A list of benefits and risks are tabulated in Table 16 in the next page. 
TABLE 16: Table showing some of the benefits and risks associated with the implementation of gamification methods in project management adapted from (Association for Project Management (APM) 2014)

\section{Benefits}

- Higher motivation levels;

- Greater productivity levels;

- An increase in feelings of shared goals;

- Increased acceptance of repetitive, less exciting tasks

- Greater individual and team achievements;

- Providing a timely understanding of team performance;

- Data collection that can assist PMs in understanding the skills base within the project team;

- Stronger commitment to the project/ organisation;

- Greater transparency;

- Clearer accountability;

- Increased staff retention rates;

- Immediate and ongoing feedback

\section{Risks}

- Alienating some members of the project team/organisation

- The system may not work for all areas and levels of the team

- Where there are winners there are losers - what effect will this have on the team?

- Some employees may react negatively to being measured

- Applying gamification to every aspect of the workplace may cause a lack of focus and prevent interest in the engaging aspects it can provide

- Points and badges may become less exclusive as time goes on, leading to a lack of interest in the initiative

- Work could be de-valued if the behaviours enhanced are not well considered and not aligned to desired work behaviours; l healthy competition could turn into destructive competition, creating divides and preventing a team culture

- Cheating could lead to demotivation and dissatisfaction

- Gamification may alienate older members of the team who are unsure and unfamiliar with the terminology (this could apply equally to any team member regardless of their age). 


\subsection{Integrations}

The Integrations/ extensions/add-ons are all similar terminology referring to features found in the reviewed software that allows users to expand the functionality of the platform that they are working with. Extensions or add-ons are generally developed for specific use cases. For example, Podio does not have built-in Gantt chart, however an extension called Smart Gantt is available that allows users to use Gantt chart for schedule planning and progress tracking purposes. There are several extensions available for different project tasks including tools such as Gantt charts, tasks management, printing templates, timesheet, project planner and calendaring etc. there are limitless opportunities with integration options. In addition, platforms can also add other popular third-party web-based applications. Figure 27 shows some of the third-party applications that are available for Podio.

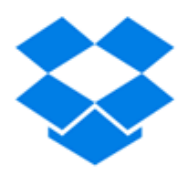

Dropbox

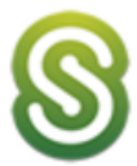

ShareFile

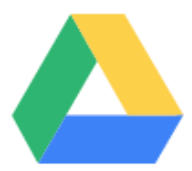

Google Drive

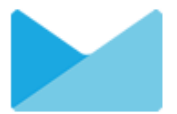

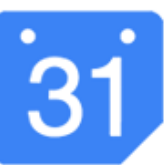

Google Calendar

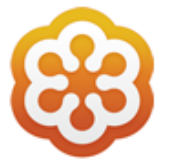

GoToMeeting
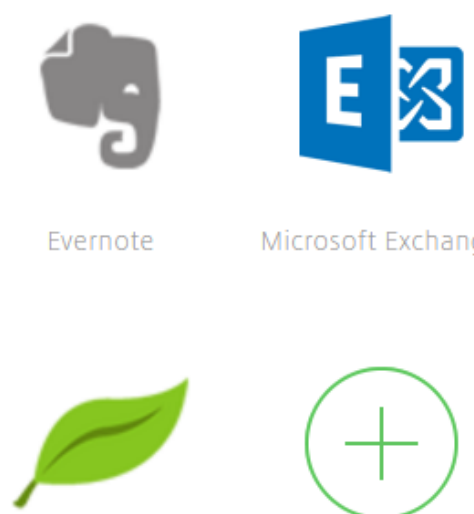

Freshbooks

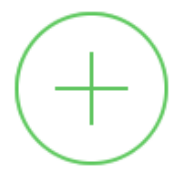

SEE ALL

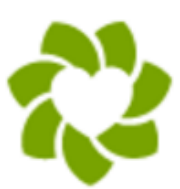

Zendesk INTEGRATIONS

FIGURE 33: Some of the integration options for Podio SOURCE: https://podio.com/site/en/tour

Since 2007, SNs have tried to offer increased functionality by providing application platforms on which external developers can build applications. This has provided a marketplace for application designers and gives users more access to functionality that SNS would otherwise not have the time or money to develop (Stuart 2013). A lot of these platforms offer open Application Program Interface (APIs) allowing users of platforms such as Podio, Project place, Mango Apps and Wrike to design and build their own tools. APIs are a set of routines, protocols and tools for building software applications. This is useful for companies who have their own IT department who can use the open API system to build applications that are suited for their needs. 


\subsection{Summary}

To summarise, the Software review was aimed at answering the research question of; How can SM be used for Project Management? The Literature has pointed that underlying aspect of SM platform is Web 2.0 technologies. Web 2.0 technologies are being integrated within SPM platforms. In addition to this, current Social software have also adopted Web 2.0 technologies. Figure 35 below shows how SPM software borrows from WPMSs and Social Software. SPM software does exactly this, by integrating PM software and Web 2.0 tools (which are also found in social software) together in single platforms. Similar work by (Roh, et al. 2006) explored the integration of web-services in a single interface for a construction information system that provided real-time information transfer and a construction information search engine

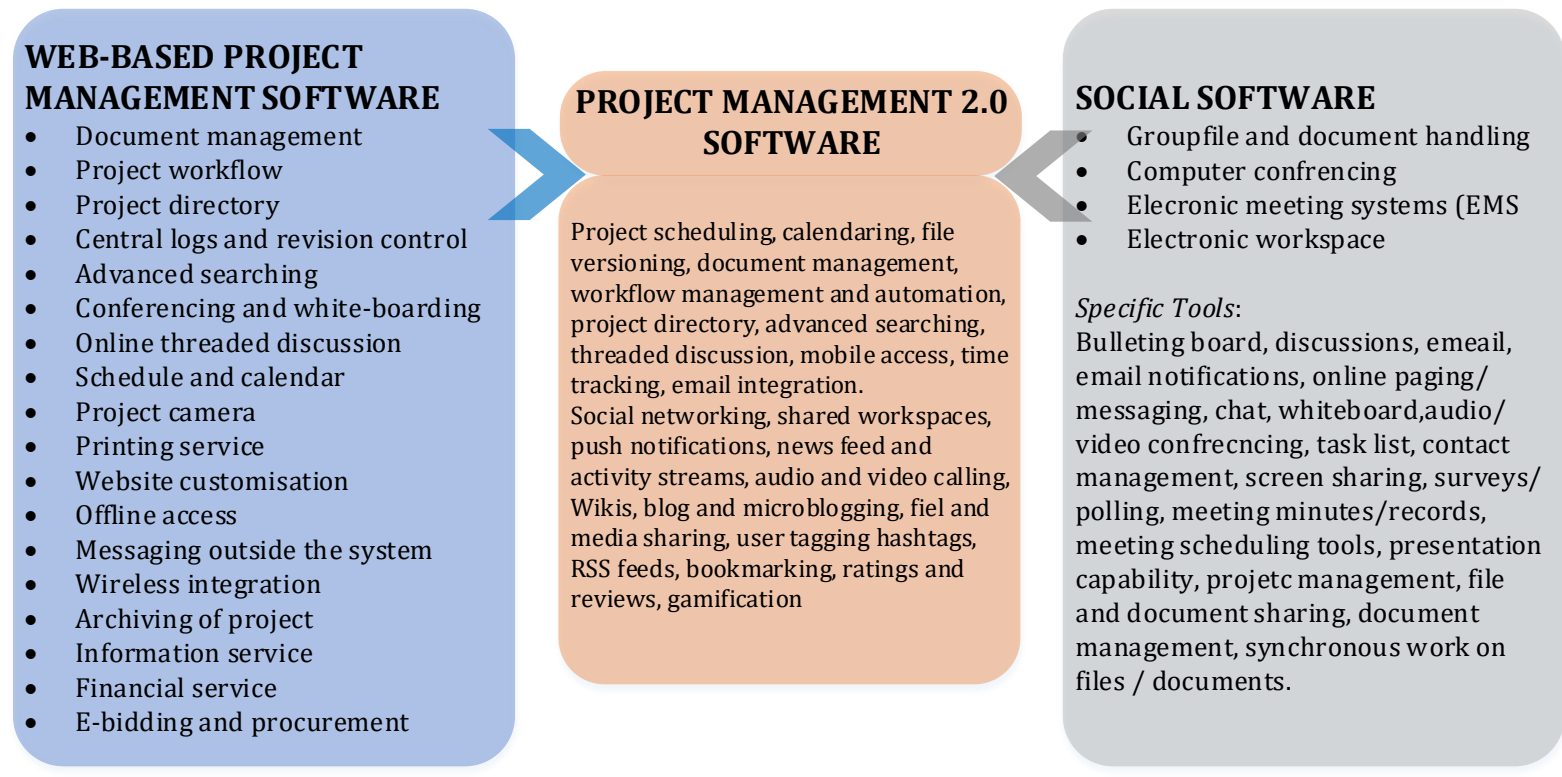

FIGURE 34: Left WPMS features by (Nitithamyong and Skibniewski 2004), Right Social software features by (Bafoutsou and Mentzaz, Review and Functional Classification of Collaborative Systems 2002)

The software review was used to identify and demonstrate some of the key features that can be used for PM and to enhance the social interaction between project participants. Most of the platforms had the following common features; scheduling tools, calendaring, document and file versioning, workflow management project directory advanced searching, threaded discussions, mobile access and email integration. Kanban boards which is an agile form of workflow management was not utilised as much across all platforms. It would be interesting to see how it could be used for CPM. It is important to note that all the software allowed for integration with third-party applications. This meant that any missing tools could be later added on an integration or developed through the software API. In terms of Web 2.0 based tools, the most common features identified across all platforms were; social networking (SN), Instant Messaging (IM), Chat, shared workspaces, push notifications, news feeds, user tagging and audio and video calling. The least used features were blogs, wikis, bookmarking and gamification. 
Blogs, wikis and bookmarking functions have been around longer, and this may reflect its low popularity as a tool. However, gamification is a more recent application of gaming mechanics for project teams. Zoho was the only software that included a gamification feature. It has been highlighted in this study however as it is an innovative approach to project management that dese4rves much more study.

To conclude, SPM platforms are being used by PMs in other industries, more so by PMs in the IT industry. It would be beneficial to the construction industry to investigate the effects of SPM software in construction projects further. However, this can only be done through more indepth studies that can give quantified data on the benefits of using such platforms. More importantly, PM 2.0 and social project management (SPM) also advocate newer management methodologies. There is not enough evidence of SPM methodology being utilised in the construction industry. As SPM software is designed to support SPM methodologies, it is important to conduct further research into how SPM methodology can be applied in construction projects. The next chapter looks towards describing a conceptual PM 2.0 platform that could be used by construction PMs. 


\section{Concept Platform - Gantt 2.0}

A Software Review conducted on SPM software demonstrated the integration of Web 2.0 technology in project management software in addition to this, SN is utilised across all platforms that were reviewed. The proceeding sections of this Chapter gives an outline of a conceptual SPM software that could potentially be utilised by PMs in the construction industry. The platform is intended to be used to enhance collaboration and strengthen relationships within construction projects while aiding the PM in core project management processes. The conceptual platform named Gantt 2.0 is fundamentally intended for Construction Project Management (CPM) with integrated collaborative tools for the whole project team.

\subsection{Intended User}

Each construction project is unique and will involve a different combination of different project participants of varying disciplines who become involved with the project along its lifecycle. This platform is intended to be a SPM for construction project teams. Potential users of the platform include; Architects, Project Managers, Engineers (Structural, electrical, mechanical etc.), Consultants etc. This study focuses more on key tools and functionalities of the platform from the PMs point of view. Klinc et al (2009) in their paper described an AEC industry knowledge worker who utilises Web 2.0 technology. Gantt 2.0 is intended to be for users who are adept at using SM and have grown up using Web 2.0 technologies. Millennials of course are the intended primary user for this platform. According to (Ferrara 2015) Millennials in the construction industry have a higher affinity for using IT then their older counterparts. In addition to this Ferrara's study also indicated that Millennials are currently taking on more managerial roles in the workplace today. This conceptual platform is geared towards a project team of Millennials.

\subsection{Precedents}

From the list of 10 software reviewed, two software are put forward as precedents for the concept platform. The concept platform borrows from relevant features found in the two platforms Clarizen and ProjExec. The scheduling tool is an imperative tool for PMs, for this reason it is intended that the design of the software will feature the Gantt chart view of scheduling tools which is where the name for the concept platform comes. Both precedent platforms have a variety of tools to offer for both project management and team collaboration. The concept platform draws from both software by finding common tools and features that can be used by construction project managers as well as construction project team members. 
The following list of features (Table 17) were identified to be found common in both precedent platforms. The list of common features which were identified are listed below. As this is only an outline of the conceptual platform, the whole list of appropriate features could not be included in this concept description.

TABLE 17: Social tools and Pm tools identified form precedent platforms, Clarizen and ProjExec

\section{Social tools}

1) Social networking

2) Threaded discussions

3) Instant messaging

4) Audio and video calling

5) Shared workspace

\section{Project Management}
a) Gantt charts
b) Kanban Boards
c) Document management
d) Email integration
e) Mobile access
f) Project camera

Table 17 above lists the Social tools and PM tools that are proposed to be contained within the concept platform. While this list is limited it is important to note that SPM platform functionality can be significantly extended through the integration of third-party software through API's which was discussed in the Software review. A use case scenario focussing on different phases of the construction process is presented below.

\subsection{Gantt 2.0 - Use Case}

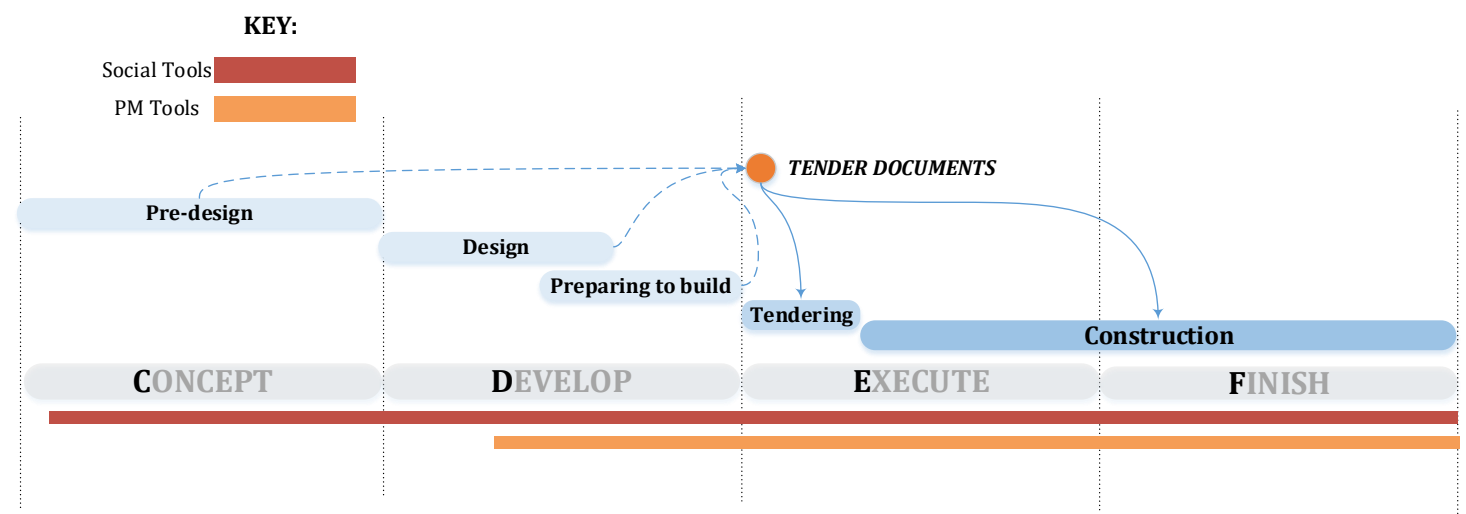

FIGURE 35: The project lifecycle and the collation of the tender document adapted from (Forcada, Casals and Roca, A model for Construction Project Management extranets 2003) (Mak 2001)

Figure 35 shows the different phases of a typical construction project according to (Mak 2001) and (Forcada, et al., 2003) in terms of information flow. This linear progression of the project lifecycle will be used as a reference for the use of the tools contained within the conceptual platform. For a description of the tools capabilities refer to the Software Review (Chapter 6). A 
more specific reference is given with the corresponding numbers and alphabets of specific tools mapped onto the lifecycle in Figure 36. As a rule, it is expected that the platform is intended to be used as a primary means of collaboration from Concept to Finish, hence the use of Social tools throughout all the phases. The PM tools must be more carefully utilised as they integrated the document management of the entire project. For security reasons these tools is intended to have limited access that should be set by the administrator. The PM is assumed to assume this role in this concept scenario.

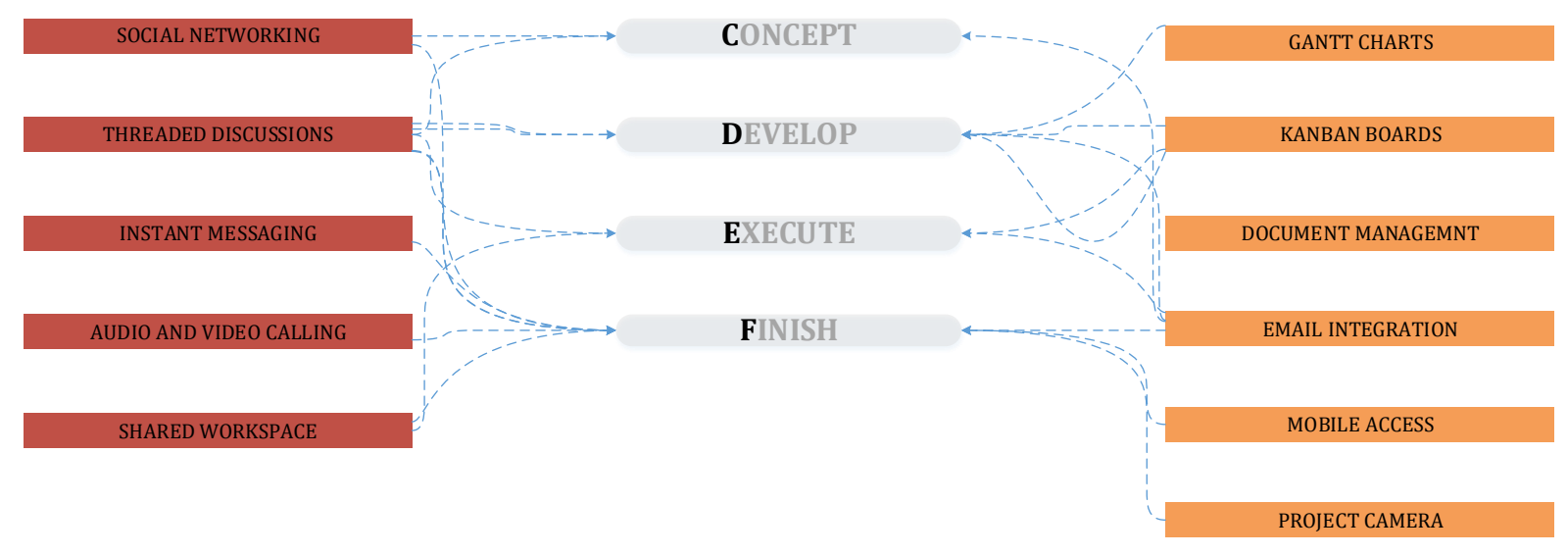

FIGURE 36: Mapping the tools onto the different phases. Social tools are to the left and the Pm tools are listed to the right.

Figure 36 shows a conceptualised map of when the tools of Gantt 2.0 can be used during the different phases of the project. The social tools of the platform can be utilised throughout the entire lifecycle of the project. Making it operable across multiple platforms and devices will enable users to be able to access the platform easier. The next sections explain when these tools are going to be used during design. It is the PM tools that must be carefully managed. The communications plan would be key in determining which communication channels to use. Nonetheless, for the most part, Social tools are general purpose tools and can be used throughout the entire lifecycle of the project.

\subsubsection{Concept to Develop Phase}

The design phase of the project involves the sharing of drawings and other documents between project participants' Essential information gathered through the concept and development phase of the project is collated in the tender documents which is where the bulk of the information arrives at the contractor (Forcada, Casals and Roca 2003).

Between these stages of the project, a team of designers working with the PM and clients would need to establish a (5) shared workspace. The most important tools needed would be the social tools including (2) instant messaging, (3) audio and video calling as well as (4) threaded 
discussions through the project wall/ news feed. The PM is supposed to set levels of access for other team members. All five of the PM tools would be needed at this stage and throughout the project life. Free flow of information is supported on the project wall and through threaded discussions. All project team members will also have access to PM tools (a) - (f) for managing their own tasks. The Kanban board is to be used by the entire project team through the Concept and Develop phase. This ensures that the workflow is managed, and information being collated in the Tender documents is being generated in a timely manner while being adequate for the Tendering process.

\subsubsection{Tendering}

Stephen Mak in his analysis of information flow in construction projects surmises that much of the information integral to a project is drawn from Tender documents. When referring back to the CDEF model by (Young 2008), the tendering process occurs during the Execute phase. Many of the contractors and construction firms, solicit jobs through the tendering process. Information in the Tender documents typically include Bill of Quantities, Specifications, Drawings and so on. Other types of information used in construction include detailed drawings and photos, cost analysis sheets, budget reports, risk analysis charts, contract documents, planning schedule (Tam 1999). A useful tool that would help in the tendering process would be the use of a third party SNS such as LinkedIn. LinkedIn could be used to pull data form the SNS regarding companies responding to the tender and help the selection process. In addition to this, project team members can be added onto the project website through invitation sent directly through SNS or through the email-integration feature which can be used to send notifications.

Document management feature together with the email integration functions should be used in conjunction to notify users of when documents are being modified or updated. This allows for synchronous working and version control of the project folders files.

\subsubsection{Preparing to Build}

In Figure 36, the tools used mainly by the PM can be used between the Develop and Execute phase but before construction begins. In this phase, the PM is responsible for developing the communications plan for the entire project team with input from both the task managers and the project team development team (PDT) (Caltrans- Office of Project ManagementProcess Improvement 2007). Table 16 in the Appendix lists some of the IT that is currently available for PMs. The use of computer-based and networked IT has substantially made the work of the PM easier. Connecting most of the project team's communication and collaboration needs within 
the SPM platform is the major goal here. Already allowing for email integration as well as mobile device access significantly aids this integration process

\subsubsection{Construction}

The construction stage mainly involves the buying and selling of building materials take place over the Internet (Forcada, Casals and Roca 2003). When a tendered project is won, the Quantity surveying department takes over the tendered project and a Project Team is assembled. The SN function of the platform is expected to be used during this team assemblage phase. At this point, a site office is set up and a (f) project camera is installed. Apart from this, the Purchasing Department is given a schedule of material requirements again the SN feature of Gantt 2.0 can be used to search for companies. The Accounting and Personnel Departments then set-up appropriate files/databases for project accounting/financing and human resource administration. Even if a Tender is not won, the tendered project will still have to be archived for record and analysis (Mak 2001). It is the responsibility of every member of the project to prepare the necessary information for the other stakeholders of the project.

Through the social network of Gantt 2.0, the whole process of collaboration and communication between project participants is made more visible. These platforms are based on both SM and SPM software that were reviewed. While Web 2.0 and SM have been identified as having role in project management software through SPM, it is up to the PMs and project participants on when to use these tools. Adoption of these software will require readiness in more than one organisation as well as a change in the way that construction industry professionals work together to fully utilise Web 2.0 technologies. This means applying SPM methodologies as prescribed by (Casanova and Bellifemine 2012) and using appropriate software to support this change. 


\section{Conclusion}

Construction projects are very dynamic requiring multi-disciplinary teams who are, culturally and organisationally disparate to work together. Web 20 and by extent SM has collaboration at its core and this is reflected in the way in which it is supporting collaborative online communities. The construction industry has a negative perception on IT adoption despite various research endeavours into its application for better communication and collaboration. This dissertation explored the concept of SM use for AEC projects under the Project management lens. Literature has pointed to the use of Web 2.0 as the underlying technology behind SM which fundamentally changed the way in which people used the Internet. Azhar and Abeln (2014) note that AEC companies in the USA are using SM on a small scale. Harrin's 2011 study revealed that PMs in other sectors were using SM.

An online administered survey for NZ construction professionals showed some insight into the current IT that was being used in the construction industry. The following conclusions were drawn based on the analysis of the survey results:

(1) Social media use is low with use only limited to external communication in addition to which many respondents noting that their companies did not have a policy that regulated its use.

(2) There is a lack of awareness and knowledge of Web 2.0 and related technology use. However, participants identified also using social software as well. Essentially participants were not aware they were using Web 2.0 technology derived from SM platforms.

(3) Participants also showed an interest in using a software that was designed based on social media platforms.

While the Survey has shed some light on the use of SM and IT in the NZ construction industry, it has fallen short in answering some of the other questions. The survey could have been utilised to further refine the collaborative features of Gantt 2.0. Much of the information regarding the needs of project participants were gleaned from literature alone and uses the information flow surrounding the Tendering process as a reference point. The literature provides a limited amount of information. What is needed is first-hand experience on project environments and collaborative need. Which can then be translated into a more fully formed concept platform in Gantt 2.0. Web 2.0 for inter-organisational/intra-organisational communication and collaboration was Enterprise 2.0 (McAfee 2006). Web 2.0 use for projects collaboration and project management saw the emergence of PM 2.0. PM 2.0 is currently being superseded by 
SPM methodology which is still in its nascent stage. This thesis has presented a review of 10 SPM software. This review has been useful in answering the question of "How SM can be used by construction PMs?" through a review of features found in SPM software. Software designed and built to support SPM methodology essentially had elements of social media within them. Remidez and Jones (2012) give a few examples of such software. This dissertation refers to these software as SPM software and presents a review of their features. SPM software essentially were found to be an amalgamation of WPMS (Nitithamyong and Skibniewski 2007) and Social Software (Bafoutsou and Mentzaz 2002) features and fundamentally built on Web 2.0 technology. The software review was conducted on SPM software identified a comprehensive list of the features that were integrated in SPM software. After identifying two precedent software, a conceptual platform, Gantt 2.0, was presented in Chapter 7.

Traditional CPM methodology and delivery methods were borne out of necessity and developed over much testing. The supporting IT was later developed and used by project participants as a supporting tool. Despite this, the rigours of CPM were kept intact and the IT adoption in the AEC has remained largely stagnant in comparison to other sectors. This has resulted in the continually highlighted shortcomings attributed to communication in building projects. In comparison, the SPM methodology and PM 2.0 were developed based on a need and a recognition for the increase in collaboration afforded by Web 2.0 technologies. While this dissertation was focused on SM use for project management, research has pointed instead to the use of underlying technology and associated ideologies that is, Web 2.0. Humans are social creatures. Construction projects are essentially communities of experts (Schnabel and Ham 2014). SPM methodology builds on this idea of 'project community' and seeks to empower project communities instead of institutions by applying the SN paradigm (Casanova and Bellifemine 2012). The implementation of SPM comes with its challenges as well as opportunities and benefits. It would be unwise to dismiss SPM without further investigation given the evidence of available tools/software that are being utilised successfully by PMs in other sectors (Kerzner 2014). In this respect, the AEC industry needs to be at the forefront of these research endeavours to realise its benefits. A study that is aimed at quantifying benefits would be an invaluable contribution to at least establishing SPM feasibility in an AEC industry context. 


\subsection{Future work}

Web 2.0 and SPM software offers new opportunities for collaborative working amongst construction project participants. For a deeper understanding of the effects of Web 2.0 technology it is time to take stock of the PM methodologies that are available for CPM. The body of literature concerning PM 2.0 and SPM is very limited. This dissertation draws mainly from the research of (Andres 2013) (Levitt 2011) (Casanova and Bellifemine 2012) and (Klinc, Turk and Matevz 2009). These researchers have looked at the use of web 2.0 for projects in other sectors apart from the AEC industry. A study comparing SPM with traditional CPM methodologies and delivery methods would be able to draw conclusions on the feasibility of SPM in the AEC industry. Furthermore, this dissertation has identified state-of-the-art SPM software and their features. These software are being used by PMs and project teams in other sectors. A cost-benefit study on its implementation within construction projects would be invaluable in providing quantifiable benefits of SPM software.

Technology is continually developing at a rapid pace. Current research is heading towards next evolution of the Internet in Web 3.0, otherwise also known as the semantic web. Web 3.0 is not a separate web, but it is an extension of the current web where information is given welldefined meaning. This area of growing knowledge for semantic web technologies, looks towards "information at the data integration level, resource discovery and classification, cataloguing, by intelligent software agents to facilitate knowledge sharing and exchange " (Klinc, Turk and Matevz 2009).What does this mean for the AEC industry and how can it be used to further support the SPM methodology in regard to CPM is another of research that can be explored.

Security was a major concern in the use of SM and web-based software for the AEC industry (Nitithamyong and Skibniewski 2004)(Azhar and Abeln 2014). Looking towards developments in security such as the use of biometrics for identification is under development. The current IPhones models use finger printing access identification. Mobile devices are ever increasing in their computing power and their compactness. Further, study into their impacts on the way AEC knowledge workers collaborate in the future could further improve the communication and the way in which project stakeholders connect. 


\section{Bibliography}

Abduh, Muhamad, and Miroslav J Skibniewski. 2002. "Utility of Internet-based Applications in Construction." International Journal of Construction Management 65-81.

Abuelmaatti, Aisha, and Vian Ahmed. 2010. Collaborative Environments and their Effect on Construction Companies: The Current Context. International Council for Research and Innovation in Building and Construction (CIB W78).

Ahmad, Irtishad U, Jeffrey S Russell, and Azza Abou-Zeid. 2006. "Information Technology (IT) and Integration in the Construction Industry." Construction Management and Economics 163-171.

Ahmad, Irtishad, Salman Azhar, and Syed M Ahmed. 2011. "Web-based Construction Project Management: Current State, Trends and Potentials."

Ahuja, Vanita, Jay Yang, and Ravi Shankar. 2008. "Study of ICT Adoption for Building Project Management in the Indian Construction Industry." Automation in Construction 415-423.

- 2006. "Web based Communication for Construction Project Management." Proceedings World Conference on Accelerating Excellence in the Built Environment.

Alexander, John, Richard Coble, John Crawford, Robin Drogemuller, and Peter Newton. 1998. "Information and Communication In Construction: Closing the Loop." Digital Library of Construction Informatics.

Allen, Christopher. 2014. "Tracing the evolution of social software." 13 October. Accessed June 27, 2016. http://www.lifewithalacrity.com/2004/10/tracing_the_evo.html.

Al-Reshaid, K, and N Kartam. 1999. Improving Construction Communication: The Impact of the On-line Technology. International Council for Research and Innovation in Buildng and Construction (CIB).

Alshawi, Mustafa, and Bingunath Ingirige. 2003. "Web-enabled Project Management: An Emerging Paradigm in Construction." Automation in Construction (Elsevier) 12: 349-364. $\begin{array}{lll}\text { Accessed } & \text { October } & 1,\end{array}$ http://citeseerx.ist.psu.edu/viewdoc/download?doi=10.1.1.133.5156\&rep=rep1\&type= pdf.

Alty, J.L. 1993. “Information technology and the construction industry: Another tower of Babel?" 
Amor, Robert, Martin Betts, Gustav OCetzee, and Martin Sexton. 2002. "Information Technology for Construction: Recent Work and Future Directions." Journal of Information Technology for Construction 7: 245-258.

Anderson, Paul. 2007. What is Web 2.0? ; Ideas, Technologies and Implications for Education. JISC Technology and Standards Watch. Accessed March 12, 2015. http://www.ictliteracy.info/rf.pdf/Web2.0_research.pdf.

Andres, Frederic. 2013. Social Project Management @ Research and Innovation. Sanwa-Printing CO.

Antonopoulos, Nick, and Lee Gillam, . 2010. Cloud Computing- Principles, Systems and Applications. Springer.

Association for Project Management (APM). 2014. "Introductionto Gamification.” Accessed May 10, 2016. https://www.apm.org.uk/sites/default/files/gamification\%20-\%20epdf.pdf.

Azhar, Salman, and John M Abeln. 2014. "Investigating Social Media Applications for the Construction Industry." Elsevier.

Bafoutsou, Georgia, and Gregory Mentzaz. 2002. "Review and Functional Classification of Collaborative Systems." International Journal of Information Management 281-305.

Bafoutsou, Georgia, and Gregory Mentzaz. 2002. "Review and Functional Classification of Collaborative Systems." International Journal of Information Management 281-305.

Bakis, N, and M Sun. 2000. Intelligent Broker for Collaborative Search and Retrieval of Construction Information on the WWW. International Council for Research and Innovation in Building and Construction (CIB).

Banwell, Sir Harold. 1964. "The Placing and Management of Contracts for Building and Civil Engineering Work." London.

Basset, Herve. 2013. “Enterprise 2.0 and Web 3.0.” In From Science 2.0 to Pharma 3.0, 169 - 193. Chandos.

Becerik, Burcin. 2004. "A review on past, present and fututre of web based project management \& collaboration tools and their adoption by the US AEC industry ." International Journal of IT in Architecture, Engineering and Construction 2 (3): 233 - 248.

Becerik, Burcin, and Spiro N Pollalis. 2006. Computer Aided Collaboration in Managing Construction. Havard University Graduate School of Design. 
Boddy, Stefan, Yacine Rezgui, Garahame Cooper, and Mathew Wetherill. 2006. Computer Intergrated Construction: A review and proposals for future direction. Elsevier. Accessed June http://www.sciencedirect.com/science/article/pii/S096599780600175X.

Bolton, Holly, Dana Galvin, Barton Malow, and Adam Kilbourne. 2011. Clients Use of Social Media and Social Networking. Whitepaper, Society for Marketing Professional Services.

Bonanni, Leonardo, Amanda Parkes, and Hiroshi Ishii. 2008. "Future Craft: how digital media is transforming product design." CHI EA '08 CHI '08 Extended Abstracts on Human Factors in Computing Systems. New York: ACM New York. 2553-2564.

Boyd, Danah. 2007. "The Significance of Social Software." In Blog Talks Reloaded, edited by Thomas N Burg, 15 - 30. Social Software Lab. Accessed November 16, 2015. http://www.danah.org/papers/BlogTalksReloaded.pdf.

Breslin, John G, Alexandre Passant, and Stefan Decker. 2009. The Social Sementic Web. Springer.

Buchel, Bettina S.T. 2001. Using Communication Technology: Creating Knowledge Organizations . Palgrave Macmillan.

Burgess, Cherl, and Mark Burgess. 2014. The Social Employee: How Great Companies Make Social Media Work. McGraw Hill.

Butcher, Scott. 2015. The State of Social Media in the A/E/C Industry. January. Accessed March 25, 2016. http://www.enr.com/blogs/22-marketropolis/post/16460-the-state-ofsocial-media-in-the-a-e-c-industry-aka-the-three-somegos-ride-again.

Caltrans- Office of Project ManagementProcess Improvement. 2007. Project Communication Handbook. 2. Sacramento. Accessed August 25, 2015. http://www.dot.ca.gov/hq/projmgmt/documents/pchb/project_communication_handb ook_2nd_ed.pdf.

Capterra. n.d. Capterra. Accessed March 12, 2016. http://www.capterra.com/.

Cardon, Peter W, and Bryan Marshall. 2015. "The Hype and Reality of Social Media Use for Work Collaboration and Team Communication." International Journal of Business Communication 52 (3): 273-293.

Casanova, Pietro, and Francesco Bellifemine. 2012. "Implementing Social Project Management: Approach and Lessons Learned." Marseille: PMI Global Congress Proceedings. Accessed April 
http://www.researchgate.net/publication/273682612_Implementing_Social_Project_M anagement_Approach_and_Lessons_Learned.

Chan, Swee-lean, and Nga-na Leung. 2004. "Prototype Web-based Construction Project Management System." Journal of Construction Engineering and Managament.

Chui, Michael, James Manyika, Jacques Bughin, Richard Dobbs, Charles Roxburgh, Hugo Sarrazin, Geoffrey Sands, and Magdalena Westergen. 2012. The Social Economy: Unlocking Value and Productivity through Social Technologies. McKinsey Global Institute (MGI).

Chung, Mike. 2011. "Assurance in the Cloud." Accessed April 12, 2016. http://www.compact.nl/articles/assurance-in-the-cloud-2/\#What_is_cloud_computing.

Coleman, David, and Stewart Levine. 2008. Collaboration 2.0 - Technology and Best Practices for Successful Collaboration in a Web 2.0 World. California: HappyAbout.

Cook, Niall. 2008. Enterprise 2.0: How Social Software Will Change the Future of Work. Gower Publishing.

Dainty, Andrew, David Moore, and Mike Murray. 2006. Comunication in Construction: Theory and Practice. London and New York: Taylor and Francis.

Dave, Bhargav, and Lauri Koskela. 2009. "Collaborative Knowledge Management - A Construction Case Study." Automation in Construction 18: 894-902.

Deng, Z.M, H Li, C.M Tam, Q.P Shen, and P.E.D Love. 2001. "An Application of the Internet-based Project Management System." Automation in Construction 239-246.

Dewing, Michael. 2010. Social Media: An Introduction. Ottawa: Library of Parliament.

Ebrahim, NaderA, Shamsuddin Ahmed, and Zahari Taha. 2009. Virtual Teams: a Literature Review. Accessed April 13, 2014. http://cogprints.org/7814/1/2653-2669.pdf.

Egan, John. 1998. "Rethinking Construction: The Report of the Construction Task Force." Department of Trade and Industry, London. http://constructingexcellence.org.uk/wpcontent/uploads/2014/10/rethinking_construction_report.pdf.

El-Tayeh, Amjad, and Nuno Gil. 2005. "IDRAK: A web-based Application to Support Cross-firm Socialisation in Construction Projects." Montreal: Joint International Conference on Computing and Decision Making in Civil and Building Engineering. 1584 - 1594.

Emmerson, Harold. 1962. "Survey of Problems before the Construction Industries: A Report Prepared for the Minister of Works." London. 
Emmitt, Stephen, and Christopher A Gorse. 2003. Construction Communication. Blackwell Publishing.

EY - Better Working World. 2013. "Younger managers rise in the ranks: EY study on generational shofts in the US workplace." Accessed May 17, 2016. http://www.ey.com/US/en/Issues/Talent-management/Talent-Survey-Thegenerational-management-shift.

Ferrara, Samuel J. 2015. "The Generational Impact in Virtual Teams." Masters Thesis. https://vtechworks.lib.vt.edu/bitstream/handle/10919/70454/Ferrara_SJ_T_2016.pdf? sequence $=1$.

Filev, Andrew. 2008. Definition of Project Management 2.0. Accessed March 21, 2016. https://www.wrike.com/blog/definition-of-project-management-2-0/.

- 2016. "Project Management 2.0 - The ultimate benefits of the new approach to project management." $\quad$ Accessed May 2016. https://www.wrike.com/pressroom/Project\%20Management\%202.0\%20The\%20Ulti mate\%20Benefits\%20of\%20the\%20New\%20Approach\%20to\%20Project\%20Manage ment.pdf.

Forbes, Lincoln H, and Syed M Ahmed. 2010. Modern Construction- Lean Project Delivery and Intergrated Practices. CRC Press.

Forcada, Nuria, Miguel Casals, and Roca Xavier. 2003. "Analysis of the most commonly used platforms for the management of construction projects in Spain." International Symposium on Automation and Robotics in Construction.

Forcada, Nuria, Miguel Casals, and Xavier Roca. 2003. "A model for Construction Project Management extranets."

Francis, Adel, and Edmond Miresco. 2005. "Toward a New Generation of Construction Management Software." Joint International Conference on Computing and Descision Making and Building Engineering.

Froese, Thomas. 2006. "Emerging Information and Communication Technologies and the Discipline of Project Management." In Intelligent Computing in Engineering and Architecture, edited by Ian F.C Smith, 230-240. Vancouver: Springer.

Froese, Thomas M. 2010. "The Impact of Emerging Information Technology on Project Management for construction." Automation in Construction 531-538. 
Gaith, Farag H, Khalim A Rashid, and Amiruddin Bin Ismail. 2012. "Application and efficacy of information technology in construction industry." Scientific Research and Essays, August: 3223-3242.

Gerogescu, Mircea, and Daniela Popescul. 2015. "Social Media- The new paradigm of collabroation and communication for business enviroment." Elsevier.

Goodhue, James. 2010. "Implementing Web-based Project Managment Systems in the New Zealand Construction Industry." Undergraduate Research Report, Unitec Institute of Technology, Auckland. Accessed $\quad$ October 2015. http://unitec.researchbank.ac.nz/bitstream/handle/10652/1786/James\%20Goodhue_ 2010.pdf?sequence=1.

Grahl, Tim. n.d. The 6 Types of Social Media. Accessed May 20, 2015. http://timgrahl.com/the-6types-of-social-media/.

Han, Sam. 2012. Shortcuts : Web 2.0 : Web 2.0 (1). Florence, US: Routledge.

Harrin, Elizabeth. 2010. Social Media For Project Managers. Project Management Institute.

Harrin, Elizabeth. 2011. "Social Media In a Project Managment Environment."

Harrison, Teresa M, and Brea Barthel. 2009. "Wielding new media in Web 2.0: exploring the history of engagement with the collaborative construction of media products." New Media \& Society 11: 155 - 178. http://nms.sagepub.com/content/11/1-2/155.full.pdf.

Higgin, Gurth, and Niel Jessop. 1965. Communication in the Building Industry: The Report of a Pilot Study. London: Tavistock Institute.

Hoezen, M. E. L, I.M.M.J Reymen, and G.P.M.R Dewulf. 2006. "The Problem of Communication in Construction." Eindhoven: International Council for Research and Innovation in Building and Construction (CIB). Accessed May 13, 2015. http://doc.utwente.nl/58078/1/06_Hoezen.pdf.

Hollingsworth, Chauncey. 2011. Collabroation To Go: Help Desk. February. Accessed September 20, 2015. http://www.pmi.org/learning/online-collaboration-software-virtual-teams2875.

Jha, Shankar. 2010. The Project Manager's Communication Toolkit. Auerbach.

Julita. 2011. Difference Between ICT and IT. Accessed March 25, 2016. http://www.differencebetween.net/technology/difference-between-ict-and-it/. 
Kabir, Ihtisham. 2006. “The Emergence of Web 2.0.” The Daily Star. Accessed May 12, 2016. http://archive.thedailystar.net/2006/06/19/d606190901122.htm.

Kaplan, Andreas M, and Haenlein Michael. 2010. "Users of the World Unite! The Challenges and Opportunities of Social Media." Business Horizons 53 (1): 59 - 68.

Kerzner, Harold R. 2014. Project Management 2.0. Wiley.

Kietzmann, Jan H, Kristopher Hermkens, Ian P McCarthy, and Bruno S Silvestre. 2011. "Social media? Get serious! Understanding the functional building blocks of social media." Business Horizons 54 (3): 241-251.

Klinc, Robert, Matevz Dolenc, and Ziga Turk. 2008. "Possibe Benefits of Web 2.0 To Construction Industry." Santiago: International Conference on Information Technology in $\begin{array}{llll}\text { Construction. } & \text { Accessed } & \text { September } & 28 \quad\end{array}$ http://www.irbnet.de/daten/iconda/CIB21321.pdf.

Klinc, Robert, Ziga Turk, and Dolenc Matevz. 2009. "Engineering Collaboration 2.0 : Requirements and Expectations." Journal of Information Technology in Construction.

Klynstra, Michael. n.d. Social Media Meets Project Management. Accessed April 14, 2014. http://www.geneca.com/social-media-meets-project-management/.

Kundu, Joydeep, Tanmoy Kumar Bishoi, Manasija Bhattacharya, and Anupam Chowdhury. 2015. "Project Management Software: An Overview." International Journal of Current Research Innovation Research 1 (6): 129- 135.

Lam, Patrick T.I, Frankie W.H Wong, and Kenny T.C Tse. 2010. "Effectiveness of ICT for Construction Information Exchange Among Multidisciplinary Project Teams." Journal of Computing in Civil Engineering (American Society of Civil Engineers (ASCE)) 24 (4): 365376.

Leankit. n.d. "What is a Kanban Board?" Accessed May 10, 2016. http://leankit.com/learn/kanban/kanban-board/.

Leeuwen, J.P van, and S Fridqvist. 2006. "An Information Model for Collaboration in the Construction Industry." Collaborative Environments for Concurrent Engineering 57 (8-9): 809-816.

Leonardi, Paul M, Marleen Huysman, and Charles Steinfield. 2013. "Enterprise Social Media: Definition, History, and Prospects for the Study of Social Technologies in Organizations." Journal of Computer-Mediated Communication 1-19. 
Levitt, Raymond E. 2011. “Towards Project Management 2.0." The Engineering Project Journal 1: 197-210.

Li, Minbo, Guangyu Chen, Zhe Zhang, and Yi Fu. 2012. "A Social Collaboration Platform for Enterprise Social Networking." Computer Supported Cooperative Work in Design (CSCWD), 2012 IEEE 16th International Conference. Wuhan: IEEE. 671-677.

Libratore, Mathew.J, Bruce Pollack-Johnson, and Coleen A. Smith. 2001. "Project Management in Construction: Sofware Use and Research Directions." JOURNAL OF CONSTRUCTION ENGINEERING AND MANAGEMENT 101-107. http://www.researchgate.net/publication/245283314_Project_Management_in_Constr uction_Software_Use_and_Research_Directions.

Lientz, Bennet P, and Kathryn P Rea. 2002. Project Management For the 21st Century. 3rd. California: Academic Press.

Lipnack, Jessica, and Jeffrey Stamps. 2000. Virtual Teams: Reaching Across Time, Space And Organisations With Technology. 2nd. New York: John Wiley and Sons.

Lococo, Anthony, and David C Yen. 1998. "Groupware: Computer Supported Collaboration." Telematics and Informatics 15 (1-2). doi:doi:10.1016/S0736-5853(98)00006-9.

Mak, Stephen. 2001. "A Model of Information Management for Construction Using Information Technology." Automation in Construction (Elsevier). http://citeseerx.ist.psu.edu/viewdoc/download?doi=10.1.1.456.8341\&rep=rep1\&type= pdf.

Matheu, N. F. 2005. "Life Cycle Document Management System For Construction." PhD Thesis, UNIVERSITAT POLITECNICA DE CATALUNYA, Spain.

Matuszak, Gary. 2007. Enterprise 2.0: Fad or Future? KPMG International. Accessed April 20. http://www.kpmg.com/CN/en/IssuesAndInsights/ArticlesPublications/Documents/en terprise-2.0-ff-0-0706.pdf.

McAfee, Andrew P. 2006. "Enterprise 2.0: The Dawn of Emergent Collaboration." MITSloan Management Review 47 (3).

McDonald, Dennis D. n.d. Project Management, Social Media, and Defining "Community". Accessed April 10, 2014. http://www.ddmcd.com/managing-technology/project-managementsocial-media-and-defining-community.html. 
Miller, Jason A. 2011. "The Implementation of Web-based Project management Systems by the General Contractor: Transferring from hard-copy to digital format." Masters Thesis, Purdue University, Indiana. Accessed October 19, 2015. http://docs.lib.purdue.edu/cgi/viewcontent.cgi?article=1037\&context=techdirproj.

Moe, Wendy W, and David A Schweidel. 2014. Social Media Intelligence. Cambridge University.

Mohan, Nikhil. 2013. "Information Communication on Construction Industry- How it works?"

Nitithamyong, Pollaphat, and Miroslaw J Skibniewski. 2004. "Web-based Construction Projetc Management Systems: How to make them successful?" Automation in Construction (Elsevier) 13 (4): 491-506.

Nitithamyong, Pollaphat, and Miroslaw Skibniewski. 2007. "Key Success/Failure Factors and Impacts on Systems Performance of Web-based Project Management Systems in Construction." $\quad$ Accessed March 2016. http://www.itcon.org/data/works/att/2007_3.content.06655.pdf.

Nuntasunti, Suchart, and Leonard E Bernhold. 2002. "Beyond Webcam: A Site-Web-Site for Building Construction." Washington: International Symposium on Automation and Robotics in Construction.

O'Driscoll, Tony. 2011. "Transforming Collaboration with Social tools." technologyforecast $\begin{array}{lll}\text { (PricewaterhouseCoopers } & (\mathrm{PwC}) \text { 6-48. }\end{array}$ http://www.pwc.co.nz/KenticoFiles/d4/d48f26c0-6372-4acd-becb-55649a51dee7.pdf.

Ollus, Martin, Kim Jansson, Iris Karvonen, Mikko Uoti, and Heli Riikonen. 2011. "Supporting Collaborative Project Management." In Production Planning \& Control - The Management of Operations , 538-553. Taylor and Francis.

Onyegiri, Ikechukwu, Chinedu C Nwachukwu, and Onyegiri Jamike. 2011. Information and communication technology in the construction industry. Thesis, American Journal of Scientific and Industrial Research.

O'Reilly, Tim. 2005. What Is Web 2.0? Accessed August 30, 2015. http://www.im.ethz.ch/education/HS08/OReilly_What_is_Web2_0.pdf.

O'Reilly, Tim, and John Battelle. 2009. Web Squared: Web 2.0 Five Years On. O'Reilly Media.

Paul, Anderson. 2007. "What is Web 2.0? Ideas, technologies and implications for education." JISC Technology and Standards Watch. 
Penichet, V.M.R, I Marin, J.A Gallud, M.D Lozano, and R Tesoriero. 2007. "A Classification Method for CSCW Systems."

Polaschek, M, W Zeppelzauer, N Kryvinska, and C Strauss. 2012. "Enterprise 2.0 Intergrated Comunication and Collaboration Platform: A Conceptual Viewpoint." Fukuoka: IEEE.

Poolvoralaks, Suriyon. 1996. “Groupware System in Construction Engineering.” Masters Thesis.

Pritchard, Carl. 2004. The Project Management communiations Toolkit. Artech House.

Project Management Institute (PMI). 2015. Project Managment Institute. https://www.pmi.org/ /media/PDF/Knowledge\%20Center/Communications_whitepa per_v2.ashx.

Project Management Institute. 2013. A Guide to the Project Management Body of Knowledge (PMBOK® Guide). 5th.

Project Management Institute. 2013. The High Cost of Low Peformance: The Essential Role of Communication. Survey, PMI. Accessed May 30, 2015. http://www.pmi.org/ /media/PDF/Business-Solutions/The-High-Cost-LowPerformance-The-Essential-Role-of-Communications.ashx.

Projectplace. 2012. Social Project Management. Accessed July 15, 2015. https://www.projectplace.com/Global/pdf/whitepaper/EN/social_project_managemen t_wp_en.pdf.

-. 2012. What is Social Project Management and Why Should We Care? ProjectPlace. Accessed May 28 , 2015. https://www.projectplace.com/Global/pdf/whitepaper/EN/what_is_spm_wp_en.pdf.

Pryke, Stephen. 2012. Social Network Analysis in Construction. Wiley-Blackwell.

$\begin{array}{lllllll}\text { Radius, } & \text { Trust. } & \text { n.d. Collaboration } & \text { Tools. Accessed } & \text { April 30, }\end{array}$ https://www.trustradius.com/collaboration.

Razmerita, Liana. 2013. "Collaboration Using Social Media: The Case of Podio in a Voluntary Organisation." Wellington: CRIWG. Accessed April 2, 2015. http://downloadv2.springer.com/static/pdf/337/chp\%253A10.1007\%252F978-3-642-413476_1.pdf?token2=exp=1428629602 acl=\%2Fstatic\%2Fpdf\%2F337\%2Fchp\%25253A10. 1007\%25252F978-3-642-41347-

6_1.pdf* $\sim$ hmac $=610002 \mathrm{ca77}$ c12ca5b97156362daa9a422714f8842dc8b66044aadb3ca 524. 
Remidez, Herbert, and Nory B Jones. 2012. “Developing a Model for Social Media in Project Management Communication." International Journal of Business and Social Science 3 (3): 33-36. Accessed November 2014. http://ijbssnet.com/journals/Vol_3_No_3_February_2012/3.pdf.

Rezgui, Yacine, Alain Zarli, and Marc Bourdeau. 2000. "Inter-enterprise Information Management in Dynamic Virtual Environments: The OSMOS Approach."

Rezgui, Yacine, Grahame Cooper, Alain Zarli, Mathieu Marache, and Abdul Samad Kazi. 2001. "Web-based Generic Services for the Construction Virtual Enterprises in the OSMOS Project." Mpumalanga: CIB-W78.

Roh, Seungjun, Moonseo Park, Hyunsoo Lee, and Eunbae Kim. 2006. "A Conceptual Model of Web Service-Based Construction Information System." In Intelligent Computing in Engineering and Architecture, edited by Ian F.C Smith, 597-605. Springer. http://download.springer.com/static/pdf/636/chp\%253A10.1007\%252F11888598_53 .pdf?originUrl=http\%3A\%2F\%2Flink.springer.com\%2Fchapter\%2F10.1007\%2F11888 598_53\&token2=exp=1446773313 acl=\%2Fstatic\%2Fpdf\%2F636\%2Fchp\%25253A10 .1007\%25252F11888598_53.pdf\%3ForiginUr.

Safko, Lon. 2010. The Social Media Bible-Tactics, Tools, and Strategies for Business Success. 2nd. John Wiley \& Sons.

Schnabel, Marc A, and J J Ham. 2014. "Social Learning Cloud." International Journal of Architectural Computing (IJAC) (MultiScience) 12 (3): 225- 241.

Scott, David, Michael Cheong, and Heng Li. 2003. "Web-based construction information management systems." Australasian Journal of Construction Economics and Building 3 (1): 43-52. Accessed 2015. http://www.icoste.org/ICMJ\%20Papers/AJCEBVol3No1Scott.pdf.

Shami, Manar, and Hazem Elzarka. 2000. An Internet-Based Communication Model For A/E/C Industry. International Association for Automation andRobotics in Construction (IAARC), 1 - 6. Accessed June 5, 2015. http://www.iaarc.org/publications/fulltext/isarc2000096_WE1.pdf.

Software Insider. n.d. Software Insider. Accessed March 12, 2016. http://construction.softwareinsider.com/.

Steglitz, Stefan, Kai Riemer, and Christian Meske. 2014. "Hierarchy or Activity? The Role of Formal and Informal Influence in Eliciting Responses from Enterprise Social Networks." 
European Conference on Information Systems (ECIS). http://aisel.aisnet.org/cgi/viewcontent.cgi?article=1114\&context=ecis2014.

Streich, Richard, and Jens Brennholt. 2015. "Communication in Projects." In Applied Psychology for Project Managers, edited by Monika Wastian, Lutz von Rosenstiel, Michael A West and Isabell Braumandl, 53-72. Springer.

Stuart, David. 2013. "The Web 2.0 revolution and the promise of Science 2.0." In From Science 2.0 to Pharma 3.0, 1 - 56. Chandos.

Symonds, Michelle. n.d. Where does social media fit into project management? Accessed April 13, 2014. http://blog.parallelprojecttraining.com/project-management-articles/wheredoes-social-media-fit-into-projectmanagement/?doing_wp_cron=1397259323.3443739414215087890625.

Tam, CM. 1999. "Use of the Internet to enhance construction communication:Total Information Transfer System." Automation in Construction 17 (2): 107 - 111.

Trenchless International. 2014. Construction industry behind with social media. Accessed November 12 , 2015. http://trenchlessinternational.com/news/construction_industry_behind_with_social_m edia1/085120/.

Trilog Group. 2012. "Social Project Managment: Engaging the social network to deliver project success." August. $\quad$ Accessed June 30, 2015. http://xsp.triloggroup.com/portal/website/content/SocialPM_WP.pdf.

Turban, Efraim, Judy Strauss, and Linda Lai. 2016. Social Commerce - Marketing, and Technology Management. Springer.

Turk, Ziga. 2006. "Construction Informatics: Definition and Ontology." Advanced Engineering Informatics 20 (2): 187-199.

Turk, Ziga, and Tomo Cerovsek. 2003. “MAPPING THE W78 PAPERS ONTO THE CONSTRUCTION INFORMATICS TOPIC MAP ." 20th International Conference on Information Technology for Construction - Construction IT Bridging the Distance (CIB W078 Proceedings) .

Usman, Nuruddeen, and Ilias Said. 2012. "Impact of Technological Devices on Information and Communication Technology Acceptance for Construction Site Management in Nigeria." Journal of Emerging Trends in Computing and Information Sciences 3: 325-333. 
Valsson, Himar Th. 2012. "The Role of Social Networking in the AEC Industry: Opportunities and Challenges." Master Thesis, Aalborg University . Accessed September 30, 2015. http://projekter.aau.dk/projekter/files/62458016/The_role_of_social_networking_in_t he_AEC_industry.pdf.

Verheij, Hans, and Godfried Augenbroe. 2005. "Collaborative Planning of AEC Projects and Partnerships." Automation in Construction 15 (4): 428 - 437.

Vukomanovic, Mladen, Mladen Radujkovic, and Zlata D Alduk. 2012. "The Use of Project Management Software in the Construction Industry." Technical Gazette 19 (2): 249.

Walker, Anthony. 2015. Project Management in Construction. 6th. Wiley Blackwell.

Walker, D, and M Betts. 1997. "Information Technology Foresight: The Future Application of the World Wide Web in Construction ." CIB w78.

Wang, Feiyue, and Shuping Zhao. 2014. "Research on the Application of Construction Project Management Based on Internet Technology." Proceedings of the 2012 International Conference on Cybernetics. New York: Springer. 395 - 201.

Weippert, Achim, Stephen Kajewski, and Paul Tilley. 2002. "Online Remote Construciton Management." International Conference on Advances in Building Technology. Hong Kong: Elsevier. 1559-1567.

Wikforss, Orjan, and Alexander Lofgren. 2007. "Rethinking Communication in Construction." Journal of Information Technology in Construction 12: 337- 345.

Young, Jim. 2008. The Framework: For Successful Projetc Management. 2nd. Accessed October 22, $2015 . \quad$ http://www.skillpower.co.nz/wpcontent/uploads/2012/12/framework_referenced-edition.pdf.

Zhang, Shufen, Hongcan Yuan, and Xuebin Chen. 2012. "Research on Key Technologies of Cloud Computing." Physics Procedia (Elsevier). doi:10.1016/j.phpro.2012.05.286.

Zulch, BG. 2014. "Communication: The Foundation of project management." ProjMAN 2014International Conference on Project MANagement. Elsevier. 1000-1009. 


\section{Appendices}

\section{Appendix A: Software background}

A short description of each software is listed in this section to give a brief idea of their capabilities and how they are utilised for project management and collaboration.

\subsubsection{Project Place}

Project Place is a pay-per-use web-based project management and collaboration software developed in 1998 before it was acquired by software development company Planview in 2014. No software installation is needed, and clients pay to access the software from a remote website. Project Place was on the very first pay-per-use web application when it was launched back in 1998.

\subsubsection{Podio}

Podio is a social collaboration platform that is offered on a freemium basis. Freemium meaning that the software is initially offered on a free basis with limited access to some of the software features. Money is charged when the user wants to utilise proprietary (other) features of the software. The software was developed in 2009 before being acquired by Citrix Systems in 2012 . Podio is a social work platform with built-in collaborative features. The way that Podio is structured puts all the collaborative power into the users' hands, by providing tools via Podio Apps which is a flexible application building tool. Podio's User Interface strongly resembles that of popular social networking site Facebook with its colour scheme and layout style.

\subsubsection{Zoho Projects}

The Zoho Projects platform is built and design for aiding collaboration and project management for project teams. The platform offers a mixture of project management and collaborative tools aimed at engaging project participants and facilitating their interactions on the platform.

\subsubsection{Mango Apps}

Mango Apps is a collaborative software that offers three services, Social Intranet, Team Collaboration and Office Chat which is a messaging application for teams. The three options are offered individually or as an all-in-one packaged deal depending on client preference. The platform can either be hosted on the client's data centres or hosted in the cloud in the form of SaaS. Mango Apps boasts the largest number of supported languages with support for about 150 different languages.

\subsubsection{Clarizen}

Clarizen cloud-based IT project management software. Clarizen is a workflow automation, collaboration and project management. The software is designed for small to medium sized enterprises. Notably, the platform allows the importing of CAD drawings and it also allows 
designers to attach them to projects. Clarizen offers tailored solutions for IT teams, Project managers, and Professional services and for marketing teams.

\subsubsection{Redbooth}

Redbooth (formerly known as Teambox) is a SaaS and on-premises collaboration and project management platform. Redbooth also offers customised solutions for its customers and as such has dedicated solutions for marketing, legal and law forms, IT project management etc.

\subsubsection{ProjExec}

ProjExec is software that is endorsed as a Social project management software and it combines the social networking paradigm with rigorous project management tools and practices. SPM software empowers people to engage in the project management process. The software is developed by IBM and integrates with the IBM Connections Platform. IBM Connections platform is an Enterprise Social Networking (ESN) tool that is developed by IBM as well.

\subsubsection{Liquid Planner}

Liquid Planner is a platform for IT project managers and was founded in 2006. The platform works well in visualising tasks and milestones and can also be used to generate analysis reports on the project progress. It also features a priority-based scheduling engine and can import tasks and projects directly form Excel or CSV. files

\subsubsection{Wrike}

Wrike is essentially a WPMS that has collaborative capabilities. The platform enables its users to manage and track projects, deadlines, schedules, and workflow processes. In addition to this. The platform is also available in 8 different languages. Wrike has a free and paid version. The free version includes basic functionalities for an unlimited number of collaborators while allowing for 5 users access to create assign and access tasks. The paid version of the platform includes other functions and features such as APIs, integrations, Gantt charts, time tracking etc.

\subsubsection{0 eXo Platform}

eXo platform is an open source (free-to-use) web based platform containing collaboration tools which is used for social networking and building social intranets. Collaboration tools such as forums, wikis and calendars are included in this platform. The tool is still quite under-developed compared to the other platforms in this study. 


\section{Appendix B: Survey Questionnaire TITTLE: "Collaboration Technology in the New Zealand AEC Industry"}

SECTION 1: PARTICIPANT BACKGROUND

Q1 What is your gender?

O Male

O Female

Other

Q2 What is your age?

O 18 to 24

O 25 to 34

○ 35 to 44

○ 45 to 54

O 55 to 64

O 65 to 74

O 75 or older

Q3 How many years have you worked in the Architecture Engineering and Construction (AEC) industry?

Less than 5 years

O $5-10$

○ $11-15$

O $16-20$

○ $20+$

Q4 What is your role in construction projects? You are allowed to choose more than one role below.

Architect/Designer 
口 Quantity Surveyor

口 Project Manager

口 Programme Manager

ㄱ Facilities Manager

口 Structural Engineer

Other. Please Specify below

Q5 Which of these technologies do you own and use for communication purposes. Please indicate on the right of the table below, which of these technologies is used for Personal or Professional purposes. You are able to tick both options for each technology listed.

\begin{tabular}{llll}
\hline & For Personal use & For Professional use & Don't own \\
\hline Smart phone & $\square$ & $\square$ & $\square$ \\
Tablet computer (this & $\square$ & $\square$ & $\square$ \\
includes such & & & \\
technologies as the & & & \\
Apple iPad, SAMSUNG & & $\square$ & $\square$ \\
Tablets etc. & $\square$ & $\square$ & $\square$ \\
Personal Laptop & $\square$ & & $\square$ \\
Company provided & $\square$ & $\square$ & $\square$ \\
computer/laptop & & $\square$ & $\square$ \\
Land-line phone & $\square$ & $\square$ & $\square$ \\
Social Media & $\square$ & $\square$ & $\square$ \\
Email & $\square$ & $\square$ & $\square$ \\
Facsimile (Fax) & $\square$ & $\square$ & $\square$ \\
Instant Messaging & $\square$ & $\square$ &
\end{tabular}


Q6 How is your organizations Information and Communications Technology (ICT) managed?

We have an in-house team that handles all ICT related issues

We do not have a structured ICT management in place and all ICT related issues are managed on a provisional basis

A third-party organization is responsible for maintaining the ICT for the company

Other. Please specify

Q7 Has your company adopted and integrated a new software for your company in the past 1 3 years?

O Yes

O No

O Don't Know

Q8 Does your company have a dedicated software that you use for internal and external communication, information sharing and general collaboration purposes on projects?

O Yes

○ No

If No Is Selected, Then Skip To Below is a list of typical and generic...

Answer If Does your company have its own software (designed and developed in-house) that you use for intern... Yes Is Selected

Q9 Can you please indicate the name of the software in the space provided below. 
Answer If Does your company have its own software (designed and developed in-house) that you use for intern... Yes Is Selected

Q10 Does the software you have identified, fit any of the descriptions below.

The software was developed in-house by hiring either a consulting company or programmers to create a system. All servers and computer hardware are maintained and provided in-house in this option.

The software was purchased from commercial software developer and installed on the company's internal server.

The piece of software is rented/leased from an Application Service Provider (ASP) for a usage fee. The usage fee is normally charged per project per amount of computer storage space requires and/or per user.

O Don't Know.

O Other

Answer If Does your company have its own software (designed and developed in-house) that you use for intern... Yes Is Selected

Q11 Is this software web-enabled? This means that the software is a web-based application that can be accessed via a standard web browser like Google Chrome, Internet Explorer, and Safari etc.

O Yes

O No

O Don't Know 
Answer If Does your company have a dedicated software that you use for internal and external communication... Yes Is Selected

Q12 In terms of the software you are currently using for communication with project team members and stakeholders, please consider the following statements below; and appropriately tick your corresponding responses for each on the right.

\begin{tabular}{|c|c|c|c|c|c|}
\hline & $\begin{array}{l}\text { Strongly } \\
\text { agree }\end{array}$ & Agree & $\begin{array}{l}\text { Neither } \\
\text { Agree nor } \\
\text { Disagree }\end{array}$ & Disagree & $\begin{array}{l}\text { Strongly } \\
\text { Disagree }\end{array}$ \\
\hline $\begin{array}{l}\text { I find it easy to } \\
\text { use the software } \\
\text { provided. }\end{array}$ & 0 & $\mathrm{O}$ & $\mathrm{O}$ & 0 & $\mathrm{O}$ \\
\hline $\begin{array}{l}\text { I think that my } \\
\text { organizations } \\
\text { communications } \\
\text { software is up- } \\
\text { to-date }\end{array}$ & 0 & 0 & 0 & 0 & 0 \\
\hline $\begin{array}{l}\text { The current } \\
\text { software } \\
\text { solutions } \\
\text { available is } \\
\text { adequate for } \\
\text { effective and } \\
\text { efficient } \\
\text { communication }\end{array}$ & $\mathrm{O}$ & 0 & 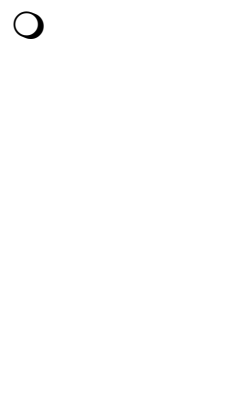 & 0 & 0 \\
\hline $\begin{array}{l}\text { There are } \\
\text { improvements } \\
\text { needed for the } \\
\text { software used in } \\
\text { my workplace }\end{array}$ & $\mathrm{O}$ & 0 & 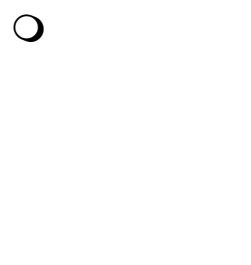 & 0 & 0 \\
\hline
\end{tabular}


Q13 Below is a list of software relevant to the construction industry. Can you please indicate which of these software you currently use on projects or have used in the past. You can tick more than one box in the options given below.

Microsoft Office Tools (Word, Excel, OneNote, Visio, PowerPoint, Mail, Calendar, Docs.com etc.)

Microsoft Project

口 Aconex

口 Revit

a ArchiCAD

口 Mavenlink

口 Procore

口 Intelex

BuildIT Systems

口 BuildTools

Synchro

口 Basecamp

口 Viewpoint

口 Relatics

- BuilderTREND

口 PMWeb

Co-construct

口 Google SketchUp

$\square$ Dropbox

Google Drive

Q14 Does your company have a policy in place that reviews the software that is being used in office to make sure that it stays up-to-date?

O Yes

O No 
Q15 Put in order according to rank which form of communication you use during projects. With 1 being the most used form of communication and 6 being the least used

Email

Face-to-face communication

Facsimile (fax)

Instant Messaging (IM)

Phone

Social media platform such as Facebook, Twitter etc.

\section{SECTION 3: PERSONAL SOCIAL MEDIA USE}

Q16 How many hours a day on average, do you spend on Social Media sites?

L Less than 1 hour

O 1 - 3 hours

O 3 - 5 hours

More than 5 hours

I don't use Social Media

Q17 What do you use social media for? You can choose more than one option

․ Personal social networking ( to keep in touch with family and friends)

C Connect with work colleagues

- For professional networking

Job searching

To keep up-to-date with project progress

To provide live progress updates to the project team

To keep in touch with work colleagues

- To look up potential employees or employers

Advertisement purposes (publicity). Please state what was being advertised

Other Reasons for social media use 
Q18 Which of the devices listed below do you use to access Social Media? Rank in order from most to least, the device you access Social Media platforms. With 1 being the most and 5 being the least used.

From your work provided computer or laptop

Personal computer

Smart phone

Tablet computer (iPad, Tablets etc.)

Public access computers (from public libraries, Internet cafes etc.)

Q19 On which of these social media platforms do you have established user accounts with and that you use on a regular basis? You can choose more than one option listed below

ㄱ Facebook

( Twitter

$\square$ Snapchat

Instagram

口 LinkedIn

YouTube

口 Skype

G Google+

口 Flickr

Wikipedia

Tumblr

Pinterest

Vine

$\square$ Tagged

口 WhatsApp

Dropbox

G Google Drive

ㄱ Yahoo Messenger

Blogger

口 Slideshare

口 Vimeo 
$\square$ Digg

a last.fm

Other. Please specify

\section{SECTION 4: SOCIAL MEDIA USE IN THE WORKPLACE}

Q20 Have you ever used Social Media for communication between project team members? You can tick more than one answer below.

Currently use or have used in past projects

口 Have never used Social Media

Would like to use Social Media

I'm against the use of Social Media for project communication and collaboration between project team members

Q21 What is your company's policy on Social Media use within the workplace?

Allowed to use social media but only for project related purposes

Not allowed to use social media at work

We do not have a policy for social media use at the workplace

Q22 If you were to use Social Media for project purposes, which of the following would you use it for?

- File transfer and general information exchange

- To host informal Wiki-like conversation/discussions relating to the project.

Keeping track of project progress.

口 Provide live updates to stakeholders using Twitter like style updates

Looking up other similar projects

Networking among project stakeholders/ participants

To have a company profile established on social media and to engage the public.

$\square$ Advertising purposes.

Other. Please specify 


\section{SECTION 5: SOCIAL MEDIA INFLUENCED COLLABORATION SOFTWARE}

Q23 Social Media platforms (Facebook, Instagram, LinkedIn, Snapchat, YouTube etc.) can all be categorized into six different types of social media. Based on their description, which platforms do you think would be useful in aiding project communications? Tick all options that you would recommend.

Social Networking Sites

Connects users with their family and friends. Users are also able to share personal media (photos, videos, text etc.) to either a closed group or wider network of people depending on the settings chosen. (Facebook, LinkedIn, Google+, Twitter etc.)

口 Blog and Forum

Short for web log. It is like an online diary containing short posts (articles) which are viewed (usually) in reverse chronological order. People have the option of commenting on these posts providing feedback.

Microblogging

It is like an on-line diary containing short posts (articles) which are viewed (usually) in reverse chronological order. People have the option of commenting on these posts providing feedback (Twitter, Facebook updates etc.)

- Social News

Social news websites are communities that encourage their users to submit news stories, articles and media (images/videos) and share them with other users or the general public. Depending on various factors, such as the number of user votes for each item, some of these articles will be given more prominence on the website.

․ Bookmarking Sites

As the name suggests it is tagging a website and saving it for later. Instead of saving them to your web browser, you are saving them to the web. And, because your bookmarks are online, you can easily share them with friends or other users of your choice.

- Media Sharing

Media sharing sites allow users to generate and share media in the form of audio, video, graphic as well as text to groups of people within their network. Media sharing sites like social networks also allow for users to dictate whom to disseminate this information to.

Q24 Tick any of the terms listed below that you are aware of and understand what they mean.

Web 2.0

ㄷnterprise 2.0

ㄱ Project Management 2.0

口 Social Project Management (SPM) 
Social Media enhanced Platforms (SPeM)

Q25 Are you aware of the existence of project management software that have been influenced by Social Media?

O Yes

O No

Q26 Are you aware of any of the following web-based project management software listed below? Please tick all software that you are aware of or have used in the past.

Aware of the software Have used in past Don't recognize the projects software

\begin{tabular}{|c|c|c|c|}
\hline Zoho & $\mathrm{O}$ & $\mathrm{O}$ & $\mathrm{O}$ \\
\hline AtDesk & $\mathrm{O}$ & $\mathrm{O}$ & $\mathrm{O}$ \\
\hline CentralDesk & $\mathrm{O}$ & $\mathrm{O}$ & $\mathrm{O}$ \\
\hline Liquid Planner & O & $\mathrm{O}$ & $\mathrm{O}$ \\
\hline Mango Projects & O & O & $\mathrm{O}$ \\
\hline Sprintr & O & $\mathrm{O}$ & $\mathrm{O}$ \\
\hline SharePoint & O & $\mathrm{O}$ & $\mathrm{O}$ \\
\hline Yammer & O & $\mathrm{O}$ & $\mathrm{O}$ \\
\hline VM Ware's Strider & $\mathrm{O}$ & $\mathrm{O}$ & $\mathrm{O}$ \\
\hline Teambox & O & $\mathrm{O}$ & $\mathrm{O}$ \\
\hline ProjectPlace & O & $\mathrm{O}$ & $\mathrm{O}$ \\
\hline UBuildNet.com & 0 & $\mathrm{O}$ & $\mathrm{O}$ \\
\hline Podio & $\mathrm{O}$ & $\mathrm{O}$ & $\mathrm{O}$ \\
\hline UPro & $\mathrm{O}$ & $\mathrm{O}$ & $\mathrm{O}$ \\
\hline Wrike & $\mathrm{O}$ & $\mathrm{O}$ & $\mathrm{O}$ \\
\hline Mavenlink & $\mathrm{O}$ & $\mathrm{O}$ & $\mathrm{O}$ \\
\hline eXo Platform & O & $\mathrm{O}$ & $\mathrm{O}$ \\
\hline Ganttic & O & $\mathrm{O}$ & $\mathrm{O}$ \\
\hline DeskAway & $\mathrm{O}$ & $\mathrm{O}$ & $\mathrm{O}$ \\
\hline Asana (software) & $\mathrm{O}$ & $\mathrm{O}$ & $\mathrm{O}$ \\
\hline
\end{tabular}


Q27 Listed below are some technologies found in Social Media platforms that are used for communication and collaboration among its users. Which of these would you choose to include in a software, if you were able to build one for your own project team?

Instant messaging

User presence detection. The ability to tell if a user is available on-line or if they are away from their desk.

F Facebook-like time-lines, that summarize in chronological order; your activities on-line in relation to what other users are doing

Activity streams that show what other users you have connected with are doing. You get updates in real time.

$\square$ Multi-media sharing

ㄴ User tagging

$\square$ Blogging features

Micro-blogging like Twitter or Facebook like status update options

Wiki-like features

C Configurable security options

口 Skype calling/video calling

File Storage, sharing and management functions (Google Drive, Dropbox etc.)

- Social networking features and being able to see and connect with people outside of your network (features found in LinkedIn, Facebook etc.)

- If you are aware of any other project appropriate social media features, please note them down below. 


\section{Appendix C: Survey Information Sheet}

Participant Information Sheet for a study of Collaboration and Communication technology use in construction Project Teams

RESEARCHER: Viliame Rawalai; School of Architecture and Design, Victoria University of Wellington

The Research Scope

I am a Masters student in Building Science (Project Management) at Victoria University of Wellington undertaking a research project leading to a thesis. This survey is set-up to investigate the information/communication technologies used in the construction industry. More specifically the survey is targeting the relevance of social media for project management communication. Your contribution to this survey will ultimately be utilised in the design of a social networking platform for managing project management communication. The target participants for this survey will be construction industry professionals who have had a number of years of experience in project management or working within a project team to participate in a study. The study will be administered in the form of a survey. The survey questionnaire should take about less than 20 minutes. The survey will be open to participants for a period of two weeks. Within the two weeks, participants are invited to complete an online survey form. Participants have the option of terminating their participation in the survey up until the submission of the survey. Participants will be unable to withdraw their responses after submitting as it will be difficult to identify individual responses.

Data Storage and Use

Your survey responses will be kept confidential and will only be accessible by myself and my supervisor. To ensure that the data is kept safe it will be stored in a password protected folder on my computer. A second backup copy may also be kept online in my Dropbox account and this will also be password protected which can only be accessed by myself. Responses collected will form the basis of my research project and will be put into a written report on an anonymous basis. It will not be possible for you to be identified personally. Only grouped responses will be presented in this report. All material collected will be kept confidential. No other person besides me and my supervisor, will see the information provided by you the participant. The thesis will be submitted for marking to the School of Architecture and Design and deposited in the University Library. It is intended that one or more articles will be submitted for publication in scholarly journals. Information provided by participants will be destroyed 2 years after the end of the project.

\section{Ethics Approval}

This research has been approved by the Victoria University of Wellington Human Ethics Committee.

\section{Commercialisable Intellectual Property}

It is intended that the information elicited through anonymous survey responses will be used as the basis for the design of a social software dedicated towards the management of information and communication within construction project teams. The designed software has the potential 
of becoming a working commercialisable piece of software. However, at this point of the research it is still unclear whether a patent is needed. This can always be applied for at any time between now and the end of the research.

If you have any questions or would like to receive further information about the project, please contact me at rawalavili@myvuw.ac.nz or contact me on this number 0221407722. Alternatively, you can contact my supervisor, Dr Marc Schnabel, at the School of Architecture and Design at Victoria University, marcaurel.schnabel@vuw.ac.nz , 123 Vivian street, Wellington, Phone number 044636095

Viliame Rawalai

Signed: 


\section{Appendix D: Supplementary Tables}

TABLE 18: Network technologies and their impacts by (Lientz and Rea 2002)

\begin{tabular}{|c|c|c|c|}
\hline Technology & Applications & Benefits & Potential abuse \\
\hline Voice mail & $\begin{array}{l}\text { Collecting project } \\
\text { status } \\
\text { Disseminating } \\
\text { information }\end{array}$ & $\begin{array}{l}\text { Reduce telephone } \\
\text { tag }\end{array}$ & $\begin{array}{l}\text { Extensive long } \\
\text { messages }\end{array}$ \\
\hline Electronic mail & $\begin{array}{l}\text { Collecting and } \\
\text { forwarding } \\
\text { information } \\
\text { Disseminating } \\
\text { information }\end{array}$ & $\begin{array}{l}\text { Obtain files as } \\
\text { attachment } \\
\text { Collect data for } \\
\text { reports easily }\end{array}$ & $\begin{array}{l}\text { Unstructured } \\
\text { Depends on } \\
\text { writing skills }\end{array}$ \\
\hline $\begin{array}{l}\text { Project management } \\
\text { software }\end{array}$ & $\begin{array}{l}\text { Project tracking } \\
\text { Joint project updating }\end{array}$ & $\begin{array}{l}\text { Team participation } \\
\text { in updates } \\
\text { Team can define } \\
\text { detailed tasks } \\
\text { Schedule represents } \\
\text { truth }\end{array}$ & $\begin{array}{l}\text { Manager runs } \\
\text { project as } \\
\text { traditional } \\
\text { projects in spite } \\
\text { of network }\end{array}$ \\
\hline $\begin{array}{l}\text { Database management } \\
\text { systems }\end{array}$ & $\begin{array}{l}\text { Issues database } \\
\text { Action item database } \\
\text { Lessons learned } \\
\text { database }\end{array}$ & $\begin{array}{l}\text { Shared information } \\
\text { Structured } \\
\text { information }\end{array}$ & $\begin{array}{l}\text { Database not } \\
\text { used } \\
\text { Database not } \\
\text { maintained }\end{array}$ \\
\hline Groupware & $\begin{array}{l}\text { Issues database } \\
\text { Action item database } \\
\text { Lessons learned } \\
\text { database } \\
\text { Project documents }\end{array}$ & $\begin{array}{l}\text { Shared information } \\
\text { Joint work on } \\
\text { documents }\end{array}$ & $\begin{array}{l}\text { Software not } \\
\text { used } \\
\text { Data not updated }\end{array}$ \\
\hline $\begin{array}{l}\text { Calendaring/scheduling } \\
\text { software }\end{array}$ & $\begin{array}{l}\text { Scheduling of } \\
\text { meetings related to } \\
\text { projects }\end{array}$ & Easier coordination & $\begin{array}{l}\text { May not be used } \\
\text { by all } \\
\text { Not kept current }\end{array}$ \\
\hline $\begin{array}{l}\text { Internet video } \\
\text { conferencing }\end{array}$ & $\begin{array}{l}\text { Issue discussion } \\
\text { Technical project } \\
\text { discussion }\end{array}$ & $\begin{array}{l}\text { Better than e-mail } \\
\text { and voice mail } \\
\text { Less chance of } \\
\text { misunderstanding }\end{array}$ & $\begin{array}{l}\text { Limited quality } \\
\text { of technology } \\
\text { Expense and } \\
\text { learning curve } \\
\text { for technology }\end{array}$ \\
\hline Internet telephone & $\begin{array}{l}\text { Standard voice } \\
\text { communications }\end{array}$ & $\begin{array}{l}\text { Cheaper than long } \\
\text { distance }\end{array}$ & $\begin{array}{l}\text { Quality and } \\
\text { compatibility } \\
\text { issues }\end{array}$ \\
\hline Web/ Internet & $\begin{array}{l}\text { Web pages and } \\
\text { applications }\end{array}$ & $\begin{array}{l}\text { Low cost } \\
\text { communications } \\
\text { Flexible }\end{array}$ & $\begin{array}{l}\text { Requires remote } \\
\text { network access } \\
\text { Limited security }\end{array}$ \\
\hline Intranet & Provide internal web & $\begin{array}{l}\text { Benefits of the } \\
\text { Internet } \\
\text { Secure because it is } \\
\text { internal }\end{array}$ & Setup costs \\
\hline
\end{tabular}




\begin{tabular}{ll} 
Type of Network & Description \\
\hline $\begin{array}{l}\text { Local Area Network } \\
\text { (LAN) }\end{array}$ & $\begin{array}{l}\text { A Local Area Network (LAN) is a high-speed communications system } \\
\text { designed to link computers and other data processing devices together } \\
\text { within a small geographic area, such as in a construction headquarters. } \\
\text { Several LANs can also be interconnected within a campus of buildings } \\
\text { to extend connectivity (also called a Wide Area Network or WAN). This } \\
\text { allows users to electronically share vital computing resources, such as } \\
\text { expensive hardware (e.g. printers and CD-ROM drives), application } \\
\text { programs, and information }\end{array}$ \\
\hline
\end{tabular}

Virtual Private Network (VPN) to permit peer connections only within a defined community of interest such as the global Internet. VPN gives extremely secure connections between private networks. Most construction companies use VPN as it proves to be the most secured of all the other types of networking

Intranet

An intranet is usually described as an internal or restricted access network that is similar to functionality as the internet, but is only available to an organization internally.

Extranet
An extranet is an extension of a firm's internal network that allows outside users to provide and access information in a secure environment. It can be accessed using a standard web browser without any software installation needed. However, an extranet requires extensive security and special software to provide user authentication and to encrypt data. 
Type of PM-ASP

Project Collaboration Network (PCN)

Project Information Portal (PIP)

Project Procurement Exchange (PPE)

\section{Description}

PCNs focus on facilitating construction project management. The system aims at sharing project specific documents, communications, and workflow and serves as a repository for documents or as an online document management system for a project team.

PIP serves mainly the general information needs of participants. These include information such as codes and permits, economic trends, product information, cost data and project planning information that is useful for a project team throughout the lifecycle of the building project.

PPEs are designed to streamline the procurement cycle of construction materials and services. The system provides electronic bidding and procurement services, which generally allow users to view online catalogues of products and services, transmit RFQs, exchange cost-related data, review work packages and conduct bidding and procurement online

TABLE 21: Categorisation of construction project extranets adapted from (Becerik 2004)

\begin{tabular}{ll}
\hline TYPE & DESCRIPTION \\
\hline $\begin{array}{l}\text { Team Communication \& } \\
\text { Document Management }\end{array}$ & $\begin{array}{l}\text { Support various modes of communication, act as a } \\
\text { repository of various documents, allow storage, sharing and } \\
\text { timely exchange of information and project documents }\end{array}$ \\
\hline $\begin{array}{l}\text { Work Flow and Process } \\
\text { Automation }\end{array}$ & $\begin{array}{l}\text { Support various business models by managing the flow of } \\
\text { information, monitoring and recording the progress of tasks } \\
\text { as a result reduces cycle time, automate workflow }\end{array}$ \\
\hline $\begin{array}{l}\text { Process and Project } \\
\text { Management }\end{array}$ & $\begin{array}{l}\text { Support process and project monitoring and management, } \\
\text { provides better management of resources }\end{array}$ \\
\hline
\end{tabular}




\begin{tabular}{ll} 
Barrier & Description \\
\hline System reliability & $\begin{array}{l}\text { Ideally, a PM-ASP should be available to users at all time to } \\
\text { ensure its high reliability. However, this is rarely the case. }\end{array}$ \\
\hline System Security & $\begin{array}{l}\text { This issue is well founded, especially in the wake of recent, } \\
\text { highly publicized "hacking" break-ins. A high-security PM- } \\
\text { ASP is a system with low or no chance of unauthorized users } \\
\text { or competitors accessing the system and data }\end{array}$ \\
\hline $\begin{array}{l}\text { Although the existing legal environment may provide } \\
\text { essentially clear guidelines for construction practitioners to } \\
\text { manage a contract in a paper-based environment, new } \\
\text { collaborative tools such as PMASPs change the work method, } \\
\text { making legal responsibilities in this new environment unclear }\end{array}$ \\
\hline $\begin{array}{l}\text { An important inhibitor to the adoption of PMASPs is the } \\
\text { technical difficulties caused by the incompatibility of systems. }\end{array}$ \\
\hline $\begin{array}{l}\text { There is still debate on who should get copies of the project } \\
\text { record and what information should be included or excluded } \\
\text { from each party's version. }\end{array}$ \\
\hline $\begin{array}{l}\text { Internet access is a prerequisite to the use of PM-ASPs and } \\
\text { this may not always be possible }\end{array}$ \\
\hline $\begin{array}{l}\text { Since other channels exist, it is easy for a project team } \\
\text { member to bypass a PM-ASP with more familiar technologies } \\
\text { bandwidth } \\
\text { channels }\end{array}$ \\
$\begin{array}{l}\text { such as a telephone, a mobile phone, a fax machine, and a } \\
\text { beeper }\end{array}$ \\
\hline $\begin{array}{l}\text { Practitioners in the construction industry generally resist } \\
\text { change and need to know how to use a PM-ASP effectively or } \\
\text { how the system can facilitate their work tasks }\end{array}$ \\
\hline Resistance to change
\end{tabular}


TABLE 23: Differences between Enterprise 1.0 and Enterprise 2.0 adapted from (Klinc, Dolenc and Turk, Possibe Benefits of Web 2.0 To Construction Industry 2008)

\begin{tabular}{ll}
\hline Enterprise 1.0 & Enterprise $\mathbf{2 . 0}$ \\
\hline Hierarchy & Flat organisation \\
\hline Friction & Ease of organisational flow \\
\hline Bureaucracy & Agility \\
\hline Inflexibility & Flexibility \\
\hline IT-driven technology/ Lack of user control & User-driven technology \\
\hline Top-down & Bottom-up \\
\hline Centralised & Distributed \\
\hline Teams are in one building/ One time-zone & Teams are global \\
\hline Silos and boundaries & Fuzzy boundaries, open borders \\
\hline Information systems are structure and dictated & Information systems are emergent \\
\hline Taxonomies & Folksonomies \\
\hline Overly complex & Simple \\
\hline Closed/ proprietary standards & Open \\
\hline Scheduled & On demand \\
\hline User search and browse & User publish and subscribe \\
\hline Messages pushed to customer & Messages pulled by customer \\
\hline Institutional control & Individual enabled \\
\hline
\end{tabular}

TABLE 24: Difference comparison of project management adapted from (Li, et al. 2012)

\begin{tabular}{|c|c|c|}
\hline & Traditional PM & Social Network Based PM \\
\hline Relationship focus on & Mainly enterprise internal & $\begin{array}{l}\text { Focus on relationships } \\
\text { among stakeholders inside } \\
\text { and outside of the enterprise } \\
\text { (suppliers, partners etc.) }\end{array}$ \\
\hline $\begin{array}{l}\text { Communication with other } \\
\text { stakeholder }\end{array}$ & $\begin{array}{l}\text { Rely mainly on offline } \\
\text { communication }\end{array}$ & $\begin{array}{l}\text { Keep in touch with all the } \\
\text { stakeholders all the time }\end{array}$ \\
\hline Technical architecture & Heavier framework & Lighter framework \\
\hline Complexity & Too complex, high cost & $\begin{array}{l}\text { Simpler, lighter and more } \\
\text { convenient to use and no } \\
\text { need to install }\end{array}$ \\
\hline Type of enterprise & $\begin{array}{l}\text { Usually larger enterprise, or } \\
\text { conglomerate }\end{array}$ & $\begin{array}{l}\text { SMEs can fully participate in } \\
\text { this platform }\end{array}$ \\
\hline Openness & Low & High \\
\hline $\begin{array}{l}\text { Interaction with third- } \\
\text { party system }\end{array}$ & Barely none & $\begin{array}{l}\text { Develop the interface to } \\
\text { interact with third-party } \\
\text { platform and exchange } \\
\text { information quickly }\end{array}$ \\
\hline
\end{tabular}




\section{Appendix E: Supplementary Figures}

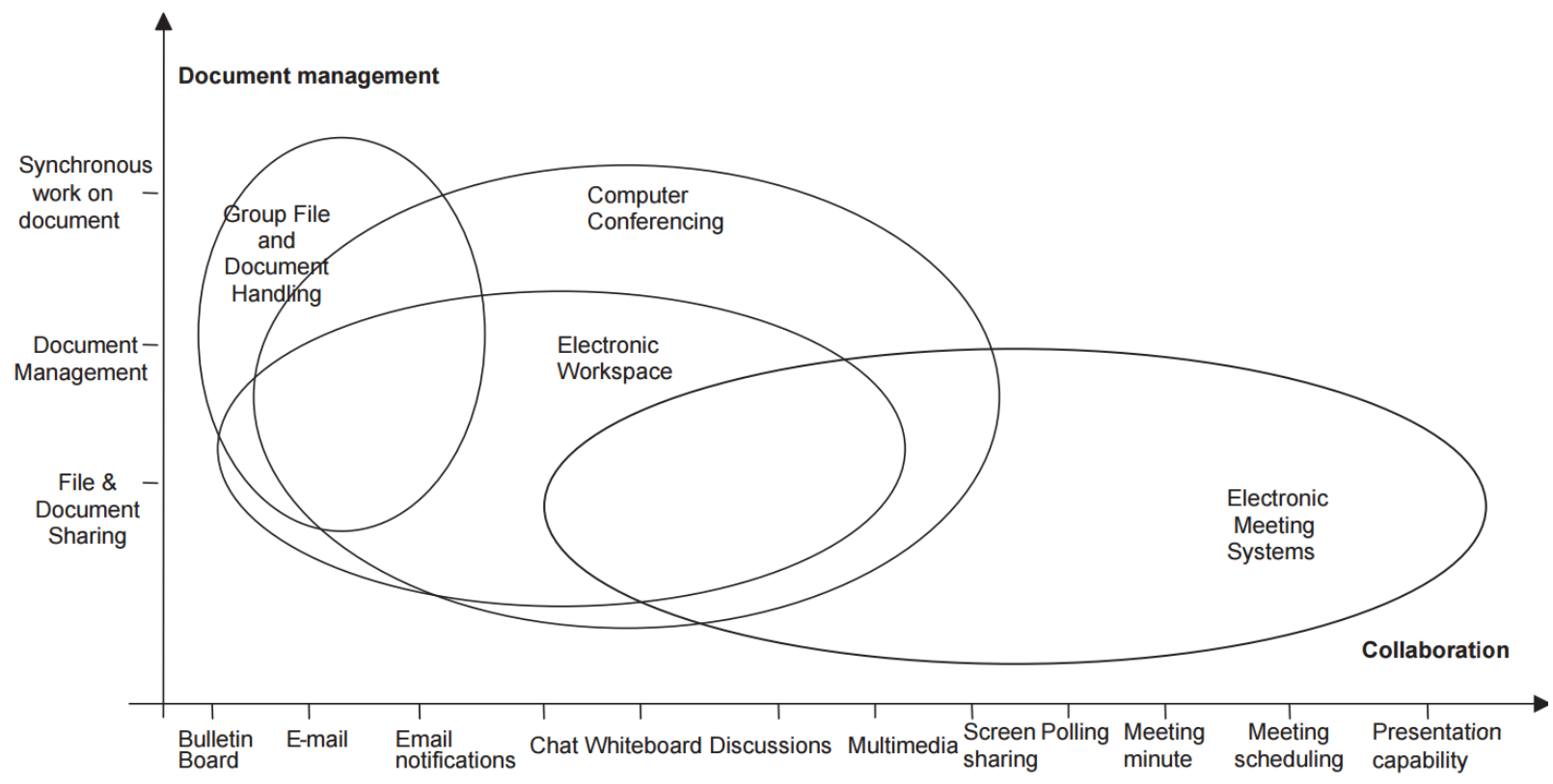

FIGURE 37: Categories of collaborative tools adapted from (Bafoutsou and Mentzaz, Review and Functional Classification of Collaborative Systems 2002)

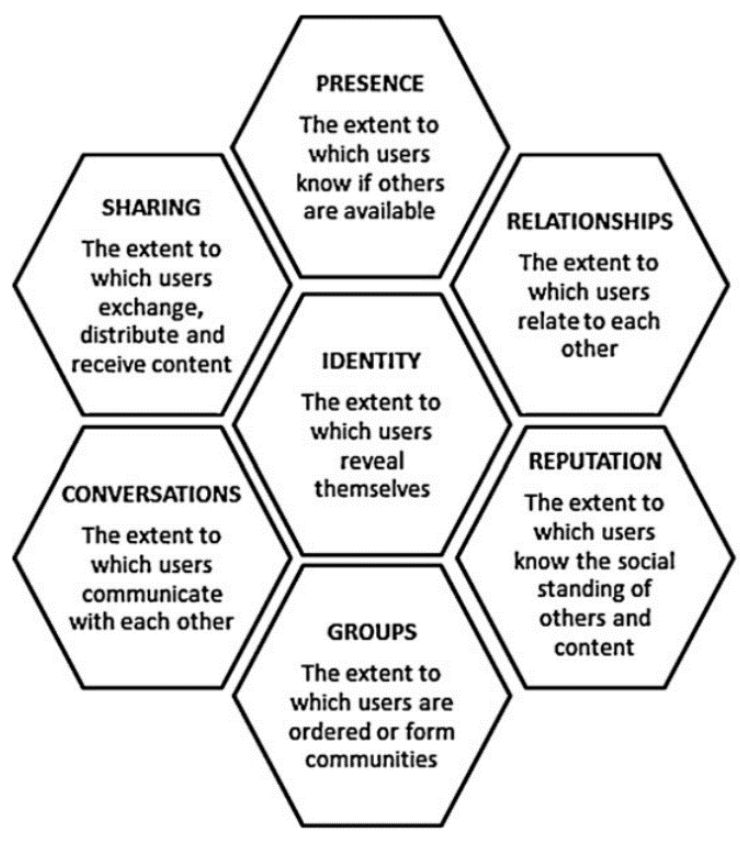

Social Media Functionality

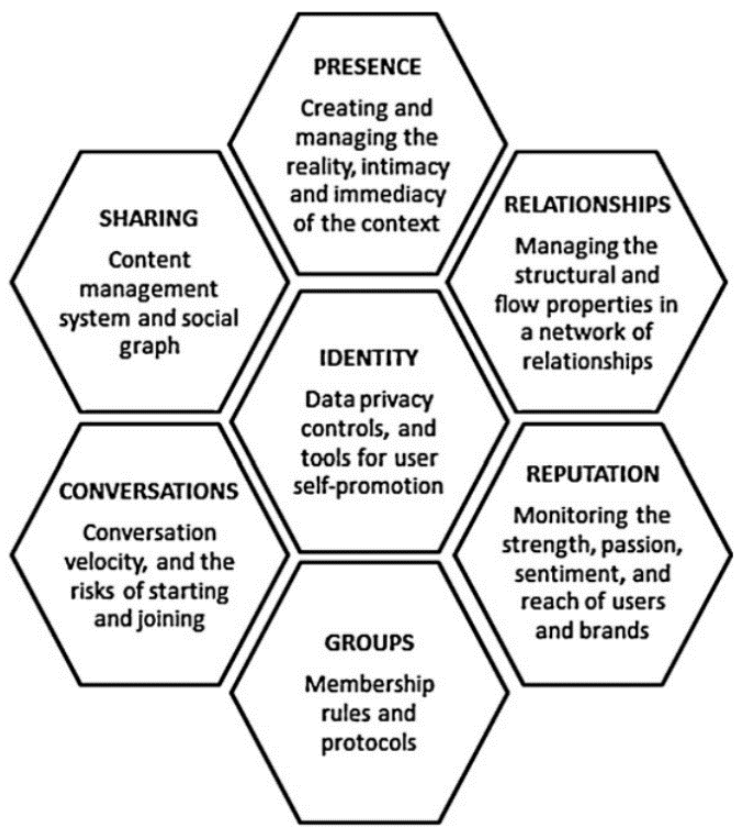

Implications of the Functionality

FIGURE 38: The honeycomb of social Media by (Kietzmann, et al. 2011) 


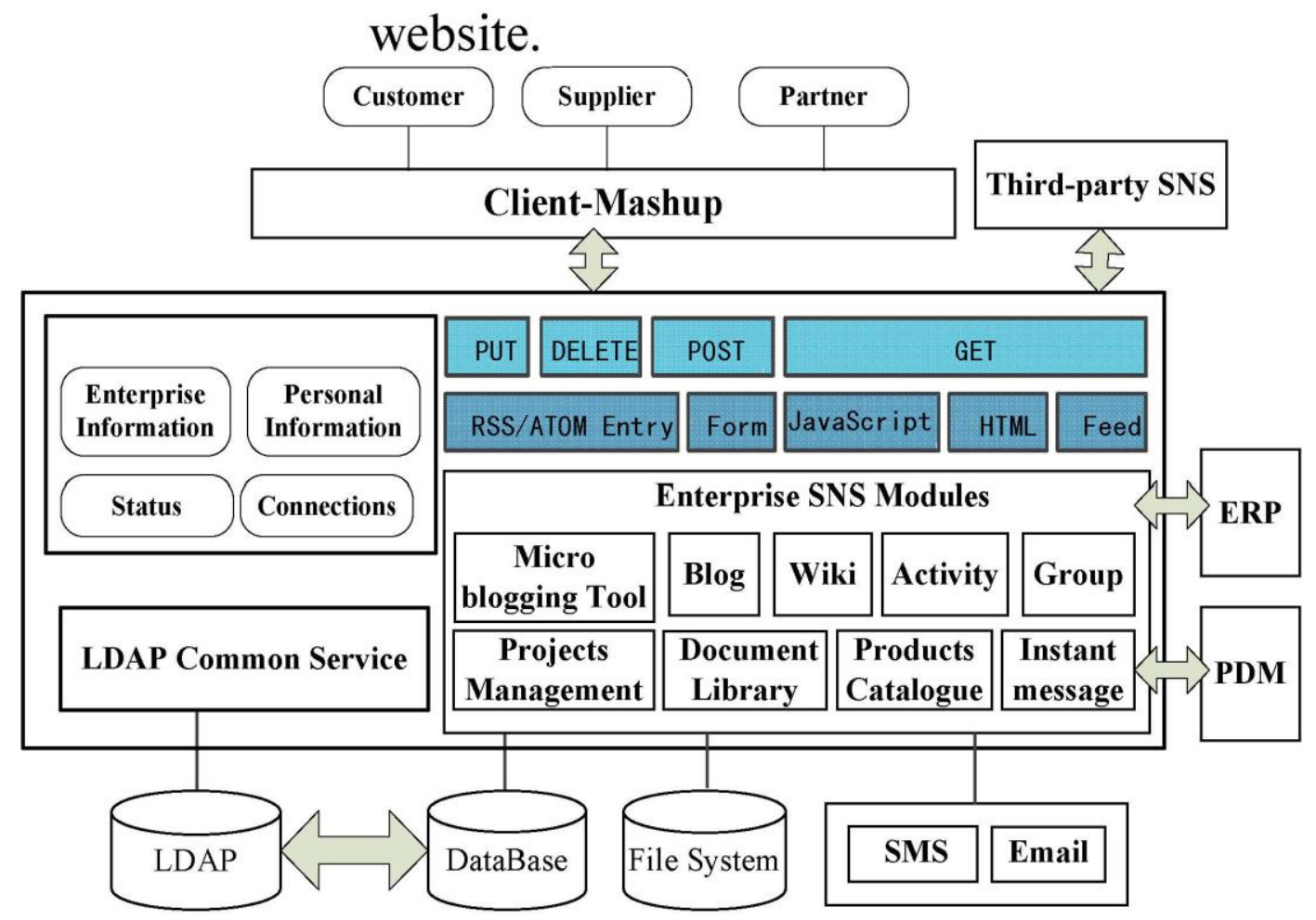

FIGURE 39: System architecture of a social collaboration platform (Li, et al. 2012)

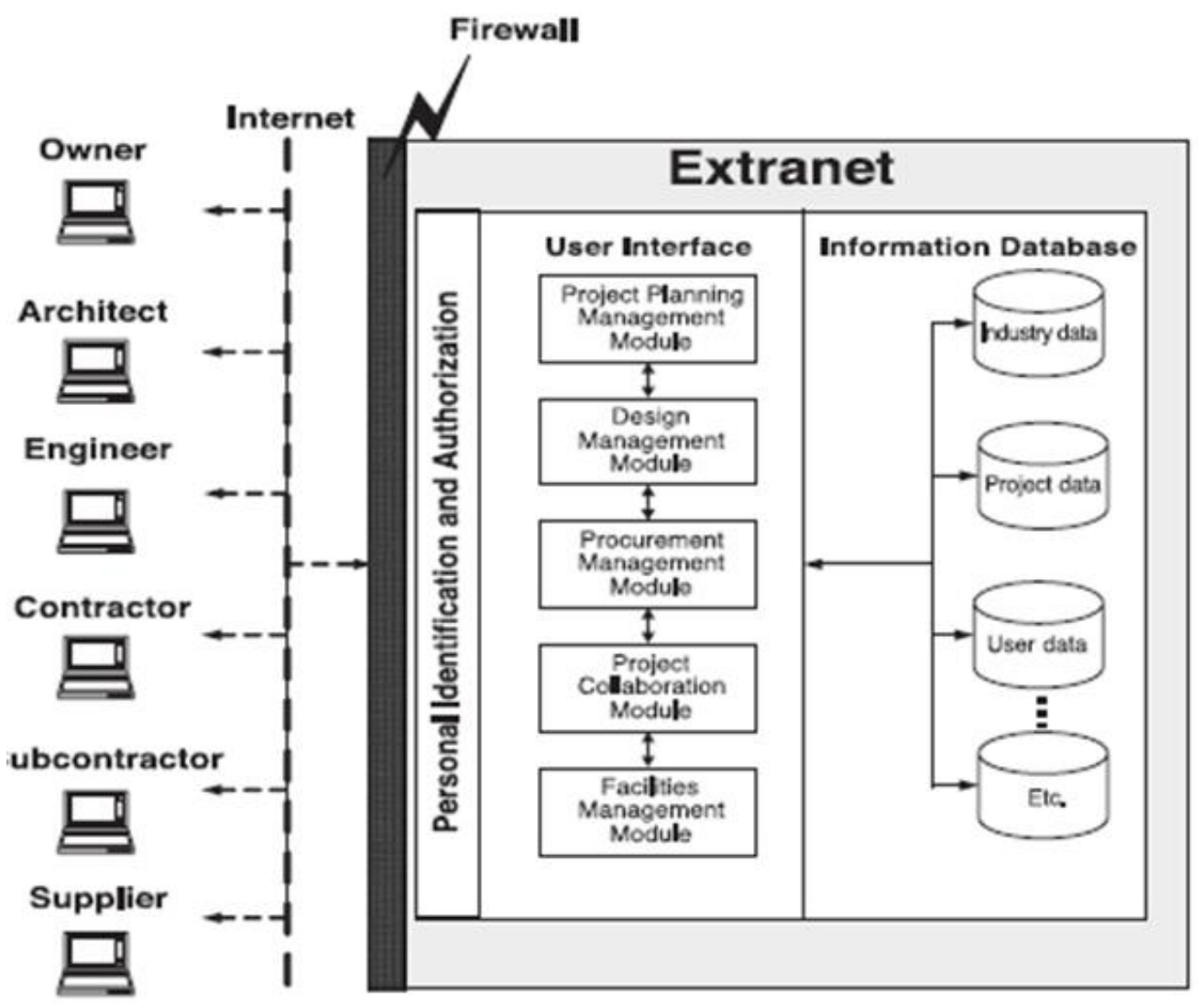

FIGURE 40: Functional scheme of a WPMS (Nitithamyong and Skibniewski 2004) 


\section{Appendix F: Ethics Approval}

TE WHARE WXNANGA O TE DFOKO O TE IKA A M KUI

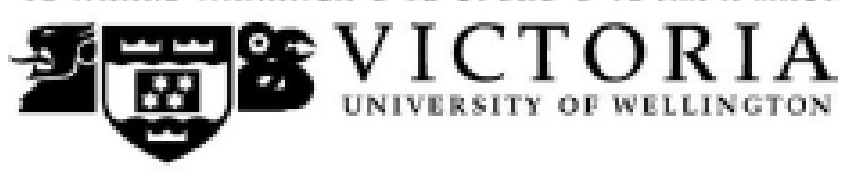

Phone $\quad 0-4-4635480$

MEMORANDUM

Email susan.corbettifruwac.na

\begin{tabular}{l|l}
\hline TO & Vili Rawalai \\
\hline COPY TO & \\
\hline FROM & AProf Susan Corbett, Convener, Human Ethics Committee \\
\hline DATE & 12 February 2016 \\
\hline PAGES & 1 \\
\hline & $\begin{array}{l}\text { Ethics Approval: 21894 } \\
\text { Creating A Social Communication Tool for Project Management }\end{array}$ \\
\hline
\end{tabular}

Thank you for your request to amend your ethics approval. This has now been considered and the request granted.

Your application has approval until 17 March 2016. If your data collection is not completed by this date you should apply to the Human Ethics Committee for an extension to this approval.

Best wishes with the research.

Kind regards

Susan Corbett

Convener, Victoria University Human Ethics Committee 
